Florida International University FIU Digital Commons

FIU Electronic Theses and Dissertations

University Graduate School

9-16-2008

\title{
Essays on Durable Goods Consumption and Firm Innovation
}

Zhao Rong

Florida International University, zrong002@fiu.edu

DOI: $10.25148 /$ etd.FI10022546

Follow this and additional works at: https://digitalcommons.fiu.edu/etd

\section{Recommended Citation}

Rong, Zhao, "Essays on Durable Goods Consumption and Firm Innovation" (2008). FIU Electronic Theses and Dissertations. 215. https://digitalcommons.fiu.edu/etd/215

This work is brought to you for free and open access by the University Graduate School at FIU Digital Commons. It has been accepted for inclusion in FIU Electronic Theses and Dissertations by an authorized administrator of FIU Digital Commons. For more information, please contact dcc@fiu.edu. 


\section{FLORIDA INTERNATIONAL UNIVERSITY}

Miami, Florida

ESSAYS ON DURABLE GOODS CONSUMPTION AND FIRM INNOVATION

A dissertation submitted in partial fulfillment of the requirements for the degree of DOCTOR OF PHILOSOPHY in ECONOMICS

by

Zhao Rong 
To: Dean Kenneth Furton

College of Arts and Sciences

This dissertation, written by Zhao Rong, and entitled Essays on Durable Goods Consumption and Firm Innovation, having been approved in respect to style and intellectual content, is referred to you for judgment.

We have read this dissertation and recommend that it be approved.

Cem Karayalcin

Prasad Bidarkota

Hassan Zahedi

Peter Thompson, Major Professor

Date of Defense: September 16, 2008

The dissertation of Zhao Rong is approved.

Dean Kenneth Furton

College of Arts and Sciences

Dean George Walker

University Graduate School

Florida International University, 2008 
C Copyright 2008 by Zhao Rong

All rights reserved. 


\section{DEDICATION}

I dedicate this dissertation to my wife, Ying, without whose love this would never have been completed; to my parents, whose belief in my abilities never wavered. 


\section{ACKNOWLEDGMENTS}

The dissertation records some of my thoughts over the past three years, and it is just a beginning of better ideas.

Special thanks to my advisor, Peter Thompson. Without him I would not accomplish my dissertation. Other individuals inspired me at the Department of Economics are John Boyd, Cem Karayalcin, Prasad Bidarkota, and Jonathan Hill.

I would also like to thank my family for their support. All my efforts become meaningful because of them. 


\section{ABSTRACT OF THE DISSERTATION \\ ESSAYS ON DURABLE GOODS CONSUMPTION \\ AND FIRM INNOVATION}

by

Zhao Rong

Florida International University, 2008

Miami, Florida

\section{Professor Peter Thompson, Major Professor}

This dissertation comprises three individual chapters. Chapter Two examines how free riding across neighbors influenced the diffusion of color television sets in rural China. Chapter Three tests for asymmetric information between a firm's management and other investors concerning its patent output. Chapter Four discusses how knowledge stocks influence a patenting firm's later diversification.

Chapter Two documents the existence of a type of network effects - free riding across neighbors - in the consumption of color television sets in rural China, which reduces the propensity of non-owners to purchase. I construct a model of the timing of the purchase of a durable good in the presence of free riding, and test its key implications using household survey data in rural China.

Chapter Three tests for asymmetric information between a firm's management and other investors about its patent output by examining insider trading patterns and stock price changes in $R \& D$ intensive firms. It demonstrates that management has considerable information about its patent output beyond what is known to investors. It also shows that 
the predictive power of insider trading patterns on patent output comes from purchases rather than sales.

Chapter Four discusses two sequential channels through which knowledge stocks may influence a firm's later diversification. One is that firms with more knowledge are more likely to enter a new industry. The other is that firms' businesses have a better chance of surviving, conditional on being formed. By examining U.S. public patenting firms in manufacturing sectors for 1984-1996, I find that knowledge stocks predict the likelihood of new industry entry when controlling for firm size. However, this predictive power is weakened when diversification effects are included. On the other hand, a survival study of newly established segments shows that initial knowledge stocks have significant positive effects on segment survival, whereas diversification effects are insignificant. 


\section{TABLE OF CONTENTS}

CHAPTER

PAGE

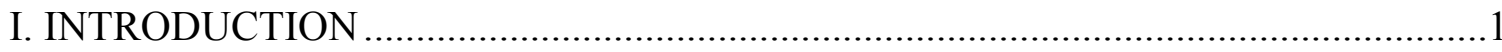

II. NETWORK EFFECTS AND DURABLE ADOPTION: A TEST USING

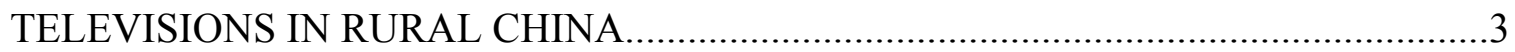

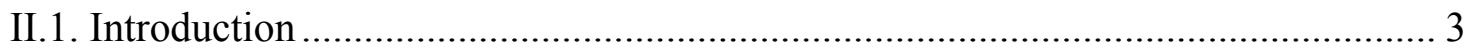

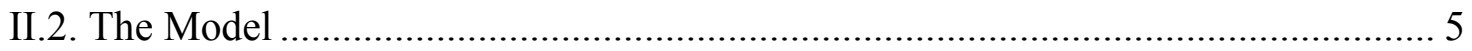

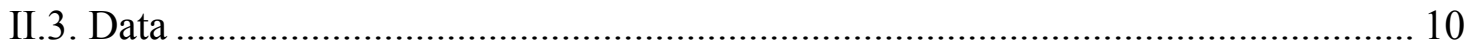

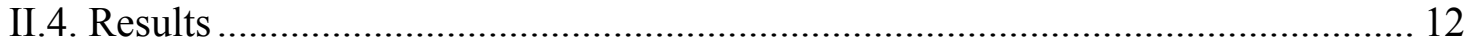

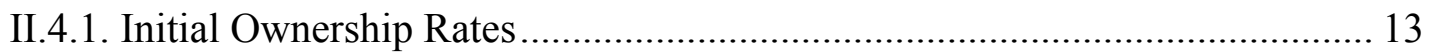

II.4.2. Lagged Ownership Rates .......................................................................... 16

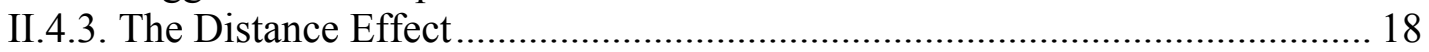

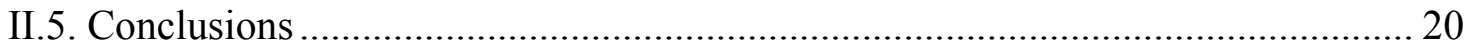

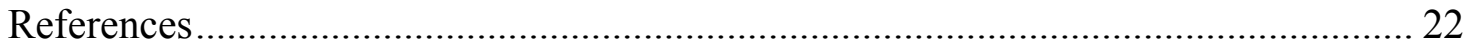

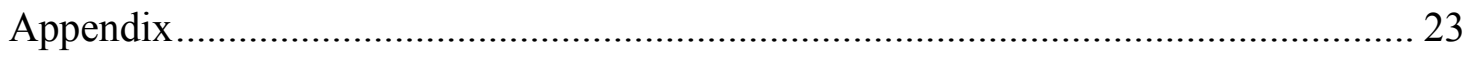

III. DO INSIDER TRADING PATTERNS PREDICT A FIRM'S PATENT

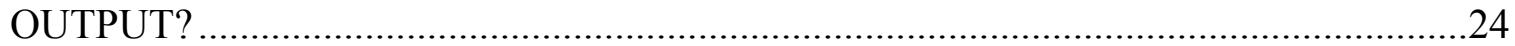

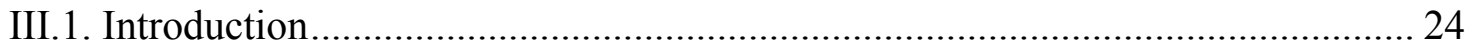

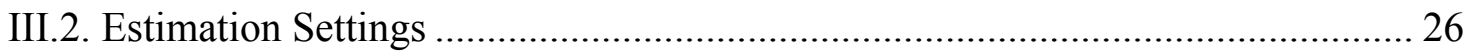

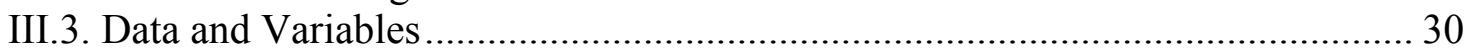

III.3.1. Dependent Variable: Patent Output ............................................................ 31

III.3.2. Independent Variable: Insider Trading Patterns .......................................... 36

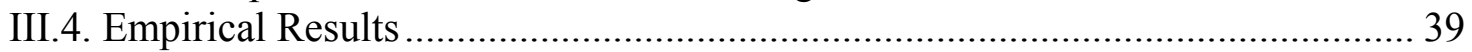

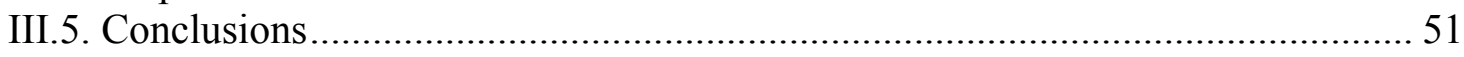

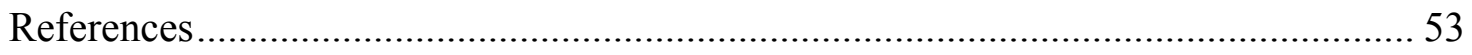

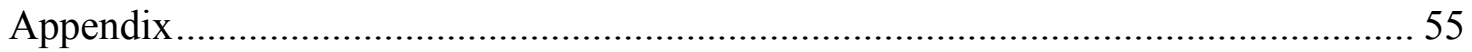

IV. HOW DO KNOWLEDGE STOCKS INFLUENCE THE START-UP AND SURVIVAL OF NEW MANUFACTURING SEGMENTS IN U.S. PATENTING

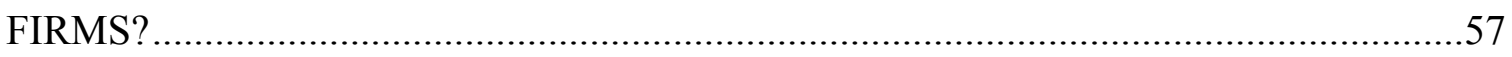

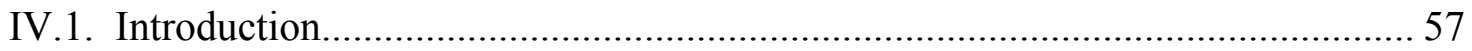

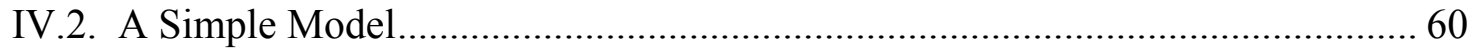

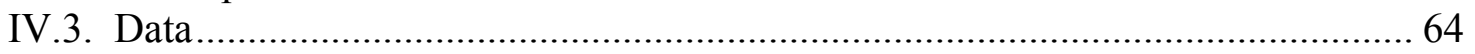

IV.3.1. Dependent Variable: New Industry Entry ................................................ 65

IV.3.2. Independent Variable: Knowledge stocks ………….................................. 69

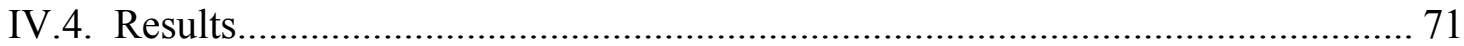

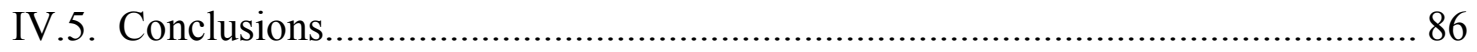

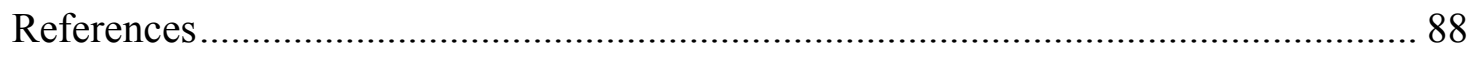

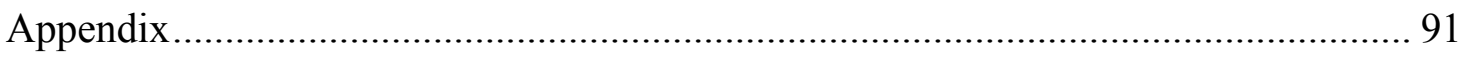

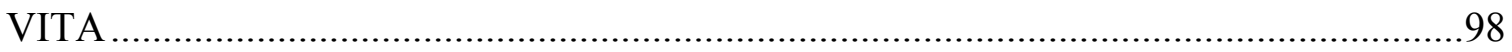




\section{LIST OF TABLES}

TABLE

PAGE

Table 2.1. Demographics of 1999 CTV Non-Owners Versus Owners............................ 11

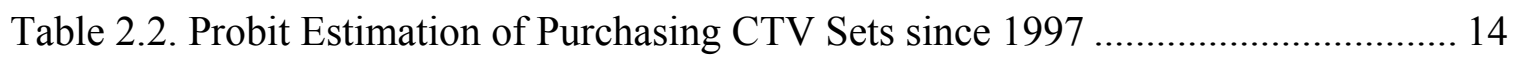

Table 2.3. Effects of Initial Ownership Rates on CTV Adoption (Probit) ...................... 15

Table 2.4. Effects of Ownership Rates on Three Durable Goods Adoption..................... 16

Table 2.5. Effects of Lagged Ownership Rates on CTV Adoption (Probit).................... 18

Table 2.6. Distance Effects on Three Durables Adoption (Probit).................................. 19

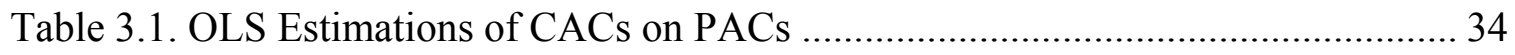

Table 3.2. Transaction Counts for Insider Types.................................................... 37

Table 3.3. Transaction Counts for Transaction Types .............................................. 38

Table 3.4. Summary Statistics of Firms for 1987-94 ................................................ 40

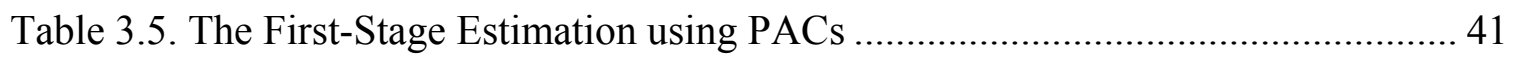

Table 3.6. Explanatory Power of Insider Trading Counts on PACs ............................... 43

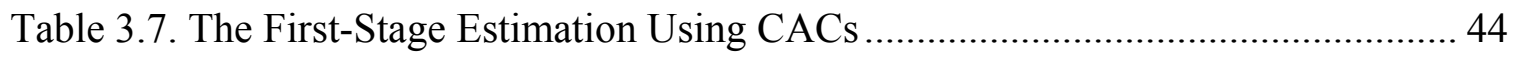

Table 3.8. Explanatory Power of Insider Trading Counts on CACs ............................. 45

Table 3.9. Explanatory Power of Insider Trading Counts ......................................... 46

Table 3.10. The First-Stage Estimations by Technological Categories......................... 47

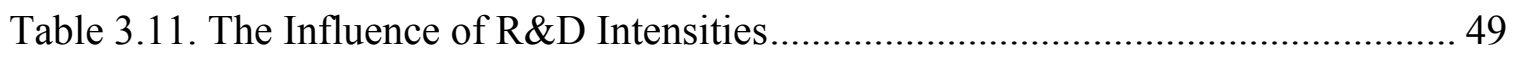

Table 3.12. Explanatory Power of Insider Trading Value on CACs ............................. 50

Table 4.1. Characteristics in 1984 of Patenting firms and Non-Patenting Firms ............. 66

Table 4.2. Characteristics in 1984 of Patenting firms with Entry VS Those without....... 72

Table 4.3. Probit Estimations of Entry Likelihood on Knowledge Stocks ...................... 73

Table 4.4. LP Estimations of Entry Likelihood on Knowledge Stocks ......................... 74 


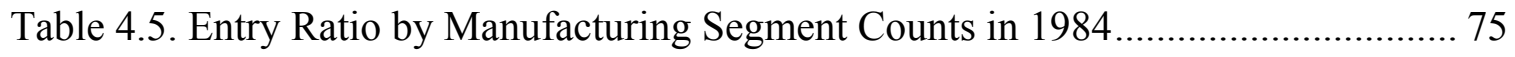

Table 4.6. LP Estimations of Entry Likelihood in all Manufacturing Firms ................... 76

Table 4.7. WLW Estimation of Entry Hazard on Knowledge Stocks ........................... 79

Table 4.8. PH Estimation for Segment Exit Hazard in Patenting Firms......................... 83

Table 4.9. PH Estimation for Segment Exit Hazard in Persistent Patenting Firms .......... 84

Table 4.10. PH Estimation for Segment Exit Hazard in Persistent Manufacturing

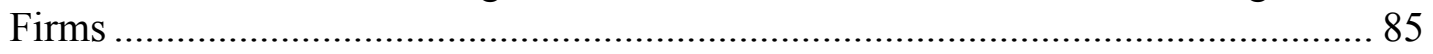

Table 4.A1. LP Estimations of Entry Likelihood with Control for Firm Fixed Effects ... 95

Table 4.A2. WLW Estimation of Entry Hazard without Control for Industry Fixed

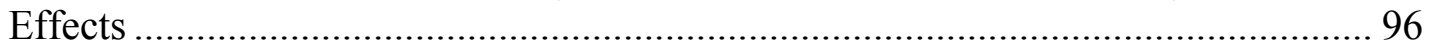

Table 4.A3. WLW Estimation of Entry Hazard in all Manufacturing Firms .................. 97 


\section{LIST OF FIGURES}

FIGURE

PAGE

Figure 2.1. Solution(s) to the Agent's Purchasing Problem ........................................ 8

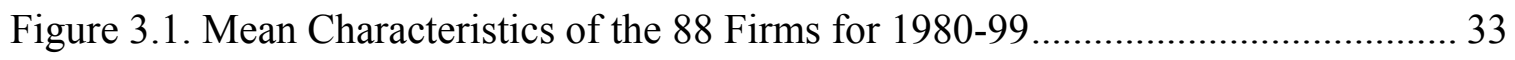

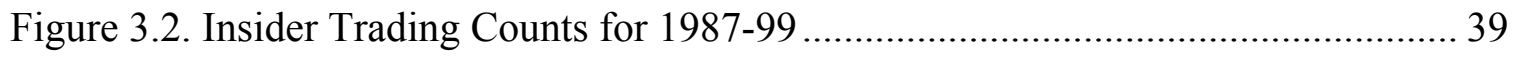

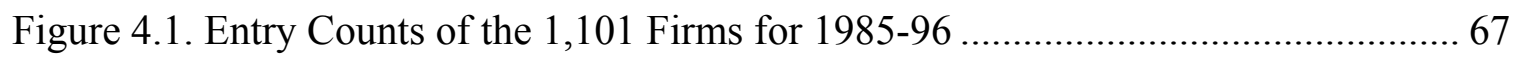

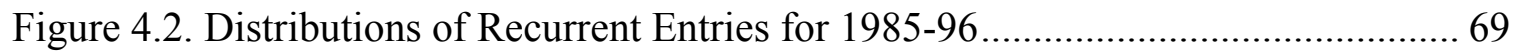

Figure 4.3. Mean Characteristics of Persistent Firms for 1984-96 ............................... 71

Figure 4.4. Kaplan Meier Survival Estimates ............................................................. 81 


\section{INTRODUCTION}

This dissertation is organized into three main chapters. Chapter II examines how free riding across neighbors influenced the diffusion of color television sets in rural China. Chapter III tests for asymmetric information between a firm's management and other investors concerning its patent output. Chapter IV discusses how knowledge stocks influence a patenting firm's later diversification.

Chapter II documents the existence of a type of network effects - free riding across neighbors - in the consumption of color television sets in rural China, which reduces the propensity of non-owners to purchase. I construct a model of the timing of the purchase of a durable good in the presence of free riding, and test its key implications using household survey data in rural China.

Chapter III tests for asymmetric information between a firm's management and other investors about its patent output by examining insider trading patterns and stock price changes in $R \& D$ intensive firms. It demonstrates that management has considerable information about its patent output beyond what is known to investors. It also shows that the predictive power of insider trading patterns on patent output comes from purchases rather than sales.

Chapter IV discusses two sequential channels through which knowledge stocks may influence a firm's later diversification. One is that firms with more knowledge are more likely to enter a new industry. The other is that firms' businesses have a better chance of surviving, conditional on being formed. By examining U.S. public patenting firms in manufacturing sectors for 1984-1996, I find that knowledge stocks predict the likelihood of new industry entry when controlling for firm size. However, this predictive power is 
weakened when diversification effects are included. On the other hand, a survival study of newly established segments shows that initial knowledge stocks have significant positive effects on segment survival, whereas diversification effects are insignificant. 


\section{NETWORK EFFECTS AND DURABLE ADOPTION: A TEST USING \\ TELEVISIONS IN RURAL CHINA}

\section{II.1. Introduction}

Over a decade ago, Liebowitz and Margolis (1994) noted that "[a]lthough network effects are pervasive in the economy, we see scant evidence of [their] existence." Since then, empirical studies establishing the existence of empirically significant network externalities remain relatively scarce. Moreover, much of this evidence relates to technology adoption by firms, ${ }^{1}$ while studies documenting network externalities among consumers are few and far between. Among the few exceptions, Gandal (1994) shows that consumers were willing to pay a premium for spreadsheet software compatible with the Lotus platform and with external database programs; Goolsbee and Klenow (2002) report that people are more likely to buy their first home computer in areas where a high fraction of households already own computers; Berndt, Pindyck and Azonlay (2001) document how network externalities influence the demand for prescription pharmaceuticals; and Park (2004) finds that network externalities in video cassette recorders explain much of the dominance of VHS relative to Betamax.

This chapter provides evidence of a type of network effects - the free-riding effect among consumers of color television sets (CTVs) in rural China. The intuition is straightforward, and it reflects a type of consumption externalities that is perhaps peculiar to developing countries. In rural China, as in other developing countries, the CTV serves

\footnotetext{
${ }^{1}$ For a recent example, see Gowrisankaran and Stavins (2004) on the adoption of electronic transfers, or Bandiera and Rasul (2006) on the adoption of new crops in Mozambique.
} 
in part the role of a public good for the neighborhood. When a household purchases a CTV, neighbors gain because they frequently visit to watch television. The nature of social interactions within a village induces the host to share use of her television. There is a network effect involved since the higher the CTV ownership rate the more convenient it is for a non-owner to free ride. As far as I know, I am the first to document a situation where a type of network effects deters the purchase of a durable good.

The difficulty in identifying the free-riding effect on CTV adoption comes from the fact that it is mixed with other effects, here especially network externalities as in Goolsbee and Klenow (2002), where the larger the size of the network, the more attractive the durable is to non-owners to purchase. These two effects influence CTV adoption in the opposite direction and both are generally measured by the local ownership rate. If one detects a negative gross effect of the ownership rate on the likelihood of household CTV adoption, he may conclude there is a free-riding effect by showing that it dominates the effect of network externalities. However, I find that this gross effect is positive, and thus I fail to detect dominance of the free-riding effect.

In this chapter I test some other implications consistent with the existence of the freeriding effect. First, in other durable goods such as washing machines and refrigerators, where there is no free-riding effect, the effect of local ownership rates should be stronger than CTV. While rural Chinese commonly watch their neighbor's television, they do not generally keep food in their refrigerators or use their washing machines. My finding is consistent with this implication. Second, a proxy to measure the free-riding effect is the distance between neighbors. As distance raises visiting cost, the free-riding effect would be weakened, thus having less negative influence on CTV adoption. My regression 
results show a significantly positive relationship between the likelihood of CTV adoption and distance when controlling for the local ownership rate. But I fail to detect this in either washing machine or refrigerator adoption. These conclusions provide evidence of a free-riding effect in CTV adoption.

The chapter is organized as follows. In Section II.2, I present a dynamic model of a durable purchase with the presence of free riding and its implications. Section II.3 describes data. Section II.4 reports empirical results. Section II.5 concludes.

\section{II.2. The Model}

The model is based on Leahy and Zeira (2005), who discuss the timing and quality choice of durable goods purchases in a general equilibrium dynamic model. In their model, both durable and non-durable goods are consumed and the durable good is lumpy. I ignore general equilibrium considerations and the question of quality choice, while introducing a free-riding effect.

I consider a village with a continuum of infinitely-lived agents, each of which derives utility from consumption of a durable and a non-durable good. Agents are identical except for the utility they receive from consumption of the durable good. The durable good is homogeneous, does not depreciate, and only a single unit of it can be purchased. Agents begin life with zero wealth at time $t=0$, earn income at the rate $y$, and must pay a price $p$ for the durable good out of savings. ${ }^{2}$ Agents discount at the rate $\rho$, which I

\footnotetext{
${ }^{2}$ The absence of consumption loans and the exogeneity of $p$ are assumptions consistent with the situation in rural China during the period of the survey. In the 1990s, the rural market for CTVs was small relative to urban demand, so consumer prices would reflect primarily urban market conditions.
} 
assume equals the interest rate $r$. Let $u(c)$ denote utility from non-durable good consumption, and let $v$ denote the flow of utility from durable good consumption. I assume $u(c)$ is the same for all agents, it is increasing, strictly concave and satisfies $\lim _{c \rightarrow 0} u^{\prime}(c)=+\infty$ and $\lim _{c \rightarrow \infty} u^{\prime}(c)=0$. The flow of utility from consumption of the durable good is given by

$$
v(t)=\left\{\begin{array}{ll}
\beta(t) \gamma v & t<T \\
v, & t \geq T
\end{array},\right.
$$

where $T$ is the time of the durable purchase, $\beta(t)$ is the local ownership rate, and $\gamma \in[0,1]$ is a parameter governing the strength of the free-riding effect. Agents differ in their valuation of $v$, which for each one is a draw from $F(v)$. Larger value of $\beta(t)$ and $\gamma$ increase the utility from consumption of other people's durable goods and will ceteris paribus discourage an agent from purchasing her own.

Since I have assumed the interest rate and discount rate are equal, consumption smoothing implies that non-durable good consumption is constant during the interval $[0, T]$ and also during the interval $(T, \infty)$. Thus, under perfect foresight on $\beta(t)$, the agent's problem is

$$
\max _{c_{1}, c_{2}, T} \int_{0}^{T} e^{-r t}\left[u\left(c_{1}\right)+\beta(t) \gamma v\right] d t+\int_{T}^{\infty} e^{-r t}\left[u\left(c_{2}\right)+v\right] d t
$$

subject to

$$
\begin{aligned}
& p e^{-r T}+\int_{0}^{T} e^{-r t} c_{1} d t+\int_{T}^{\infty} c_{2} e^{-r t} d t \leq \int_{0}^{\infty} y e^{-r t} d t \\
& p e^{-r T}+\int_{0}^{T} e^{-r t} c_{1} d t \leq \int_{0}^{T} y e^{-r t} d t .
\end{aligned}
$$


The consumer maximizes her discounted lifetime utility by choosing the amount of non-durable good consumption at each point in time, and the time of the durable good purchase, subject to her lifetime budget constraint, (2.3), and her financing constraint, (2.4).

It is helpful to begin with the situation without externalities, where $\gamma=0$. Local nonsatiation implies that both (2.3) and (2.4) are binding, and that $c_{2}=y .^{3}$ It then follows that $c_{1}=y-s$, where

$$
s=\frac{r p e^{-r T}}{1-e^{-r T}}
$$

is the constant saving rate during $[0, T]$. Equation (2.5) enables me to rewrite the agent's problem as

$$
U=\max _{T \geq 0} \frac{\left(1-e^{-r T}\right)}{r} u\left(y-\frac{r p e^{-r T}}{1-e^{-r T}}\right)+\frac{e^{-r T}}{r}(u(y)+v),
$$

with necessary condition

$$
e^{-r T}\left[(v+u(y))-u\left(c_{1}\right)\right] \leq u^{\prime}\left(c_{1}\right) s
$$

The left hand side is the discounted present value of a marginal change in $T$, at which time the flow of utility changes from $u\left(c_{1}\right)$ to $v+u\left(c_{2}\right)$. At an interior optimum, this must equal the cost of a marginal change in $T$, which is given by $d\left[\int_{0}^{T} u^{\prime}(y-s) e^{-r t} d t\right] / d T=u^{\prime}\left(c_{1}\right) s$. If $v<r p u^{\prime}(y)$, then (2.7) is a strict inequality and the

\footnotetext{
${ }^{3}$ After time $T$, the only good available for purchase is the non-durable, so $c_{2} \geq y$. The inequality is strict only when the consumer saves in the interval $[0, T]$ more than is necessary to purchase the durable good. The financing constraint imposes the strict inequality $c_{1}<y$ for any finite $T$. Hence, $c_{1}<c_{2}$ and there is no incentive to save more than $p$ in the interval $[0, T]$ because of consumption smoothing.
} 
agent never purchases the durable good. Let $T=T(v)$ satisfy (2.7) when the solution is interior. I verify that $T^{\prime}(v)<0$. Thus, its inverse $v=V(T)$ exists, with $V^{\prime}(T)<0$.

Reintroducing the free-riding effect simply adds an additional term to the objective function, (2.6):

$$
U=\max _{T \geq 0} \frac{\left(1-e^{-r T}\right)}{r} u\left(y-\frac{r p e^{-r T}}{1-e^{-r T}}\right)+\frac{e^{-r T}}{r}(u(y)+v)+\gamma v \int_{0}^{T} \beta(t) d t .
$$

yielding the first-order condition

$$
v[1-\beta(T) \gamma]=V(T) .
$$

Figure 2.1. Solution(s) to the Agent's Purchasing Problem

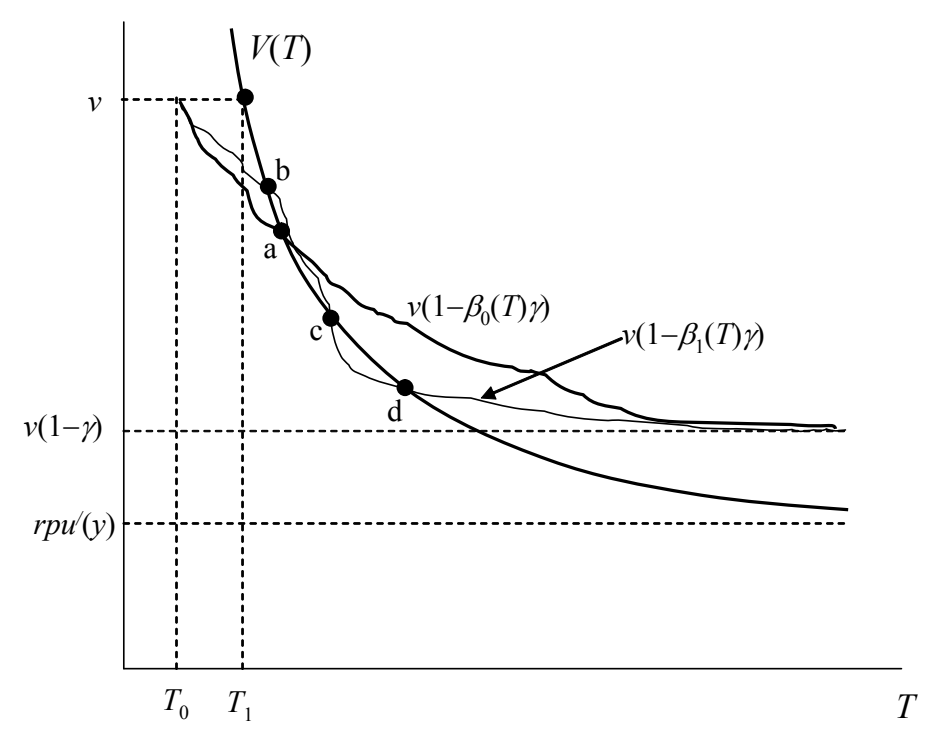

For any time path of ownership $\beta(t), V(T)$ is decreasing in $\gamma$, so $T$ is increasing in $\gamma .{ }^{4}$ Thus, the free-riding effect induces agents to postpone their purchase of the consumer durable, conditional on the existing ownership rate. This much is

\footnotetext{
${ }^{4}$ Of course, if $\gamma$ changes for every household, the equilibrium path of $\beta(t)$ changes.
} 
straightforward. A somewhat more complicated issue is whether the solution to (2.10) is unique. The right hand side of (2.10) is decreasing in $T$, but so is the left-hand side, and consequently there may be multiple equilibria. Figure 2.1 illustrates for two arbitrary paths of $\beta(t) . V(T)$ is a decreasing function, with an asymptote at $T_{0}$ (the minimum time required to save an amount $p$ ) and a lower bound of $r p u^{\prime}(y)$. Given the agent's valuation $v$, there is a unique solution, $T_{1}$, in the absence of free-riding effects. In contrast, the solution for any $\gamma>0$ depends on the time path of $\beta(t)$. For the path $\beta_{0}(t)$, there is a unique solution at $\mathbf{a}$, while for the time path $\beta_{1}(t)$, three solutions are shown, at $\mathbf{b}, \mathbf{c}$, and d.

Ensuring a unique solution requires that the absolute value of the slope of the LHS of (10), $v \gamma \beta^{\prime}(T)$, is not too large. But $\beta(t)$ is of course a function of the model's parameters, most notably the distribution $F(v)$. The expected path of $\beta(t)$ influences the timing of purchase, but then aggregation of all the consumers' decisions determines the equilibrium $\beta(t)$, which must be the same as the expected $\beta(t)$. In the appendix I show that there always exists one equilibrium path of $\beta(t)$ that implies a unique solution $T$ for each agent. This does not imply, however, that other paths do not exist.

I assume for the remainder of the paper that there is a unique $T$ for each agent. Under this assumption, the key testable implication is that higher ownership rates in a neighborhood reduce the likelihood that non-owners will purchase a CTV. To test this implication adequately requires controlling for agents' willingness to pay. A household would postpone its purchase when either its annual income is lower, or its reservation value is lower. I am able to control for income. While I cannot directly observe a 
household's reservation value, I will examine several likely correlates, including the stability of electricity, the quality of TV reception, and the electricity price, each of which would influence the utility of TV consumption.

\section{II.3. Data}

The data used in this chapter are mainly from an October 1999 survey of rural durable goods consumption conducted by the Rural Survey Organization (RSO), the National Bureau of Statistics (NBS) of China. ${ }^{5}$ I also use data from the RSO's regular annual household survey of 1998. The consumption survey covered 20,000 households from all the Chinese continental provinces except Tibet. They were drawn by a stratified random sampling method from the RSO regular survey frame of about 68,300 households. The survey was designed to assess the potential demand for durables in rural China. I exclude from my sample the 0.7 percent of households with no power. Further eliminating households with invalid data entries leaves me with around 18,800 households.

Since owning more than one CTV is rare in rural China, I follow convention in the literature on the demand for durable goods (e.g. Dubin and McFadden (1984); Farrell (1954)) and treat the demand for CTVs as a binary decision of buying or not. I also treat CTV purchases in rural China during the 1990s as first purchases rather than replacements. Before 1980, the start of China's reform program, televisions were scarce even in urban China, CTVs even more so. Most rural households didn't purchase CTVs until the 1990s. If the replacement cycle is 10 years or more, the assumption that most

\footnotetext{
${ }^{5}$ Rong and Yao (2003) used the same data set to study the impact of public service provision on the rural consumption of electric appliances.
} 
rural CTV purchases in the late 1990's were first purchases seems reasonable. This assumption is important because the external effect would be severely weakened if the purchases recorded in the household survey were replacements. CTVs may have replaced black and white sets, but in such cases I still treat CTV purchase as a first purchase. ${ }^{6}$

Table 2.1. Demographics of 1999 CTV Non-Owners Versus Owners

\begin{tabular}{lrlrrc}
\hline \multicolumn{1}{c}{ Variable } & \multicolumn{2}{c}{ Non-owners } & \multicolumn{2}{c}{ Owners } & $t$ statistic \\
\hline Average age & 31.64 & $(10.35)$ & 32.36 & $(9.47)$ & 4.9 \\
Average years of education & 5.33 & $(1.97)$ & 6.08 & $(1.85)$ & 26.4 \\
Population & 4.27 & $(1.34)$ & 4.21 & $(1.31)$ & 3.1 \\
Fraction male & 0.56 & $(0.30)$ & 0.56 & $(0.28)$ & 0.2 \\
Fraction in rural village & 0.94 & & 0.90 & & 9.57 \\
Average net income & 1.79 & $(1.37)$ & 2.75 & $(2.32)$ & 30.7 \\
Fraction with stable electricity & 0.86 & & 0.90 & & 8.4 \\
Electricity price & 0.83 & $(0.64)$ & 0.74 & $(0.50)$ & 11.1 \\
Fraction with strong TV signal & 0.84 & 0.91 & & 14.6 \\
Fraction with TV tower & 0.11 & \multicolumn{5}{c}{0.11} \\
\hline \multicolumn{1}{c}{ Observations } & \multicolumn{3}{c}{7,106} \\
\hline
\end{tabular}

Standard deviations are in parentheses. The last column reports two-sample ttests.

Table 2.1 provides some summary statistics, separating households by ownership status. At the time of the survey, 38 percent of households reported owning a CTV. Compared to non-owners, owners were better educated, earned higher income, and had a slightly smaller household size. As expected, owners also enjoyed lower electricity prices and stronger television signals.

\footnotetext{
${ }^{6}$ There are large quality differences between the two. First, the median purchase price of a black and white television in 1999 was 350 yuan while a CTV's median price was 1620 yuan. Second, I estimated a logit model to test the choices between a black and white television and a CTV, and found that net income has a significant negative effect on black and white television purchases.
} 


\section{II.4. Results}

I analyze the effect of local ownership rates on CTV purchases using cross-sectional probit regressions of household purchases on local ownership rates. The dependent variable is a binary variable that equals one if a household purchased a CTV after the initial year. The independent variable of interest is the village ownership rate before the initial year. The ownership rate within a village is an ideal proxy for network effects. However, I have on average fewer than ten households in each village, and as a result one might be concerned that the sample village ownership rates are imprecise estimates of their population means. To reduce this measurement error, I restrict my sample to villages with at least ten observations when using the village ownership rate. ${ }^{7}$

My control variables are divided into three groups. The first group includes variables describing household characteristics. They are household population, average age, the fraction of the household that is male, average schooling years of members above sixteen years of age, location of the household (town, suburban village, or rural village), and net income per capita. Income measures the household's budget constraint. All other variables are intended to control for a household's preference for electric appliances. The location variable needs a little more elaboration. Location favors a rural household close to a town in two ways. First, living in or close to a town provides households easy access to the market and complementary services, and thus reduces its cost of buying and using durable goods. Second, a household's consumption style may be more like an urban household if it lives in or close to a town.

\footnotetext{
${ }^{7}$ I repeat the regressions with the sample of villages with at least 5 observations. I also run the regressions using the county-level ownership rate. In either case, the main results are persistent.
} 
The second group collects variables describing the public service conditions enjoyed by a household. They are binary variables for stability of the power supply (stable $=1$ ), availability of tap water (yes=1), access to a TV signal receiving tower (yes=1), and TV signal strength $(\operatorname{good}=1){ }^{8}$ Continuous controls in this group are the average prices of electricity (in yuan/ kWh) and tap water (in yuan/ton) in 1997-99. If a village did not have tap water, the average price in the county is used.

The third group of controls includes price indices for CTVs, as well as for refrigerators, washing machines, bicycles, housing, fertilizers, and food. For CTVs, refrigerators and washing machines, I calculate price indices from my survey data. The remaining indices are constructed from RSO's 1998 annual household survey. I am unable to control for possible quality differences among the goods purchased by households. I include province dummies to control for the fixed effect across provinces.

\section{II.4.1. Initial Ownership Rates}

To provide a complete picture of these regressions, I report in Table 2.2 the complete sets of coefficients for CTV adoption since 1997. Half of the estimates are significant at the one percent level, with signs consistent with expectations. In the group of family characteristics, higher household population, greater average education, and higher income increase a household's probability of purchasing a CTV set. The effects of average age and the fraction of the household that is male are not significant. The positive effect of income is as expected. More family members reduce the cost per capita of

\footnotetext{
${ }^{8}$ Power supply stability and TV signal strength are subjective measures. Since the survey did not provide respondents with clear definitions for these two variables, there may be considerable measurement error in these variables.
} 
sharing a CTV, which increases the household's willingness to buy. Higher educational levels have two effects. First, people with more education tend to have a higher desire for a modern living style. Second, more education implies easier adaptation to modern technologies. Geographic location also matters. Households living in a rural village are less likely to purchase than those in town or a suburban village. As expected, a stronger TV signal makes a household more likely to purchase a CTV set. However, the effects of electricity stability and electricity price are not significant.

Table 2.2. Probit Estimation of Purchasing CTV Sets since 1997

\begin{tabular}{|c|c|c|c|}
\hline Variable & Coeffici & ient & $\begin{array}{c}\text { Standard } \\
\text { Error }\end{array}$ \\
\hline Intercept & -3.29 & $* * *$ & 0.64 \\
\hline Average age & -0.13 & & 0.15 \\
\hline Average years of education & 0.06 & $* * *$ & 0.01 \\
\hline Population & 0.07 & $* * *$ & 0.01 \\
\hline Fraction male & 0.06 & & 0.06 \\
\hline Town dummy & -0.08 & & 0.11 \\
\hline Rural village dummy & -0.2 & $* * *$ & 0.06 \\
\hline Average net income & 0.09 & $* * *$ & 0.01 \\
\hline Electricity stability & 0.05 & & 0.06 \\
\hline Electricity price & -0.01 & & 0.02 \\
\hline Strength of TV signal & 0.13 & $* * *$ & 0.05 \\
\hline Having TV tower or not & 0 & & 0.05 \\
\hline PI: bicycles & 0.13 & $* *$ & 0.06 \\
\hline PI: Housing & -0.01 & & 0.04 \\
\hline PI: Fertilizers & 0.05 & & 0.07 \\
\hline PI: Food & 1.16 & $* * *$ & 0.15 \\
\hline PI: CTVs & -0.03 & & 0.09 \\
\hline PI: Refrigerators & -0.17 & & 0.37 \\
\hline PI: Washing machines & 0.57 & & 0.86 \\
\hline Ownership rate & 0.83 & $* * *$ & 0.1 \\
\hline Province dummies & & $\mathrm{Y}$ & \\
\hline Mean Log-likelihood & & -0.49 & \\
\hline Observations & & 10370 & \\
\hline
\end{tabular}

*, **, ***: Coefficient different from zero at 10, 5, 1 percent significance levels, respectively. 
The results clearly show that a household was more likely to purchase a CTV set in a given period when the ownership rate was higher at the beginning of the period. I change the time scale and report the regressions in Table 2.3. The positive effect remains significant. These indicate that either the free-riding effect did not influence household CTV adoption or it was overwhelmed by the effect of network externalities.

\section{Table 2.3. Effects of Initial Ownership Rates on CTV Adoption (Probit)}

\begin{tabular}{cccccc}
\hline & Adoption & \multicolumn{4}{c}{ Adoption } \\
Variable & 1998 & 1997 & 1996 & 1995 & 1994 \\
& $(1)$ & $(2)$ & $(3)$ & $(4)$ & $(5)$ \\
\hline Ownership rate & 0.94 & 0.83 & 1.00 & 1.25 & 1.34 \\
& $(0.10)$ & $(0.10)$ & $(0.14)$ & $(0.12)$ & $(0.14)$ \\
\hline Mean log-likelihood & -0.39 & -0.49 & -0.52 & -0.54 & -0.55 \\
Observations & 9423 & 10370 & 10904 & 11539 & 11844 \\
\hline
\end{tabular}

Notes: Standard errors are in parentheses. Each column regresses the decision to buy a CTV starting at the beginning of 1998-1994, respectively.

If it is the case that free riding influenced CTV adoption but was overwhelmed, one should expect that the estimated coefficient on the ownership rate in regressions of either washing machine or refrigerator adoption will be larger than for CTV because it is unlikely that neighbors share the former two durable goods. Table 2.4 reports results from probit regressions of washing machine and refrigerator adoption since 1997. As expected, the estimated coefficient on the initial ownership rate in the regression of CTV adoption is significantly lower than the other two. Since coefficient values are hard to compare across probit regressions, Table 2.4 also reports the logit and linear probability regression, respectively. The differences are persistently significant. 


\section{II.4.2. Lagged Ownership Rates}

Based on my theoretical model, it is the ownership rate at the purchase time that really matters. Therefore, the initial ownership rate may not properly represent the gross network effect. The ownership rate of each durable increased over time in the survey data. If the ownership rate at the purchase time is a better measure, using the initial ownership rate would result in overestimation of the gross effect. As shown in Table 2.3, except for the adoption since 1998, the estimated coefficient on the initial ownership rate rises as the time scale is expanded.

\section{Table 2.4. Effects of Ownership Rates on Three Durable Goods Adoption}

\begin{tabular}{ccccccc}
\hline \multirow{3}{*}{ Model Setting } & \multicolumn{3}{c}{ Initial Ownership Rates } & \multicolumn{3}{c}{ Lagged Ownership Rates } \\
& CTV & $\begin{array}{c}\text { Washing } \\
\text { Machine }\end{array}$ & Refrigerator & CTV & $\begin{array}{c}\text { Washing } \\
\text { Machine }\end{array}$ & Refrigerator \\
& & & & & \\
\hline Probit & 0.83 & 1.75 & 2.04 & -1.06 & 0.99 & 0.75 \\
& $(0.10)$ & $(0.12)$ & $(0.21)$ & $(0.08)$ & $(0.10)$ & $(0.16)$ \\
Logit & 2.1 & 3.09 & 3.41 & -1.92 & 1.73 & 1.21 \\
& $(0.31)$ & $(0.21)$ & $(0.38)$ & $(0.14)$ & $(0.18)$ & $(0.30)$ \\
LP & 0.28 & 0.4 & 0.49 & -0.3 & 0.2 & 0.16 \\
& $(0.03)$ & $(0.02)$ & $(0.02)$ & $(0.02)$ & $(0.02)$ & $(0.02)$ \\
\hline
\end{tabular}

Standard errors are in parentheses.

An alternative approach to measure the gross network effect is to use the ownership rate the year before a household made a purchase, and use the ownership rate of 1999 to those who had not purchased by the time of the survey (hereafter called the lagged ownership rate). This measure would lead to an underestimation of the gross effect because households with no CTV at the time of the survey are matched to the highest local ownership rates. Keeping this in mind, I rerun regressions using the lagged ownership rate and report the results in Table 2.4. As expected, the estimated coefficient 
on the ownership rate in the regression of CTV adoption decreases significantly and in fact becomes negative. In contrast, although they too decline, the corresponding coefficient for washing machine and refrigerator adoption remain significantly positive. Both are consistent with the hypothesis of that there is a free-riding effect in CTV adoption.

In Table $2.5 \mathrm{I}$ report two robustness tests of the negative effect of the lagged ownership rate on CTV adoption. To save space, I again restrict attention to purchases made since 1997. To ensure that results are not driven by excessive variation in reported income, I keep only those households whose income is within one standard deviation of the mean. The result is reported in column 1 of Table 2.5. The effect of the lagged ownership rate remains significantly negative after the refinement.

I next add more variables that are plausibly correlated with a household's purchase decision. If the results are due to unobserved factors, adding these variables should reduce the effect of the lagged ownership rate. In column 2 of Table 2.5, I add three interactions of the demographic variables (income*education, education*age, and income*age), and three dummies for ownership of other electrical appliances (black and white televisions, washing machines, and refrigerators). I have no particular expectations for the coefficients on the interaction terms, so they are suppressed in the table. As one should expect, ownership of a black and white television reduces the likelihood that the household owns a CTV. In contrast, households that own a washing machine or a refrigerator are more likely also to own a CTV. I conjecture that ownership of these other appliances is correlated with unobserved household characteristics that affect the likelihood of durable purchases. It is notable that addition of these additional controls 
causes the estimated coefficient on the lagged ownership rate to fall from -0.69 to -0.81 , while remaining statistically significant. The consistency of the coefficient on the lagged ownership rate to the addition of these controls increases my confidence that it does not merely reflect a correlation between the lagged ownership rate and the unobservables.

Table 2.5. Effects of Lagged Ownership Rates on CTV Adoption (Probit)

\begin{tabular}{lcc}
\hline \multicolumn{1}{c}{ Variable } & $(1)$ & $(2)$ \\
\hline Lagged ownership rate & $-0.69(0.08)$ & $-0.81(0.09)$ \\
Controls: & & \\
Household characteristics & Yes & Yes \\
Public service conditions & Yes & Yes \\
Prices indices & Yes & Yes \\
Province dummies & No & No \\
Interactions terms & No & Yes \\
Owns B\&W TV & & $-1.75(0.04)$ \\
Owns refrigerator & & $0.58(0.09)$ \\
Owns washing machine & & $0.67(0.05)$ \\
\hline \multicolumn{1}{c}{ Mean log-likelihood } & -0.48 & -0.35 \\
$\quad$ Observations & 9,164 & 10,231 \\
\hline
\end{tabular}

Standard errors are in parentheses. Column (1) is a reduced sample eliminating reported incomes more than one standard deviation from the mean. Column (2) is for the full sample, but missing data reduce the sample size.

\section{II.4.3. The Distance Effect}

I now test another implication of the free-riding effect. Greater distances between rural households are likely negatively correlated with the magnitude of the free-riding effect. As distance raises visiting cost, the free-riding effect should be weakened. Thus, greater distance should promote CTV adoption. To test this, I add in the regressions another independent variable, living space per capita, as a proxy for the average distance 
between neighbors. I drop province dummies because I only have the value of the proxy at the provincial level. I report the results in Table 2.6. With the inclusion of either the initial or the lagged ownership rate, the estimated coefficient on this proxy remains significantly positive.

\section{Table 2.6. Distance Effects on Three Durables Adoption (Probit)}

\begin{tabular}{cccccccccc}
\hline Variable & \multicolumn{3}{c}{ CTV } & \multicolumn{3}{c}{ Washing Machine } & \multicolumn{3}{c}{ Refrigerator } \\
\hline Distance between neighbors & 0.07 & 0.04 & 0.09 & 0.08 & 0.01 & 0.03 & -0.04 & -0.02 & -0.03 \\
& $(0.02)$ & $(0.02)$ & $(0.02)$ & $(0.03)$ & $(0.03)$ & $(0.03)$ & $(0.04)$ & $(0.04)$ & $(0.04)$ \\
Initial ownership rate & ---- & 1.14 & ---- & --- & 2.08 & ---- & ---- & 2.46 & ---- \\
& & $(0.09)$ & & & $(0.11)$ & & & $(0.18)$ & \\
Lagged ownership rate & ---- & ---- & -0.58 & ---- & ---- & 1.38 & ---- & ---- & 1.32 \\
& & & $(0.08)$ & & & $(0.09)$ & & & $(0.14)$ \\
\hline
\end{tabular}

Standard errors are in parentheses.

If this significance really comes from the existence of free-riding effects, one should not expect the same effect from adding distance in either washing machine or refrigerator adoption. For the latter two, since there is no distance effect from network externalities, the null hypothesis is that the coefficient on the distance measure is zero. With the inclusion of this measure, I rerun the probit regressions for washing machine and refrigerator adoption, and report the results in Table 2.6. Again I drop province dummies. The estimated coefficient on this measure in washing machine adoption is significantly positive without controlling for village ownership rates. However, the significance disappears when controlling for either the initial or the lagged ownership rate. The estimated coefficient on the distance measure in refrigerator adoption remains insignificant. Therefore, I conclude the unique existence of the free-riding effect on CTV adoption. 


\section{II.5. Conclusions}

Motivated by the observation that CTV owners in rural China typically welcome their non-owner neighbors to watch television with them, I set out to evaluate how this free riding would influence CTV adoption. I constructed a model of the timing of purchasing a durable good in the presence of this free-riding effect, and showed that the stronger the effect and the greater the local ownership rate, the more likely a non-owner is to postpone purchase.

Using micro level data on nearly 19,000 rural China households surveyed in 1999, I produce evidence that the free-riding effect exists in household CTV adoption. Because of the coexistence of network externalities and free riding, I find that the greater the initial ownership rate, the more likely a non-owner is to purchase a CTV. However, the estimated coefficient on initial ownership rates is significantly lower than that in either washing machine or refrigerator adoption. These differences are similar across different specifications. Moreover, when I estimate CTV adoption using the lagged ownership rate, its estimated coefficient turns to be significantly negative. The negative sign persists with the inclusion of numerous controls. I fail to detect this change in sign when I estimate washing machine and refrigerator adoption using the lagged ownership rate. These results are consistent with the hypothesis that the free-riding effect exists in CTV adoption in rural China.

I further test another implication of the free-riding effect. Greater distances between rural households are likely negatively correlated with the magnitude of the free-riding effect. Controlling for the ownership rate, the distance effect on CTV adoption is significantly positive. In contrast, it is insignificant in washing machine or refrigerator 
adoption. While this effect is not evident in the data for washing machines and refrigerators, it is likely not unique to rural CTV adoption. Other durable goods with the characteristic of a public good should lead to similar results. One notable example is that of local phone service. 


\section{References}

Bandiera, O., and I. Rasul (2006): "Social Networks and Technology Adoption in Northern Mozambique." The Economic Journal, 116(514):869-902.

Berndt, E. R., R. S. Pindyck, and P. Azoulay (2000): "Consumption Externalities and Diffusion in Pharmaceutical Markets: Antiulcer Drugs." NBER Working Paper No. 7772.

Dubin, J. A., and D. McFadden (1984): "An Econometric Analysis of Residential Electric Appliance Holdings and Consumption.” Econometrica, 52(2):345-362.

Farrell, M. J. (1954): “The Demand for Motor Cars in the United States." Journal of the Royal Statistical Society, Series A, 117(2):171-201.

Gandal, N. (1994): "Hedonic Price Indexes for Spreadsheets and an Empirical Test for Network Externalities." RAND Journal of Economics, 25(2):160-170.

Goolsbee, A., and P. J. Klenow (2002): "Evidence on Learning and Network Externalities in the Diffusion of Home Computers." Journal of Law and Economics, 45(2):317-343.

Gowrisankaran, G., and J. Stavins (2004): "Network Externalities and Technology Adoption: Lessons from Electronic Payments." RAND Journal of Economics, 35(2):260-276.

Karshenas, M., and P. L. Stoneman (1993): "Rank, Stock, Order, and Epidemic Effects in the Diffusion of New Process Technologies: An Empirical Model." Rand Journal of Economics, 24:503--28.

Leahy, J. V., and J. Zeira (2005): "The Timing of Purchases and Aggregate Fluctuations." Review of Economic Studies, 72(6):1127-1151.

Liebowitz, S. J., and S. E. Margolis (1994): "Network Externality: An Uncommon Tragedy." Journal of Economic Perspectives, 8(2):133-150.

Manski, C. F. (1993): "Identification of Endogenous Social Effects: The Reflection Problem", Review of Economic Studies, 60(3):531-542.

Park, S. (2004): "Quantitative Analysis of Network Externalities in Competing Technologies: The VCR Case." Review of Economics and Statistics, 86(4):937945.

Rong, Z., and Y. Yao (2003): "Public Service Provision and the Demand for Electric Appliances in Rural China.” China Economic Review, 14(2):131-141. 


\section{Appendix}

If there is a unique solution to equation (2.10) for any $v$, then $\beta(t)$ is uniquely defined for all $t$. The ownership rate must satisfy

$$
\beta(t)=\left\{\begin{array}{cc}
0, & t \in\left[0, T_{\text {min }}\right] \\
1-F\left(\frac{V(t)}{1-\beta(t) \gamma}\right), & t \in\left(T_{\min }, \infty\right)
\end{array}\right.
$$

where $T_{\min }=r^{-1} \ln ((r p+y) / y)$. I need only consider values of $t \geq T_{\min }$. It is easy to verify that

$$
\beta=1-F\left(\frac{V}{1-\beta \gamma}\right)
$$

has a unique solution for any given $V$. The LHS of (2.A2) is increasing in $\beta$ while the

RHS is decreasing. At $\beta=0$, the RHS is $F(V) \geq \beta=0$. At $\beta=1$ the RHS is $F\left(\frac{V}{1-\gamma}\right)$ $\leq \beta=1$. Since both functions are continuous, there exists a unique solution $\beta(V) \in[0,1]$ satisfying (2.A2). But as $V(t)$ is uniquely defined for any $t \geq T_{\min }$ then $\beta(t) \in[0,1]$ is uniquely defined for all $t \geq T_{\min }$. 


\section{DO INSIDER TRADING PATTERNS PREDICT A FIRM'S PATENT OUTPUT?}

\section{III.1. Introduction}

Numerous studies have documented that "corporate insiders" 9 earn excess returns from trading the securities of their firms (e.g., Jaffe (1974); Finnerty (1976); Seyhun (1986)). However, the specific sources of information asymmetry that lead to insider gains have not been comprehensively investigated. Aboody and Lev (2000) demonstrate that $R \& D$ is a major contributor to information asymmetry by finding that insider gains in R\&D intensive firms are substantially larger than those in firms that conduct little R\&D. ${ }^{10}$ They argue that the uniqueness of R\&D investments ${ }^{11}$ makes it difficult for outsiders to learn about the productivity of a given firm's R\&D. The absence of organized $R \& D$ markets and the ambiguity of $R \& D$ accounting rules further exacerbate the information asymmetry associated with R\&D.

It is interesting to further ask how each R\&D-related source contributes to information asymmetry. This chapter explores a potential source, the value of a firm's patent output, which has been widely used to measure a firm's R\&D success. The value of patent output (hereafter patent output) refers to the discounted present value of a firm's

\footnotetext{
${ }^{9}$ Corporate insiders are defined by the 1934 Securities and Exchange Act as corporate officers, directors, and owners of 10 percent or more of any equity class of securities.

${ }^{10}$ There is other empirical evidence consistent with a relatively large information asymmetry associated with R\&D. Barth, Kasznik, and McNichols (1998) report that analyst coverage is significantly larger for R\&D intensive firms. Similarly, Tasker (1998) reports that R\&D intensive firms conduct more conference calls with analysts than less R\&D intensive firms.

${ }^{11}$ According to Kothari, Laguerre, and Leone (1998), in the regression of future earnings variability on investment in R\&D, PP\&E (property, plant, and equipment), and other determinants of earning variability like firm size and leverage, the coefficient on R\&D is three times as large as that on PP\&E.
} 
future net cash flow contributed by its granted patents. Since it is practically impossible to distinguish the contribution of patents from many other factors, a considerable literature uses the count of granted patents as a proxy for R\&D success (e.g., Scherer (1965); Schmookler (1966); Griliches (1995)). But this proxy is limited by the large variance in the value of individual patents. One way to account for this heterogeneity is to use citation-weighted patent counts. That is, a firm's patent counts are supplemented with the number of subsequent citations. ${ }^{12}$

Patents are economically valuable, and their potential impact on firm value has been recognized by investors in the stock market. Empirical evidence shows that patent value is partially reflected in the stock price before relevant information is fully released. Hall, Jaffe, and Trajtenberg (2005) report that the market value of a listed firm is positively correlated with the portion of forward citations that cannot be predicted based upon past citations of its granted patents. Deng, Lev, and Narin (1999) find that the number of granted patents and patent citations are strongly related to investors' growth expectations in the chemicals, drugs, and electronics industries. Given this recognition by investors, it is interesting to ask whether management possesses information about its patent output beyond what is known to investors. However, as far as I know little evidence has been provided on this question.

In this chapter I use corporate insider trading records during the period of patent application to test whether management possesses privileged information about its patent output. I only include corporate officers and directors, which are regarded as the

\footnotetext{
${ }^{12}$ See Section III.3 for a detailed discussion on measures of patent output.
} 
management. Hereafter, "insider trading" refers to corporate officers and directors trading in their own stocks, which has been reported to the SEC. The motivation for examining insider trading records is that the information management has about patent output, but that is not known to other market participants, is likely to be reflected in insider trading when management exploits its information advantage in the stock market.

Specifically, I ask whether, given market reactions, insider trading patterns have significant effects on predicting patent output. To analyze this question, I examine regressions of patent output on insider trading patterns and abnormal stock returns. I find that management possesses statistically significant additional information. Moreover, the predictive power of insider trading patterns on patent output comes from purchases while insider sales appear to have little predictive power. These findings are similar across different measures of patent output, across different time scales, and across different measures of insider trading patterns.

This chapter is organized as follows. Section III.2 develops a two-stage estimation model. Section III.3 describes the data and variables. Section III.4 reports the empirical results. Section III.5 concludes.

\section{III.2. Estimation Settings}

The rational expectations hypothesis implies that investors react only to unexpected shocks. The occurrence of a fully expected event should not influence investment behavior, and hence should have no impact on the stock price. The same logic applies to patent output. Both management and investors react only when they observe unexpected fluctuations of patent output. To examine the relationship between insider trading 
patterns and a firm's patent output, one should first estimate the unexpected portion of this output.

Pakes and Grilliches (1980) provide an empirical model to estimate the relationship between patents applied for and R\&D expenditures. A statistically significant relationship has been found. I use a similar model here to estimate market expectations about a firm's patent output given the current $R \& D$ expenditures. I choose a linear production function instead of Cobb-Douglas because OLS estimation results show that the $\mathrm{R}^{2}$ with the linear function is higher. ${ }^{13}$ I ignore the lagged effects of R\&D expenditures in light of the finding of Hall, Griliches, and Hausman (1986) that the contribution of the observed R\&D history to the current year's patent application is quite small. Thus, the first-stage estimation model is as follows.

$$
P C_{i, t}=\alpha_{1}+\theta R D_{i, t}+\eta_{1}{ }^{\prime} F^{\prime R} M_{i}+\eta_{2}{ }^{\prime} Y E A R_{t}+\varepsilon_{i, t}^{1}
$$

where $P C_{i, t}$ is a measure of firm $i$ 's patent output in year $t$. It is not directly observable in year $t$ because no one knows the future net cash flow that these patents will contribute to. $R D_{i, t}$ is the $\mathrm{R} \& \mathrm{D}$ expenditures in year t. It measures firm $i$ 's patent-related $\mathrm{R} \& \mathrm{D}$ investment. FIRM $i$ is a vector of firm dummies to control for the fixed effects across firms. $Y E A R_{i}$ is a vector of year dummies to control for annual differences of the patent granting process. $\varepsilon_{i, t}^{1}$ includes the contribution of ignored factors, such as managerial skills in $R \& D$ process, and uncertainty in $R \& D$ investment. They are not publicly observable.

\footnotetext{
${ }^{13}$ Redoing the regressions using the Cobb-Douglas function has little effect on the main results.
} 
In the second stage, I use the difference between the realized and the estimated patent output from model (3.1), $\left(P C_{i, t}-P \hat{C}_{i, t}\right)$ to measure the unexpected portion of patent output. Management should not react promptly to $\left(P C_{i, t}-P \hat{C}_{i, t}\right)$ unless it has considerable information about the realized patent output, $P C_{i, t}$. Thus, if the effects of contemporary insider trading patterns are significant to explain $\left(P C_{i, t}-P \hat{C}_{i, t}\right)$, it would indicate that management does have timely considerable information about $P C_{i, t}$.

Since my interest is in management's timely knowledge about realized patent output, I only include insider trading measures in the years around the observation year. Those measures in the later years may help to explain $\left(P C_{i, t}-P \hat{C}_{i, t}\right)$ either because additional information about patent value is gradually released or because management strategically delays its reaction. Because it is impossible to distinguish between these two effects, I ignore the possible delay effect and focus on examining contemporary insider activities. I use the following empirical model to examine how insider trading patterns explain $\left(P C_{i, t}-P \hat{C}_{i, t}\right)$

$$
P C_{i, t}-P \hat{C}_{i, t}=\alpha_{2}+\sum_{j=-1}^{1} \beta_{j} I P_{i, t+j}+\sum_{j=-1}^{1} \gamma_{j} I S_{i, t+j}+\varepsilon_{i, t}^{2}
$$

where the insider purchase measures, $I P$ and insider selling measures, $I S$ from year $t-1$ to $t+1$ are included. I treat insider purchases and insider sales separately in case that they have different explanatory power. Several empirical studies have revealed this difference. By examining listed companies for 1975-95, Lakonishok and Lee (2001) find that the informative of insider activities in predicting stock returns comes from purchases while 
insider sales appear to have no predictive power. Jeng, Metrick, and Zeckhauser (2003) report that for a one year holding period insider gains on purchases are 0.4 percent abnormal returns per month while the abnormal returns for sales are insignificant.

Admittedly, this approach may not reveal management's knowledge about the realized patent output. Insider trading patterns should reflect the aggregation effect of all shocks during the period, among which fluctuations in patent output may be a small part. However, as long as we detect significant estimated coefficients on either IP or $I S$ in model (3.2), we should confirm management's timely considerable information about patent output. Even if the effects of insider trading patterns are significant to explain $\left(P C_{i, t}-P \hat{C}_{i, t}\right)$ in model (3.2), it is still unclear whether management knows better about patent output than investors.

An alternative explanation is that management follows the market, and the market knows about $\left(P C_{i, t}-P \hat{C}_{i, t}\right)$. To reject this hypothesis, I then test whether management possesses considerable information about patent output beyond what is known to investors. Romer and Romer (2000) find out that the Federal Reserve has considerable information about inflation beyond what is known to commercial forecasters by examining whether individuals who know the commercial forecasts could make better forecasts if they also knew the Federal Reserve's. I use a similar approach by testing whether investors who know the market reactions would know better about $\left(P C_{i, t}-P \hat{C}_{i, t}\right)$ if they also knew insider trading patterns. The empirical model is as follows. 


$$
\begin{aligned}
P C_{i, t}-P \hat{C}_{i, t}= & \alpha_{3}+\sum_{j=-1}^{1} \beta_{j} I P_{i, t+j}+\sum_{j=-1}^{1} \gamma_{j} I S_{i, t+j} \\
& +\sum_{j=-1}^{4} \delta_{j}\left(R_{i, t+j}-R_{t+j}^{m}\right)+\varepsilon_{i, t}^{3}
\end{aligned}
$$

where the abnormal returns from year $t-1$ to $t+4$ are included. These measure the market reactions around the patent application period as well as in the later years. ${ }^{14} R_{i, t}$ is the rate of return on firm $i$ 's stock in year t. $R_{t}^{m}$ is the S\&P Industrial Index annual return in year $t$. If any estimated coefficient on either $I P$ or $I S$ in model (3.3) remains significant, I would reject the null hypothesis that management knows about patent output no more than the market while accepting that it knows better.

Model (3.3) would be seriously flawed if the interaction between management and investors is significant. Fortunately, this problem is minor due to their weak relationship revealed by empirical evidence. Lakonishok and Lee (2001) find that little market movement is observed when insiders trade or when they report their trades to the SEC. Seyhun (1986) and Rozeff and Zaman (1988) show that, net of transaction costs, investors do not benefit by imitating insiders. ${ }^{15}$

\section{III.3. Data and Variables}

The variables used in this chapter are extracted from three major data sources. One is patent data from the NBER, which includes information on granted patents and their

\footnotetext{
${ }^{14}$ Redoing the regressions using different length of leads in abnormal returns has little effect on the results.

${ }^{15}$ It is still debatable whether investors can profit from knowing what insiders are doing. Bettis, Vickrey, and Vichrey (1997) show that investors can earn abnormal returns, net of transaction costs, by analyzing publicly available information about transactions by top management.
} 
citations. Another is firm-level financial data from the Compustat annual company files. Both active and subsequently delisted companies are included. The last are insider trading data starting at 1986 from the Thomson Financial (TFN), containing all purchase and sales transactions made by insiders and reported to the SEC.

If insiders react to fluctuations of patent output, it would be more likely to happen in R\&D intensive firms where fluctuations are much stronger. For this reason, I focus on examining R\&D intensive firms. In the analysis, I only include firms whose average patent annual counts (hereafter PACs) for 1986-94 are greater than 30. The PACs refer to the number of granted patents that are applied for in a given year. After excluding firms with no insider trading record, I end up with 88 firms. ${ }^{16}$

\section{III.3.1. Dependent Variable: Patent Output}

Before November 2000, patent applications in the US were kept secret until the patent issues. ${ }^{17}$ The USPTO only published the granted patents. Access to pending patent applications in the USPTO was governed by 35 USC 122, which states:

Applications for patents shall be kept in confidence by the Patent and Trademark Office and no information concerning the same given without authority of the applicant or owner unless necessary to carry out the provisions of any Act of Congress or in such special circumstances as may be determined by the Commissioner.

\footnotetext{
${ }^{16}$ A list of the 88 firms is in the Appendix.

${ }^{17}$ After 2000, patent applications in the USPTO are required to publish within 18 months after the earliest date of the application. Even so, management's foreknowledge of patent applications is still apparent.
} 
Since the invention date of a patent is not available, I treat its application date as its invention date. Proxies are used to measure patent output by examining granted patents, valid patents ${ }^{18}$, international patent applications, or patent citations (Earnst (1999)) due to the absence of an organized patent market. To measure the realized patent output, I count the number of granted patents that are applied for in a given year, which comes to be PACs.

A truncation bias is involved in patent counting. In a later year a larger fraction of patent applications are likely to stay in the examination process. Thus, fewer patents are expected to appear in the data set. My last observation year is 1994, with granting records until 1999 as the reference. This truncation bias is ignorable because the likelihood that a 1994 patent application still stayed in the examination process in 1999 was rare. ${ }^{19}$

According to the USPTO website, a lag between the application time and the granted time (hereafter called grant lag) is 24.6 months on average. The grant rate historically was about $66 \%$, which has dropped to $54 \%$ recently, as claimed by the USPTO. Therefore, the current PACs were unobservable to either management or investors.

The fluctuation in PACs is hard to predict within a firm. Pakes and Grilliches (1980) find that R\&D expenditures can only explain on average $20-30 \%$ of the volatility of PACs in the within-firm time-series dimension. This percentage is expected to be even lower in R\&D intensive firms in which PACs are more volatile.

\footnotetext{
${ }^{18}$ A patent is valid if it has been previously granted and its protection fee is still paid.

${ }^{19}$ According to Hall, Jaffe, and Trajtenberg (2001), less than 2\% of applications submitted during 1990-92 had a grant lag of more than 4 years.
} 
I also use citation annual counts (hereafter CACs) to measure patent output. The CACs refer to the summed citation counts of those granted patents that are applied for in a given year. The number of citations received by a patent in subsequence is often interpreted as a signal of economic importance (Albert, Avery, Narin, and McAllister (1991)). Hall, Jaffe, and Trajtenberg (2005) find that patent citations are useful to measure the "importance" of a firm's patents as the intangible assets of knowledge.

There are two types of truncation biases associate with CACs. Besides the one coming from patent counting, There is another bias from the citing side: the citation lifetime is long, with some patents receiving citations even after 30 years. In my case, I do not know how many more citations will come after 2006. The effect is biased since citation counts of a 1987 patent are less likely to be affected than a 1994 patent. I use year dummies to control for this bias.

Figure 3.1. Mean Characteristics of the 88 Firms for 1980-99

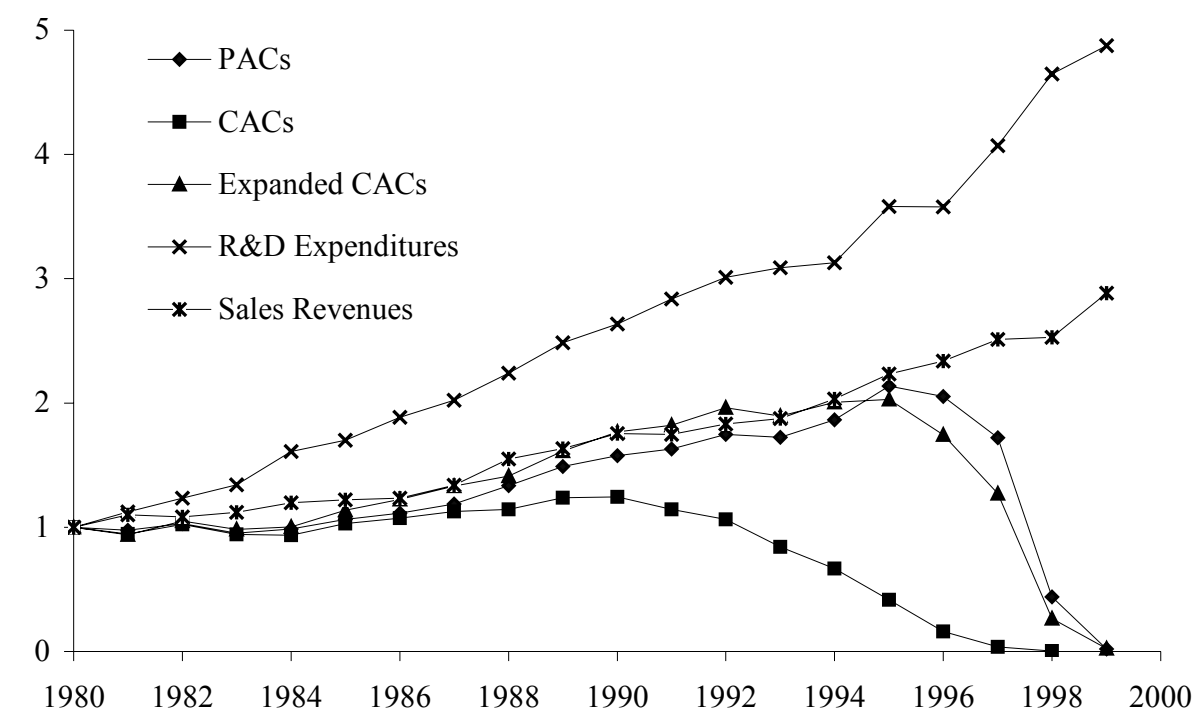


Figure 3.1 shows some mean characteristics of the 88 firms for 1980-99 in Figure 3.1. Each variable is normalized by dividing by its 1980 value. R\&D expenditures increased four-fold from 1980 to 1999 while sales increased only 2-fold. The upward trend in PACs reversed in 1995. The same reverse in CACs happened in 1990. These are because the granting records in the NBER data stop in 1999. For the same reason, both variables dropped to near zero in 1999.

\section{Table 3.1. OLS Estimations of CACs on PACs}

\begin{tabular}{|c|c|c|c|c|c|c|c|c|}
\hline \multirow{3}{*}{ Variable } & \multicolumn{4}{|c|}{ All Observations } & \multicolumn{4}{|c|}{88 Firms } \\
\hline & \multicolumn{2}{|c|}{ (1) } & \multicolumn{2}{|l|}{ (2) } & \multicolumn{2}{|l|}{ (3) } & \multicolumn{2}{|l|}{ (4) } \\
\hline & Est. & S.E. & Est. & S.E. & Est. & S.E. & Est. & S.E. \\
\hline Intercept & $-46 * * *$ & 17 & $-27 * * *$ & 6 & $-410 * * *$ & 164 & $-294 * * *$ & 69 \\
\hline PACs & $14.5 * * *$ & 0.1 & $14.5 * * *$ & 0.1 & $16.7 * * *$ & 0.3 & $16.7 * * *$ & 0.3 \\
\hline \multicolumn{9}{|l|}{ Year dummy } \\
\hline 87 & 29 & 23 & & & 199 & 223 & & \\
\hline 88 & 18 & 23 & & & 91 & 222 & & \\
\hline 89 & 19 & 23 & & & 100 & 222 & & \\
\hline 90 & 24 & 23 & & & 156 & 222 & & \\
\hline 91 & 23 & 23 & & & 144 & 222 & & \\
\hline 92 & 21 & 23 & & & 132 & 222 & & \\
\hline 93 & 17 & 23 & & & 88 & 222 & & \\
\hline $\mathrm{R}^{2}$ & \multicolumn{2}{|l|}{0.85} & \multicolumn{2}{|l|}{0.85} & \multicolumn{2}{|l|}{0.84} & \multicolumn{2}{|c|}{0.84} \\
\hline Observations & \multicolumn{2}{|l|}{8338} & \multicolumn{2}{|l|}{8338} & \multicolumn{2}{|l|}{703} & \multicolumn{2}{|l|}{703} \\
\hline
\end{tabular}

To create more observation years when using CACs, I expand citation records for each patent to August 2006 by retrieving citation information from the USPTO website, and recalculate the CACs. ${ }^{20}$ As shown in Figure 3.1, the trend of this expanded CACs fits

\footnotetext{
${ }^{20}$ It is more complicated to expand PACs. One needs to track all subsidiaries of the 88 firms. Moreover, each subsidiary may not be uniquely identified in the USPTO data.
} 
well with the PACs till $1995 .^{21}$ I only use the expanded CACs in my estimations for 1987-94.

To better understand the relationship between PACs and CACs, I run the OLS estimations of CACs on PACs for the years 1987-94 and report the results in Table 3.1. I first use all observations that have at least one PAC. In column (1), I include year dummies to control for the second truncation bias. It shows that the model explains $85 \%$ of the volatility in CACs. The estimated coefficient on PACs is significantly positive while those on year dummies are insignificant. I test the null hypothesis that each coefficient on year dummies is zero and fail to reject the null at the significance level of $10 \%$. Thus, the effect of the second truncation bias is negligible. In column (2) I exclude year dummies. The effect of PACs remains significant with the same $\mathrm{R}^{2}$. In column (3) and (4), I repeat the estimations using the 88-firm observations with at least one PAC. The $\mathrm{R}^{2}$ is slightly lower while the estimated coefficient on PACs increases by $15 \%$, indicating higher citation counts per patent in $R \& D$ intensive firms. ${ }^{22}$

Though they are similar, these two measures are different in information utilization. Hall, Jaff and Trajtenberg (2001) document that it took over 10 years for a 1975 patent to receive $50 \%$ of its citations, the total of which is measured within a 35 -year time

\footnotetext{
${ }^{21}$ To check the correctness of the citation data that I retrieve from the USPTO website, I compare it with the NBER data by examining the patents with patent number from 6000001 to 6009554 . It turns out that my data is quit precise with respect to the NBER data. I find 4 patents with citation errors, with an error rate of only $0.04 \%$. Among them, 3 patents have citations incomplete because a rare situation is not taken into account in my program, and 1 patent has no citation due to the download problem. Since the error rate is within tolerance and no sampling bias is expected, I use the data as it is. Comparatively, the NBER data has 15 patents with errors, of which 10 patents have been withdrawn and 5 have updated citations.

${ }^{22}$ It may be because R\&D intensive firms tend to focus on more influential R\&D programs. Or it may simply reflect that the distribution of citation counts is right-skewed.
} 
window. ${ }^{23}$ In my case, CACs utilize citation records for at least 12 years. Comparatively, more than $95 \%$ of patent applications during $1973-75$ were granted in four years.

\section{III.3.2. Independent Variable: Insider Trading Patterns}

Insiders were required to inform the SEC of any trades in the firm's stock by filing a "Statement of Change in Beneficial Ownership of Securities" form by the tenth of the month ${ }^{24}$ following the month in which they trade. Trading on privileged information is illegal, by Sections 17(a) and 10(B) of the Securities and Exchange Act of 1934 and SEC Rule 10(b)-5. However, since patent applications are submitted frequently in an R\&D intensive firm, insider trading based on them is less likely to face legal jeopardies. ${ }^{25}$

Table 3.2 summarizes the transaction counts of each insider type for $1987-94 .{ }^{26}$ The Vice President, Officer, and Director are the three types who engage in the heaviest trading. They account for $73 \%$ of the total counts. Since my interest is in management, I exclude the following personals: $\mathrm{SH}, \mathrm{AF}, \mathrm{B}, \mathrm{UT}, \mathrm{T}, \mathrm{R}, \mathrm{TR}, \mathrm{GC}, \mathrm{CP}, \mathrm{AI}$, and IA. About $6 \%$ of the total transaction counts are eliminated.

\footnotetext{
${ }^{23}$ It would be useful to know how reliable it is to estimate a firm's life-time (say 35 years) CACs by examining the CACs of the first 10 years. Unfortunately, no one did it so far as I know.

${ }^{24}$ Effective on August 29, 2002, insiders must report to the SEC certain changes in their beneficial ownership of their company's securities within 2 business days after the date of the transaction.

${ }^{25}$ Insider trading has been found in many corporate events, such as bankruptcy (Seyhun and Bradley (1997)), dividend initiation (John and Lang (1991)), seasoned equity offerings (Karpoff and Lee (1991)), stock repurchases (Lee, Mikkelson, and Parch (1992)), and takeover (Seyhun (1990)).

${ }^{26}$ See TFN Insider Filing Data for details.
} 
Table 3.2. Transaction Counts for Insider Types

\begin{tabular}{|c|c|c|c|}
\hline Code & Count & Percentage & Description \\
\hline $\mathrm{VP}$ & 40060 & 37.77 & Vice President \\
\hline $\mathrm{O}$ & 22501 & 21.21 & Officer \\
\hline $\mathrm{D}$ & 14749 & 13.91 & Director \\
\hline OX & 6532 & 6.16 & Divisional Officer \\
\hline OD & 5092 & 4.80 & Officer and Director \\
\hline $\mathrm{CB}$ & 4838 & 4.56 & Chairman of the Board \\
\hline$P$ & 3070 & 2.89 & President \\
\hline$* \mathrm{SH}$ & 2655 & 2.50 & Shareholder \\
\hline$* \mathrm{AF}$ & 1542 & 1.45 & $\begin{array}{l}\text { Affiliated Person (A person who is able to exert influence on a } \\
\text { corporation, often as a result of minority ownership.) }\end{array}$ \\
\hline OS & 1538 & 1.45 & Officer of Subsidiary Company \\
\hline * B & 1520 & 1.43 & Beneficial Owner of more than $10 \%$ of a Class of Security \\
\hline $\mathrm{MC}$ & 570 & 0.54 & Member of Committee or Advisory Board \\
\hline $\mathrm{CF}$ & 294 & 0.28 & Chief Financial Officer \\
\hline * UT & 269 & 0.25 & Unknown \\
\hline$* \mathrm{~T}$ & 221 & 0.21 & Trustee \\
\hline OT & 180 & 0.17 & Officer and Treasurer \\
\hline $\mathrm{H}$ & 142 & 0.13 & Officer, Director and Beneficial Owner \\
\hline * $\mathrm{R}$ & 97 & 0.09 & Retired \\
\hline DO & 53 & 0.05 & Director and Beneficial Owner of more than $10 \%$ of a Class of Security \\
\hline $\mathrm{CE}$ & 35 & 0.03 & Chief Executive Officer \\
\hline$* \mathrm{TR}$ & 28 & 0.03 & Treasurer \\
\hline $\mathrm{CO}$ & 23 & 0.02 & Chief Operating Officer \\
\hline CEO & 16 & 0.02 & Chief Executive Officer \\
\hline GM & 13 & 0.01 & General Manager \\
\hline * GC & 8 & 0.01 & General Counsel \\
\hline $\mathrm{VC}$ & 8 & 0.01 & Vice Chairman \\
\hline $\mathrm{F}$ & 6 & 0.01 & Founder \\
\hline * CP & 3 & 0.00 & $\begin{array}{l}\text { Controlling Person ("Control" means ownership of, or the power to vote, } \\
\text { twenty-five percent }(25 \%) \text { or more of the outstanding voting securities of } \\
\text { a licensee or controlling person.) }\end{array}$ \\
\hline * AI & 1 & 0.00 & Affiliate of Investment Advisor \\
\hline $\mathrm{CFO}$ & 1 & 0.00 & Chief Financial Officer \\
\hline * IA & 1 & 0.00 & Investment Advisor \\
\hline Sum & 106063 & 100 & \\
\hline
\end{tabular}

Table 3.3 summarizes the counts of each transaction type for 1987-94. I only take into account two of them: $\mathrm{P}$ and $\mathrm{S}$, which represent "open market or private purchase of nonderivative or derivative security" and "open market or private sale of non-derivative or derivative security", respectively. Even though these definitions do not preclude the 
possibility that there may be derivatives, they do so in practice. I end up with about $16 \%$ of the valid trading records after the screening process.

Table 3.3. Transaction Counts for Transaction Types

\begin{tabular}{|c|c|c|c|}
\hline Code & Count & Percent & Description \\
\hline$* \mathrm{~S}$ & 12120 & 13.89 & Open market or private sale of non-derivative or derivative security \\
\hline B & 10955 & 12.56 & $\begin{array}{l}\text { Participant-directed transaction in ongoing acquisition plan pursuant to Rule } \\
16 \text { b-3(d)(2)(except for intra-plan transfers specified in Code I) (no longer in } \\
\text { use as of 8-96) }\end{array}$ \\
\hline A & 10574 & 12.12 & Grant or award transaction pursuant to Rule $16 b-3(c)$ \\
\hline M & 9662 & 11.07 & $\begin{array}{l}\text { Exercise of in-the-money or at-the-money derivative security acquired } \\
\text { pursuant to Rule } 16 \mathrm{~b}-3 \text { plan }\end{array}$ \\
\hline $\mathrm{J}$ & 8952 & 10.26 & Other acquisition or disposition (describe transaction) \\
\hline $\mathrm{X}$ & 6932 & 7.94 & $\begin{array}{l}\text { Exercise of in-the-money or at-the-money derivative security Other Section } \\
16 \text { (b) Exempt Transactions and Small Acquisition Codes (except for } \\
\text { employee benefit plan codes above) }\end{array}$ \\
\hline $\mathrm{T}$ & 4468 & 5.12 & $\begin{array}{l}\text { Acquisition or disposition transaction under an employee benefit plan other } \\
\text { than pursuant to Rule 16b-3 (no longer in use as of 8-96) }\end{array}$ \\
\hline $\mathrm{U}$ & 4283 & 4.91 & Disposition pursuant to a tender of shares in a change of control transaction \\
\hline 3 & 3979 & 4.56 & Unidentifiable Historic Transaction Codes (1986 - 1995) from Form 3 \\
\hline $\mathrm{H}$ & 3732 & 4.28 & Expiration (or cancellation) of long derivative position \\
\hline $\mathrm{G}$ & 2500 & 2.87 & Bona fide gift \\
\hline $\mathrm{F}$ & 2309 & 2.65 & $\begin{array}{l}\text { Payment of option exercise price or tax liability by delivering or withholding } \\
\text { securities incident to exercise of a derivative security issued in accordance } \\
\text { with Rule 16b-3 }\end{array}$ \\
\hline * $\mathrm{P}$ & 2282 & 2.62 & Open market or private purchase of non-derivative or derivative security \\
\hline Z & 1790 & 2.05 & Deposit into or withdrawal from voting trust \\
\hline $\mathrm{R}$ & 1378 & 1.58 & $\begin{array}{l}\text { Acquisition pursuant to reinvestment of dividends or interest (DRIPS) (no } \\
\text { longer in use as of 8-96) }\end{array}$ \\
\hline $\mathrm{D}$ & 445 & 0.51 & Disposition to the issuer of issuer equity securities pursuant to Rule $16 \mathrm{~b}-3(\mathrm{e})$ \\
\hline $\mathrm{C}$ & 415 & 0.48 & Conversion of derivative security \\
\hline $\mathrm{N}$ & 177 & 0.20 & $\begin{array}{l}\text { Participant-directed transactions pursuant to Rule 16b-3(d)(1) (no longer in } \\
\text { use as of 8-96) }\end{array}$ \\
\hline I & 130 & 0.15 & $\begin{array}{l}\text { Discretionary transaction in accordance with Rule } 16 \mathrm{~b}-3(\mathrm{~F}) \text { resulting in an } \\
\text { acquisition or disposition of issuer securities }\end{array}$ \\
\hline $\mathrm{K}$ & 41 & 0.05 & Transaction in equity swap or instrument with similar characteristics \\
\hline Q & 37 & 0.04 & $\begin{array}{l}\text { Transfer pursuant to a qualified domestic relations order (no longer in use as } \\
\text { of 8-96) }\end{array}$ \\
\hline 9 & 35 & 0.04 & $\begin{array}{l}\text { Transaction code cannot be determined from the reported transaction code } \\
\text { (i.e., there are two or more valid characters reported, or at least one invalid } \\
\text { character, reported in the transaction code field) }\end{array}$ \\
\hline $\mathrm{L}$ & 25 & 0.03 & Small acquisition under Rule $16 a-6$ \\
\hline $\mathrm{W}$ & 17 & 0.02 & Acquisition or disposition by will or laws of descent or distribution \\
\hline 8 & 13 & 0.01 & $\begin{array}{l}\text { A holdings record (without an associated transaction record) was reported on } \\
\text { Form } 4 \text { or } 5\end{array}$ \\
\hline $\mathrm{O}$ & 4 & 0.00 & Exercise of out-of-the-money derivative security \\
\hline Sum & 87255 & 100 & \\
\hline
\end{tabular}

Note: * indicates the type is included. There are 18823 trading records with the code empty. 
It is common to measure insider trading patterns by the number of insiders trading rather than the value of trades. For example, insider trading newsletters, such as Insiders' Chronicle and Insider Indicator, compute insider trading measures based on the number of buyers and sellers. I follow this approach.

Figure 3.2 shows annual means of insider purchase counts (hereafter IPCs) and insider selling counts (hereafter ISCs) of the 88 firms for 1987-99. The IPCs refer to the number of insiders who net sell the stock in a given year. The ISCs refer to the number of insiders who net sell the stock in a given year. I omit observations in 1986 because both counts in 1986 are significantly lower than the following years, indicating that some records are missing. Neither curve reveals a strong trend. IPCs were much higher than ISCs because stock compensation arrangements may lead to routine insider sales.

Figure 3.2. Insider Trading Counts for 1987-99

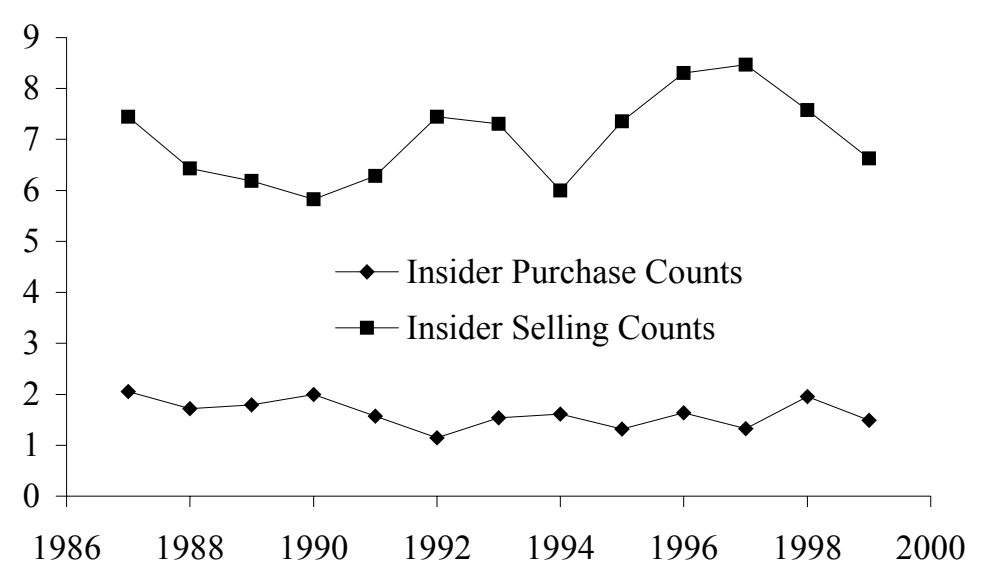

\section{III.4. Empirical Results}

Table 3.4 provides some summary statistics of the 88 firms for 1987-94. The definition of each variable is given in the Appendix. For comparison, I also report the 
summary statistics of 68 firms with average PACs between 10 and 30. The 88 firms conducted more R\&D. Their R\&D intensity ${ }^{27}$ was $4.5 \%$, compared to $2.5 \%$ for the 68 firms. Meanwhile, their average patenting propensity to $R \& D$ expenditures was lower. The citation counts per patent were similar, indicating similar average patent quality across groups. Comparatively, ISCs were much higher in the 88 firms while IPCs were similar. A reasonable explanation is that larger firms are more likely to use stock-related compensation arrangements, resulting in routine insider sales and reduced the incentive for management to purchase. $^{28}$

Table 3.4. Summary Statistics of Firms for 1987-94

\begin{tabular}{|c|c|c|}
\hline Variable & $\mathrm{PACs}>30$ & $10<$ PACs $<30$ \\
\hline PACs & $149(198)$ & $17(9)$ \\
\hline CACs & $2187(3609)$ & $251(269)$ \\
\hline R\&D expenditures (100 mil. \$) & $5.4(9.4)$ & $0.5(0.8)$ \\
\hline Sales revenues (10 bil. $\$$ ) & $1.2(2.0)$ & $0.2(0.4)$ \\
\hline Abnormal returns & $0.03(0.34)$ & $0.04(0.34)$ \\
\hline ISCs & $6.6(6.6)$ & $4.3(4.0)$ \\
\hline IPCs & $1.7(1.8)$ & $1.6(1.9)$ \\
\hline Firm counts & 88 & 68 \\
\hline
\end{tabular}

Notes: Standard deviations are in parentheses.

I first use PACs to measure realized patent output. Table 3.5 reports the first-stage estimation with the 88-firm observations for 1987-94. R\&D expenditures are in real value. ${ }^{29}$ The $\mathrm{R}^{2}$ indicates that the model accounts for $89 \%$ of the variance in PACs. The

\footnotetext{
${ }^{27} \mathrm{R} \& \mathrm{D}$ intensity is the ratio of $\mathrm{R} \& \mathrm{D}$ expenditures to sales revenues.

${ }^{28}$ Ofek and Yermack (2000) examine whether stock-related compensation drives insider trading. They find that for executives with large pre-existing positions in firm stocks, new grants of equity incentives are associated with stock sales.

${ }^{29}$ I use the GDP implicit deflator from the FRED (Federal Reserve Economic Data). Its value in 2000 is set to 1 . I rerun the estimations using nominal R\&D expenditures, and reach similar conclusions.
} 
estimated coefficient on R\&D expenditures is significantly positive. With a rise of 100 million dollars in R\&D expenditures, the PACs would increase by 10.5 . The estimated coefficients on year dummies from 1987 to 1989 are significantly negative and gradually increase, indicating an upward trend in PACs over time. I have no particular expectation for the coefficients on firm dummies. They are suppressed in the table, as is the intercept.

\section{Table 3.5. The First-Stage Estimation using PACs}

\begin{tabular}{cccc}
\hline Variable & Estimate & Std. Error & $\operatorname{Pr}>|t|$ \\
\hline R\&D expenditures & 10.5 & 1.5 & 0.00 \\
Year dummy & & & \\
87 & -36.4 & 11.5 & 0.00 \\
88 & -27.3 & 11.3 & 0.02 \\
89 & -18.0 & 11.1 & 0.11 \\
90 & -13.8 & 11.0 & 0.21 \\
91 & -14.1 & 10.9 & 0.20 \\
92 & -7.0 & 10.8 & 0.52 \\
93 & -11.5 & 10.8 & 0.29 \\
Intercept & & $\mathrm{Y}$ & \\
Firm fixed effects & & $\mathrm{Y}$ & \\
\hline $\mathrm{R}^{2}$ & & 0.89 & \\
Observations & & 704 & \\
\hline
\end{tabular}

I then go to the second stage and examine whether contemporary insider trading counts, ISCs and IPCs, explain the unexpected portion of PACs. To ensure that either measure is comparable across firms, I standardize it by calculating the difference between its current value and the firm mean, and then dividing it by the firm standard deviation. The standardization eliminates the differences in insider trading patterns across firms due to other factors, such as different compensation arrangements.

I report the second-stage estimations in Table 3.6. Observations in 1987 are invalid as the one-year lag of each insider trading measure is included. First, I use the residual 
directly from the first-stage estimation. In column (2), I do not include abnormal returns. The estimated coefficients on IPCs in each year and that on ISCs in year $t+1$ are significantly different from zero with the expected sign, indicating that management possesses timely considerable information about its patent output and trade accordingly. The effects of ISCs are less influential than IPCs. This difference may lie in stock-related compensations. Take stock bonuses for example. Suppose that the annual amount of stock bonus payment is higher than what management wants to purchase. In a regular year, we should expect routine insider sales. Management may reduce the amount of sales when they realize the stock is underpriced. Only when the magnitude of this underpricing is great enough would they begin to purchase. Therefore, the effects of IPCs are more significant explanations of fluctuations of patent output than ISCs.

In column (3), I add abnormal returns to control for market effects. The estimated coefficients on abnormal returns in year $t$ and $t+4$ are significantly positive, indicating that the unexpected portion of realized patent output is gradually reflected in stock price. The effects of both IPCs and ISCs are persistent. For comparison, in column (1) I include abnormal returns only. The estimation fails to pass the overall F-test at the significance level of $10 \%$, indicating that abnormal returns have little explanatory power on the PACs residual. The different explanatory power between insider trading patterns and abnormal returns further confirms that management does process timely considerable information about its realized patent output beyond what is known to investors.

With firm dummies in the first-stage estimation, the difference in the mean PACs across firms is eliminated from the estimated residual. Thus, the residual only reflects 
fluctuations of patent output within a firm. The second-stage estimation results mainly indicate how well management knows about fluctuations of its own patent output.

\section{Table 3.6. Explanatory Power of Insider Trading Counts on PACs}

\begin{tabular}{|c|c|c|c|c|c|c|c|c|c|c|c|c|}
\hline \multirow{3}{*}{ Variable } & \multicolumn{6}{|c|}{ Regular Residual } & \multicolumn{6}{|c|}{ Standardized Residual } \\
\hline & \multicolumn{2}{|l|}{ (1) } & \multicolumn{2}{|c|}{ (2) } & \multicolumn{2}{|l|}{ (3) } & \multicolumn{2}{|l|}{ (4) } & \multicolumn{2}{|c|}{ (5) } & \multicolumn{2}{|l|}{ (6) } \\
\hline & Est. & S.E. & Est. & S.E. & Est. & S.E. & Est. & S.E. & Est. & S.E. & Est. & S.E. \\
\hline Intercept & -1.5 & 2.7 & 0.1 & 2.6 & -1.8 & 2.7 & $-0.07 *$ & 0.04 & $-0.06 *$ & 0.04 & $-0.08 * *$ & 0.04 \\
\hline \multicolumn{13}{|c|}{ Abnormal returns } \\
\hline $\mathrm{t}-1$ & 6.8 & 7.9 & & & 12.6 & 8.0 & 0.03 & 0.11 & & & 0.11 & 0.11 \\
\hline $\mathrm{t}$ & 13.5 & 8.5 & & & $20.2 * *$ & 8.6 & 0.02 & 0.12 & & & 0.13 & 0.12 \\
\hline $\mathrm{t}+1$ & 0.0 & 8.1 & & & 4.1 & 8.2 & -0.09 & 0.11 & & & -0.04 & 0.11 \\
\hline $\mathrm{t}+2$ & $13.9 *$ & 8.3 & & & 10.5 & 8.1 & 0.07 & 0.11 & & & 0.03 & 0.11 \\
\hline $\mathrm{t}+3$ & 4.7 & 8.2 & & & 2.2 & 8.1 & 0.09 & 0.11 & & & 0.06 & 0.11 \\
\hline $\mathrm{t}+4$ & $17.4 * *$ & 8.0 & & & $15.2 *$ & 7.8 & $0.33^{* * *}$ & 0.11 & & & $0.31 * * *$ & 0.11 \\
\hline \multicolumn{13}{|l|}{ ISCs } \\
\hline $\mathrm{t}-1$ & & & -0.7 & 2.9 & 0.5 & 2.9 & & & 0.03 & 0.04 & 0.03 & 0.04 \\
\hline $\mathrm{t}$ & & & 0.4 & 3.0 & -1.1 & 3.1 & & & -0.03 & 0.04 & -0.04 & 0.04 \\
\hline $\mathrm{t}+1$ & & & $-4.8 *$ & 2.9 & $-6.0 * *$ & 3.0 & & & $-0.09 * *$ & 0.04 & $-0.09 * *$ & 0.04 \\
\hline \multicolumn{13}{|l|}{ IPCs } \\
\hline $\mathrm{t}-1$ & & & $7.5 * * *$ & 2.7 & $7.9 * * *$ & 2.8 & & & $0.08 * *$ & 0.04 & $0.09 * *$ & 0.04 \\
\hline $\mathrm{t}$ & & & $7.5 * *$ & 2.9 & $7.9 * * *$ & 2.9 & & & $0.09 * *$ & 0.04 & $0.09 * *$ & 0.04 \\
\hline $\mathrm{t}+1$ & & & $8.7 * * *$ & 2.9 & $8.4 * * *$ & 2.9 & & & $0.09 * *$ & 0.04 & $0.08 * *$ & 0.04 \\
\hline $\mathrm{R}^{2}$ & 0.02 & & 0.05 & & 0.07 & & 0.02 & & 0.04 & & 0.06 & \\
\hline Observations & 607 & & 607 & & 607 & & 607 & & 607 & & 607 & \\
\hline
\end{tabular}

It is possible that the explanatory power of insider trading patterns in less R\&D intensive firms is overwhelmed due to larger variance of PACs in R\&D intensive firms. To test this hypothesis, I standardize the residual by dividing by its firm standard deviation. Doing so places a heavier weight on observations in less R\&D intensive firms. I repeat the second-stage estimations using the standardized residual, and report the results in column (4) and (5) of Table 3.6. The effects of IPCs remain significant with a consistent $\mathrm{R}^{2}$, indicating that patterns in less $\mathrm{R} \& \mathrm{D}$ intensive firms were overwhelmed. 
Meanwhile, the estimated coefficient on abnormal returns is significant only in year $t+4$. A possible reason for the delay may lie in that a less $R \& D$ intensive firm draws less attention from the stock market, thus it takes longer before a shock in patent output is reflected in its stock price.

Using the other measure of patent output, CACs, I rerun these estimations and report results in Table 3.7 and 3.8. These two tables are comparable with Table 3.5 and 3.6, respectively. CACs are well estimated in the first-stage regression with an $\mathrm{R}^{2}$ of 0.89 . The regularities previously found in the second-stage estimations persist. Specifically, the effects of IPCs are persistently significant. Also, the effects of ISCs are ignorable. Third, the significant effects of abnormal returns in the early years disappear when switching from using the regular residual to the standardized one.

\section{Table 3.7. The First-Stage Estimation Using CACs}

\begin{tabular}{cccc}
\hline Variable & Estimate & Std. Error & $\operatorname{Pr}>|t|$ \\
\hline R\&D expenditures & 152 & 27 & 0.00 \\
Year dummy & & & \\
87 & -466 & 207 & 0.02 \\
88 & -415 & 203 & 0.04 \\
89 & -239 & 200 & 0.23 \\
90 & -104 & 197 & 0.60 \\
91 & -109 & 195 & 0.58 \\
92 & 6 & 195 & 0.98 \\
93 & -108 & 194 & 0.58 \\
Intercept & & $\mathrm{Y}$ & \\
Firm fixed effects & & $\mathrm{Y}$ & \\
\hline $\mathrm{R}^{2}$ & \multicolumn{5}{c}{0.89} \\
Observations & \multicolumn{5}{c}{704} \\
\hline
\end{tabular}

Given these findings, it is natural to consider the source of management's information advantage on patent output. First, management watches its investment more closely than 
investors, which may lead to a better understanding of its patent output. Second, management has instant access to its patent applications. This information was available to management as early as when a firm was preparing for patent applications. Based on application counts, management may have a timely and reliable estimation on the realized patent output. Comparatively, it took a long time for the public to know that a patent had been invented. ${ }^{30}$ As mentioned, the USPTO kept patent applications secret until patent issues, and the grant lag was over 2 years on average.

Table 3.8. Explanatory Power of Insider Trading Counts on CACs

\begin{tabular}{|c|c|c|c|c|c|c|c|c|c|c|c|c|}
\hline \multirow{3}{*}{ Variable } & \multicolumn{6}{|c|}{ Regular Residual } & \multicolumn{6}{|c|}{ Standardized Residual } \\
\hline & \multicolumn{2}{|l|}{ (1) } & \multicolumn{2}{|c|}{ (2) } & \multicolumn{2}{|l|}{ (3) } & \multicolumn{2}{|l|}{ (4) } & \multicolumn{2}{|l|}{ (5) } & \multicolumn{2}{|l|}{ (6) } \\
\hline & Est. & S.E. & Est. & S.E. & Est. & S.E. & Est. & S.E. & Est. & S.E. & Est. & S.E. \\
\hline Intercept & -41 & 49 & 2 & 47 & -43 & 48 & $-0.10 * * *$ & 0.04 & $-0.09 * *$ & 0.04 & $-0.11 * * *$ & 0.04 \\
\hline \multicolumn{13}{|l|}{ Abnormal returns } \\
\hline $\mathrm{t}-1$ & -21 & 140 & & & 47 & 143 & -0.04 & 0.11 & & & 0.01 & 0.11 \\
\hline $\mathrm{t}$ & $277 *$ & 150 & & & $365 * *$ & 155 & 0.06 & 0.11 & & & 0.15 & 0.12 \\
\hline $\mathrm{t}+1$ & 101 & 144 & & & 152 & 147 & -0.07 & 0.11 & & & -0.02 & 0.11 \\
\hline $\mathrm{t}+2$ & $507 * * *$ & 147 & & & $467 * * *$ & 146 & $0.20 *$ & 0.11 & & & 0.17 & 0.11 \\
\hline$t+3$ & 112 & 146 & & & 80 & 145 & 0.04 & 0.11 & & & 0.02 & 0.11 \\
\hline $\mathrm{t}+4$ & $296 * *$ & 142 & & & $272 *$ & 141 & $0.38 * * *$ & 0.11 & & & $0.36 * * *$ & 0.11 \\
\hline \multicolumn{13}{|l|}{ ISCs } \\
\hline$t-1$ & & & -10 & 52 & 27 & 52 & & & 0.03 & 0.04 & 0.05 & 0.04 \\
\hline $\mathrm{t}$ & & & -8 & 54 & -12 & 56 & & & -0.02 & 0.04 & -0.02 & 0.04 \\
\hline $\mathrm{t}+1$ & & & -42 & 53 & -61 & 54 & & & $-0.07 *$ & 0.04 & $-0.07 *$ & 0.04 \\
\hline \multicolumn{13}{|l|}{ IPCs } \\
\hline $\mathrm{t}-1$ & & & $120 * *$ & 50 & $109 * *$ & 50 & & & $0.09 * *$ & 0.04 & $0.09 * *$ & 0.04 \\
\hline $\mathrm{t}$ & & & $114 * *$ & 52 & $116^{* *}$ & 52 & & & $0.08 * *$ & 0.04 & $0.08 * *$ & 0.04 \\
\hline $\mathrm{t}+1$ & & & $117 * *$ & 53 & $118 * *$ & 53 & & & $0.11 * * *$ & 0.04 & $0.10 * *$ & 0.04 \\
\hline $\mathrm{R}^{2}$ & 0.03 & & 0.03 & & 0.06 & & 0.03 & & 0.04 & & 0.07 & \\
\hline Observations & 607 & & 607 & & 607 & & 607 & & 607 & & 607 & \\
\hline
\end{tabular}

\footnotetext{
${ }^{30}$ Firms may announce that they have filed a patent or release related information by launching of a new product. However, a systematic way for the public to instantly know the current status of patent applications was not available.
} 
With this persistence established, the following robust tests focus on CACs. One concern with PACs is that they are strongly influenced by firms' different propensities to apply for small patents. ${ }^{31}$ Firm dummies only partially solve this heterogeneity problem because the different propensities mainly influence the slope of R\&D expenditures.

\section{Table 3.9. Explanatory Power of Insider Trading Counts}

\begin{tabular}{|c|c|c|c|c|c|c|c|c|c|c|c|c|c|}
\hline \multirow{3}{*}{ Stage } & \multirow{3}{*}{ Variable } & \multicolumn{4}{|c|}{ Quadratic Effects } & \multicolumn{4}{|c|}{ By Industries } & \multicolumn{4}{|c|}{ Expanded PACs } \\
\hline & & \multicolumn{2}{|l|}{ (1) } & \multicolumn{2}{|c|}{ (2) } & \multicolumn{2}{|c|}{ (3) } & \multicolumn{2}{|c|}{ (4) } & \multicolumn{2}{|l|}{ (5) } & \multicolumn{2}{|l|}{ (6) } \\
\hline & & Est. & S.E. & Est. & S.E. & Est. & S.E. & Est. & S.E. & Est. & S.E. & Est. & S.E. \\
\hline \multirow{3}{*}{$1 \mathrm{st}$} & $\mathrm{R} \& \mathrm{D}$ & $348 * * *$ & 55 & & & & & & & $7.0 * * *$ & 1.4 & & \\
\hline & $\mathrm{R} \& \mathrm{D} * \mathrm{R} \& \mathrm{D}$ & $-3 * * *$ & 1 & & & & & & & & & & \\
\hline & $\mathrm{R}^{\wedge} 2$ & \multicolumn{2}{|c|}{0.89} & & & & & \multicolumn{6}{|c|}{0.79} \\
\hline \multirow{18}{*}{ 2nd } & Intercept & -43 & 48 & $-0.10 * * *$ & 0.04 & -35 & 44 & -0.02 & 0.04 & -1.0 & 4.0 & -0.05 & 0.03 \\
\hline & Abnormal returns & & & & & & & & & & & & \\
\hline & $\mathrm{t}-1$ & 83 & 141 & 0.03 & 0.11 & 50 & 131 & 0.06 & 0.11 & $32.4 * *$ & 12.3 & $0.24 * *$ & 0.10 \\
\hline & $\mathrm{t}$ & $361 * *$ & 153 & 0.17 & 0.12 & 179 & 141 & -0.03 & 0.12 & $33.1 * * *$ & 13.1 & $0.18 *$ & 0.11 \\
\hline & $\mathrm{t}+1$ & 164 & 145 & 0.03 & 0.11 & 72 & 134 & -0.10 & 0.12 & -0.6 & 12.6 & -0.16 & 0.10 \\
\hline & $t+2$ & $454 * * *$ & 144 & 0.17 & 0.11 & $403 * * *$ & 133 & -0.04 & 0.12 & 15.2 & 11.7 & 0.11 & 0.10 \\
\hline & $t+3$ & 53 & 143 & 0.00 & 0.11 & 175 & 132 & -0.02 & 0.12 & $22.7 * *$ & 10.5 & $0.22 * *$ & 0.09 \\
\hline & $\mathrm{t}+4$ & $239 *$ & 139 & $0.34 * * *$ & 0.11 & 168 & 128 & -0.05 & 0.11 & 1.3 & 10.6 & 0.00 & 0.09 \\
\hline & ISCs & & & & & & & & & & & & \\
\hline & $\mathrm{t}-1$ & 30 & 51 & 0.06 & 0.04 & -23 & 47 & 0.00 & 0.04 & -2.7 & 4.4 & 0.03 & 0.04 \\
\hline & $\mathrm{t}$ & -4 & 55 & -0.02 & 0.04 & 19 & 51 & 0.06 & 0.04 & -3.8 & 4.6 & $-0.08 * *$ & 0.04 \\
\hline & $\mathrm{t}+1$ & -61 & 53 & -0.06 & 0.04 & -32 & 49 & -0.01 & 0.04 & $-9.9 * *$ & 4.4 & $-0.14 * * *$ & $=0.04$ \\
\hline & IPCs & & & & & & & & & & & & \\
\hline & $\mathrm{t}-1$ & $107 * *$ & 49 & $0.07 * *$ & 0.04 & $75 *$ & 45 & 0.06 & 0.04 & $13.0 * * *$ & 4.0 & $0.09 * * *$ & $=0.03$ \\
\hline & $\mathrm{t}$ & $113 * *$ & 51 & 0.06 & 0.04 & $109 * *$ & 47 & $0.11 * *$ & 0.04 & $10.4 * *$ & 4.2 & $0.08 * *$ & 0.03 \\
\hline & $t+1$ & $112 * *$ & 52 & $0.09 * *$ & 0.04 & $98 * *$ & 48 & 0.05 & 0.04 & 3.7 & 4.3 & 0.03 & 0.04 \\
\hline & $\mathrm{R}^{2}$ & 0.06 & & 0.05 & & 0.05 & & 0.02 & & 0.06 & & 0.08 & \\
\hline & Observations & 607 & & 607 & & 607 & & 607 & & 751 & & 751 & \\
\hline
\end{tabular}

Note: $*, * *$ and $* * *$ indicate the coefficient is statistically significant at the $10 \%, 5 \%$ and $1 \%$ significance level, respectively. The regression in column (4) fails to pass the overall F-test at the significance level of $10 \%$.

${ }^{31}$ Take the following two firms for example. Intel had 162 PACs and 4105 CACs on average for the years 1987-94 while Eastman Kodak had 826 PACs and 8528 CACs. Apparently, Intel's average citation counts of each patent were much higher than Eastman Kodak during these years. 
A concern with the first-stage estimation is that the $R \& D$ production function may take other forms. In column (1) and (2) of Table 3.9, I include a quadratic term for R\&D expenditures. Though the quadratic effect is significant, it does not improve the estimation much. In column (2) I standardize the residual while in column (1) I do not. The regularities persist.

Another concern with the first-stage estimation is that the propensities of CACs to R\&D expenditures may be different across industries. Following Hall, Jaff, and Trajtenberg (2001), I classify the 88 firms into five categories. They are Chemical, Computers \& Communications, Drugs \& Medical, Electrical \& Electronic, and Mechanical \& Others. I rerun the first-stage estimation by categories and report the results in Table 3.10. The CAC propensities to $\mathrm{R} \& \mathrm{D}$ expenditures are different across categories, with the highest of 399 in Electrical \& Electronic and the lowest of -92 in Drugs \& Medical. The negative sign may indicate that larger firms in Drugs \& Medical were less productive in $R \& D$.

Table 3.10. The First-Stage Estimations by Technological Categories

\begin{tabular}{|c|c|c|c|c|c|c|c|c|c|c|}
\hline \multirow{2}{*}{ Variable } & \multicolumn{2}{|l|}{ (1) } & \multicolumn{2}{|l|}{ (2) } & \multicolumn{2}{|c|}{ (3) } & \multicolumn{2}{|l|}{ (4) } & \multicolumn{2}{|c|}{ (5) } \\
\hline & Est. & S.E. & Est. & S.E. & Est. & S.E. & Est. & S.E. & Est. & S.E. \\
\hline$R \& D$ expenditures & $177 * * *$ & 49 & $403 * * *$ & 85 & $-90 *$ & 48 & $233 * * *$ & 98 & $37 * * *$ & 11 \\
\hline $\mathrm{R}^{2}$ & 0.92 & & 0.90 & & 0.6 & & 0.97 & & 0.96 & \\
\hline Observations & 176 & & 192 & & 10 & & 56 & & 176 & \\
\hline
\end{tabular}

I report the second-stage estimations in Table 3.9. In column (3) I use the regular residual. The estimated coefficients on IPCs are significantly positive, so does the 
coefficient on abnormal returns in year $\mathrm{t}+2$. In column (4) I use the standardized residual. The estimation fails to pass the overall F-test at the significance level of $10 \%$. However, it passes the test when abnormal returns are excluded. To verify that the significance of insider trading effects does not come from the poor estimation in Drugs \& Medical firms, I exclude these firms, and reach similar estimation results.

I manage to extend the patent granting record up to 2002 based on the updated patent file in Bronwyn Hall's website. I repeat the estimations in Table 3.5 and 3.6 with observations of two more years, and report the results briefly in column (5) and (6) of Table 3.9. The estimated PAC propensity to R\&D expenditures drops significantly from 7.7 to 5.2 with these additional observations. In column (6) I standardize the residual while in column (5) I do not. In either case, the estimated coefficients on IPCs remain significant but only for year $\mathrm{t}-1$ and $\mathrm{t}$, indicating management's prompt reactions to patent output after 1994. It is interesting to see that market reactions also happened earlier. It is hard to explain why the effects of ISCs become more influential. Again, the $\mathrm{R}^{2}$ increases significantly when I switch to using the standardized residual.

To double check how the explanatory power of insider trading patterns is influenced by firms' R\&D intensity, I divide the 88 firms into two groups based on the mean PACs, with the highest 44 firms in one group and the lowest 44 firms in the other. I rerun the estimations for each group, and report the results in Table 3.11. The estimated coefficients on IPCs are significantly postive in the highest 44 firms but not in the lowest 44 firms. Therefore, I conclude that it is more likely to detect the explanatory power of IPCs in R\&D intensive firms. In the estimations of the highest 44 firms, the $\mathrm{R}^{2}$ increases significantly from 0.09 to 0.14 when switching from using the regular residual to the 
standardized one. It indicates that the explanatory power of IPCs is stronger among less R\&D intensive firms in this group.

Table 3.11. The Influence of R\&D Intensities

\begin{tabular}{|c|c|c|c|c|c|c|c|c|c|c|c|c|c|}
\hline \multirow{3}{*}{ Stage } & \multirow{3}{*}{ Variable } & \multicolumn{4}{|c|}{ Highest 44 firms } & \multicolumn{4}{|c|}{ Lowest 44 firms } & \multicolumn{4}{|c|}{ Highest 40 firms } \\
\hline & & \multicolumn{2}{|c|}{ (1) } & \multicolumn{2}{|l|}{ (2) } & \multicolumn{2}{|c|}{ (3) } & \multicolumn{2}{|l|}{ (4) } & \multicolumn{2}{|c|}{ (5) } & \multicolumn{2}{|l|}{ (6) } \\
\hline & & Est. & S.E. & Est. & S.E. & Est. & S.E. & Est. & S.E. & Est. & S.E. & Est. & S.E. \\
\hline \multirow{4}{*}{$1 \mathrm{st}$} & \multicolumn{13}{|c|}{$* *$} \\
\hline & R\&D & $130 * * *$ & 39 & & & $300 *$ & 80 & & & & & & \\
\hline & $\mathrm{R}^{2}$ & \multicolumn{2}{|l|}{0.88} & \multicolumn{6}{|c|}{0.59} & & & & \\
\hline & Observations & \multicolumn{2}{|l|}{352} & \multicolumn{6}{|c|}{352} & & & & \\
\hline \multirow{18}{*}{$2 \mathrm{nd}$} & Intercept & -76 & 89 & $-0.11 * *$ & 0.05 & -25 & 33 & -0.08 & 0.05 & -83 & 97 & $-0.11 * *$ & 0.05 \\
\hline & Abnormal returns & & & & & & & & & & & & \\
\hline & $\mathrm{t}-1$ & 227 & 296 & 0.05 & 0.16 & $-178 * *$ & 90 & -0.06 & 0.15 & 238 & 310 & 0.07 & 0.17 \\
\hline & $\mathrm{t}$ & $612 * *$ & 304 & 0.16 & 0.17 & $179 *$ & 102 & 0.08 & 0.17 & $532 *$ & 319 & 0.09 & 0.18 \\
\hline & $\mathrm{t}+1$ & 126 & 297 & 0.01 & 0.17 & $197 * *$ & 93 & -0.01 & 0.15 & 157 & 310 & 0.00 & 0.17 \\
\hline & $\mathrm{t}+2$ & $801 * * *$ & 296 & 0.16 & 0.16 & $230 * *$ & 92 & 0.18 & 0.15 & $707 * *$ & 312 & 0.09 & 0.17 \\
\hline & $t+3$ & 52 & 290 & -0.13 & 0.16 & 95 & 93 & 0.14 & 0.15 & 167 & 306 & -0.09 & 0.17 \\
\hline & $t+4$ & $668 * *$ & 297 & $0.43 * * *$ & 0.16 & -3 & 87 & $0.27 *$ & 0.14 & $659 * *$ & 316 & $0.42 * *$ & 0.17 \\
\hline & ISCs & & & & & & & & & & & & \\
\hline & $t-1$ & 50 & 95 & $0.13 * *$ & 0.05 & 19 & 36 & -0.03 & 0.06 & 3 & 104 & $0.11 * *$ & 0.06 \\
\hline & $\mathrm{t}$ & 24 & 109 & 0.01 & 0.06 & -11 & 36 & -0.05 & 0.06 & -24 & 119 & -0.02 & 0.07 \\
\hline & $\mathrm{t}+1$ & -156 & 104 & -0.08 & 0.06 & -1 & 35 & -0.05 & 0.06 & -152 & 112 & -0.08 & 0.06 \\
\hline & \multicolumn{13}{|l|}{ IPCs } \\
\hline & $\mathrm{t}-1$ & $170 *$ & 93 & $0.14 * * *$ & 0.05 & 1 & 34 & 0.00 & 0.06 & 156 & 101 & $0.14 * *$ & 0.06 \\
\hline & $\mathrm{t}$ & $186^{*}$ & 94 & $0.17 * * *$ & 0.05 & 49 & 37 & -0.01 & 0.06 & 116 & 101 & $0.13 * *$ & 0.06 \\
\hline & $t+1$ & $169 *$ & 96 & $0.15 * * *$ & 0.05 & 24 & 36 & 0.03 & 0.06 & 154 & 103 & $0.14 * *$ & 0.06 \\
\hline & $\mathrm{R}^{2}$ & \multicolumn{2}{|l|}{0.10} & \multicolumn{2}{|c|}{0.14} & \multicolumn{2}{|c|}{0.08} & \multicolumn{2}{|c|}{0.04} & \multicolumn{2}{|c|}{0.08} & \multicolumn{2}{|c|}{0.11} \\
\hline & Observations & \multicolumn{2}{|l|}{306} & 306 & & \multicolumn{2}{|l|}{301} & \multicolumn{2}{|c|}{301} & 278 & & \multicolumn{2}{|l|}{278} \\
\hline
\end{tabular}

Note: $*, * *$ and $* * *$ indicate the coefficient is statistically significant at the $10 \%, 5 \%$ and $1 \%$ significance level, respectively. The regression in column (4) fails to pass the overall F-test at the significance level of $10 \%$.

Concerned that a number of firms with a nearly perfect correlation between the CACs residual and IPCs would lead to the same $\mathrm{R}^{2}$ level, I exclude 4 firms that have the highest correlation in the highest 44 firms and rerun the second-stage estimations with the rest 40 firms. The effects of IPCs are significant when using the standardized residual, but are 
overwhelmed when using the regular residual. This indicates that the explanatory power of IPCs is not unique among the highest 44 firms.

Table 3.12. Explanatory Power of Insider Trading Value on CACs

\begin{tabular}{|c|c|c|c|c|c|c|c|c|c|c|c|c|}
\hline \multirow{3}{*}{ Variable } & \multicolumn{4}{|c|}{ Regular Residual } & \multicolumn{4}{|c|}{ Standardized Residual } & \multicolumn{4}{|c|}{ Highest 44 firms } \\
\hline & \multicolumn{2}{|c|}{ (1) } & \multicolumn{2}{|l|}{ (2) } & \multicolumn{2}{|l|}{ (3) } & \multicolumn{2}{|l|}{ (4) } & \multicolumn{2}{|l|}{$(5)$} & \multicolumn{2}{|l|}{$(6)$} \\
\hline & Est. & S.E. & Est. & S.E. & Est. & S.E. & Est. & S.E. & Est. & S.E. & Est. & S.E. \\
\hline Intercept & -2 & 48 & -42 & 49 & $-0.09 * * *$ & 0.04 & $-0.11 * * *$ & 0.04 & -64 & 90 & $-0.11 * *$ & 0.05 \\
\hline \multicolumn{13}{|l|}{ Abnormal returns } \\
\hline $\mathrm{t}-1$ & & & -18 & 147 & & & 0.01 & 0.11 & 135 & 307 & 0.12 & 0.17 \\
\hline $\mathrm{t}$ & & & $306 *$ & 160 & & & 0.13 & 0.12 & $587 *$ & 315 & 0.20 & 0.18 \\
\hline $\mathrm{t}+1$ & & & 117 & 148 & & & -0.06 & 0.11 & 90 & 301 & -0.02 & 0.17 \\
\hline $\mathrm{t}+2$ & & & $518 * * *$ & 148 & & & 0.18 & 0.11 & $858 * * *$ & 299 & 0.17 & 0.17 \\
\hline $\mathrm{t}+3$ & & & 114 & 146 & & & 0.04 & 0.11 & 56 & 292 & -0.10 & 0.16 \\
\hline $\mathrm{t}+4$ & & & $313 * *$ & 143 & & & $0.37 * * *$ & 0.11 & $766 * *$ & 302 & $0.47 * * *$ & 0.17 \\
\hline \multicolumn{13}{|l|}{ Insider sales } \\
\hline $\mathrm{t}-1$ & -43 & 54 & 9 & 56 & -0.02 & 0.04 & 0.01 & 0.04 & 33 & 102 & 0.05 & 0.06 \\
\hline $\mathrm{t}$ & -5 & 53 & 7 & 56 & $-0.07 *$ & 0.04 & $-0.07 *$ & 0.04 & 33 & 107 & -0.08 & 0.06 \\
\hline $\mathrm{t}+1$ & 20 & 50 & 23 & 52 & $-0.06 *$ & 0.04 & -0.05 & 0.04 & -15 & 99 & -0.08 & 0.06 \\
\hline \multicolumn{13}{|l|}{ Insider purchases } \\
\hline $\mathrm{t}-1$ & 78 & 51 & 70 & 51 & 0.05 & 0.04 & 0.05 & 0.04 & 129 & 92 & $0.12 * *$ & 0.05 \\
\hline $\mathrm{t}$ & $103 * *$ & 50 & $115 * *$ & 50 & -0.01 & 0.04 & -0.01 & 0.04 & $242 * * *$ & 93 & $0.12 * *$ & 0.05 \\
\hline $\mathrm{t}+1$ & 73 & 50 & $84 *$ & 50 & $0.07 *$ & 0.04 & $0.07 *$ & 0.04 & $163 *$ & 92 & $0.15 * * *$ & 0.05 \\
\hline $\mathrm{R}^{2}$ & \multicolumn{2}{|c|}{0.01} & \multicolumn{2}{|l|}{0.05} & \multicolumn{2}{|l|}{0.02} & \multicolumn{2}{|c|}{0.04} & \multicolumn{2}{|l|}{0.09} & \multicolumn{2}{|c|}{0.11} \\
\hline Observations & \multicolumn{2}{|l|}{607} & \multicolumn{2}{|l|}{607} & \multicolumn{2}{|l|}{607} & \multicolumn{2}{|l|}{607} & \multicolumn{2}{|l|}{306} & \multicolumn{2}{|l|}{306} \\
\hline
\end{tabular}

I then turn to another pair of proxies to measure insider trading patterns. They are insider purchase value and insider selling value. The insider purchase value refers to the sum of the value of each insider purchase transaction within a given year. The insider purchase value refers to the sum of the value of each insider sale transaction within a given year. I standardize either measure by calculating the difference between its current value and the firm mean, and then dividing it by the firm standard deviation. The first- 
stage estimation remains the same as in Table 3.7. The second-stage estimations are reported in Table 3.12. In column (1) and (3) the estimations without control for abnormal returns fail to pass the overall F-test at the significance level of $10 \%$.

In column (5) and (6) I only include the highest 44 firms. The estimated coefficient on IPCs turn to be significant while the $\mathrm{R}^{2}$ of the regression using the standardized residual is lower than that in column (2) of Table 3.11. It indicates that the explanatory power of insider trading patterns on patent output is stronger when using the number of insiders trading instead of insider trading values as the measure. This finding is consistent with the business convention of using the number of insiders engaged in trading. The reason may lie in that good news becomes less reliable when it is spread from top management to ordinary managers. When an ordinary manager, whose income is not comparable to top management, makes a relatively small purchase based on this less reliable information, it should add more credit to the significance of the good news than what is reflected by his purchase value.

\section{III.5. Conclusions}

My purpose of this chapter is to identify how informative insider trading patterns are in predicting a firm's patent output. By examining R\&D intensive firms, I found strong evidence that the effects of contemporary insider trading patterns are significant to explain fluctuations of patent output when controlling for market effects, as well as R\&D input effects. The findings are consistent across different measures of patent output, across different time scales, and across different measures of insider trading patterns. Therefore, I concluded that management has timely and privileged information about its 
realized patent output beyond what is known to investors. I also found that the explanatory power of insider trading patterns on patent output comes from purchases rather than sales.

In business practice, comparing patent output between firms may help to evaluate which firm stands a better chance to beat the market. My findings suggest that, to obtain a timely estimate of a firm's realized patent output, it is worth to take IPCs into account. Moreover, this approach is more effective in R\&D intensive firms. My further study would be to investigate whether the explanatory power of insider trading patterns on patent output is consistent over time at the firm level; and if so, what factors would explain the consistency.

In this study I do not join the debate on the social consequence of insider trading. However, for those concerned with this issue, my results point to an important source of private information - patent output. Improved disclosure on its relevant information, such as patent applications, may be considered as means for reducing information asymmetry. Doing so would make investors better informed of a firm's R\&D performance. Since document preparation takes time, management would still have early access to application information. Thus, management would not have much incentive to change the pattern of patent applications when this disclosure is required. 


\section{References}

Aboody, D., and B. Lev (2000): "Information Asymmetry, R\&D, and Insider Gains." Journal of Finance 55(6):2747-2766.

Albert, M. B., D. Avery, F. Narin, and P. McAllister (1991): "Direct Validation of Citation Counts as Indicators of Industrially Important Patents." Research Policy 20:251-259.

Barth, M., R. Kasznik, and M. McNichols (2001): "Analyst Coverage and Intangible Assets." Journal of Accounting Research 39(1):1-34.

Bettis, C., D. Vickrey, and D. W. Vickrey (1997): "Mimickers of Corporate Insiders Who Make large Volume Trades." Financial Analysts Journal 53:57-66.

Deng, Z., B. Lev, and F. Narin (1999): "Science and Technology as Predictors of Stock Performance." Financial Analysts Journal 55:20-32.

Earnst, H. (1999): "Evaluation of Dynamic Technological Developments by Means of Patent Data." The Dynamics of Innovation: Strategic and Managerial Implications. K. Brochhoff, A. K. Chakrabarti, and J. Hauschildt ed. Springer, Berlin.

Finnerty, J. E. (1976): “Insiders and Market Efficiency.” Journal of Finance 31(4):11411148.

Griliches, Z. (1995): "R\&D and Productivity: Econometric Results and Measurement Issues." Handbook of the Economics of Innovation and Technological Change. Paul Stoneman ed. Blackwell, Oxford.

Hall, B. H., A. B. Jaffe and M. Trajtenberg (2001): "The NBER Patent Citation Data File: Lessons, Insights and Methodological Tools." National Bureau of Economic Research Working Paper No. 8498.

Hall, B. H., A. B. Jaffe and M. Trajtenberg (2005): "Market Value and Patent Citations." RAND Journal of Economics 36(1):16-38.

Hall, B. H., Z. Griliches, and J. A. Hausman (1986): "Patents and R and D: Is There a Lag?" International Economic Review 27(2):265-283.

Jaffe, J. (1974): "Special Information and Insider Trading." Journal of Business 47:410428.

Jeng, L., A. Metrick, and R. Zeckhauser (2003): "Estimating the Returns to Insider Trading: A Performance-Evaluation Perspective." Review of Economics and Statistics 85(2):453-471. 
John, K., and L. Lang (1991): "Strategic Insider Trading around Dividend Announcements: Theory and Evidence.” Journal of Finance 46:1361--1398.

Karpoff, J. M., and D. Lee (1991): "Insider Trading before New Issue Announcements." Financial Management 20:18--26.

Kothari, S. P., T. Laguerre, and A. Leone (2002): "Capitalization versus Expensing: Evidence on the Uncertainty of Future Earnings from Capital Expenditures versus R\&D Outlays." Review of Accounting Studies 7:355-382.

Lee, D. S., W. H. Mikkelson, and M. M. Partch (1992): "Managers' Trading around Stock Repurchases.” Journal of Finance 47:1947-1961.

Lakonishok, J., and I. Lee (2001): “Are Insider Trades Informative?” Review of Financial Studies 14: 79-111.

Ofek, E., and D. Yermack, (2000): "Taking Stock: Equity-Based Compensation and the Evolution of Managerial Ownership.” Journal of Finance 55:1367-1384.

Pakes, A., and Z. Griliches (1980): "Patents and R\&D at the Firm Level: A First Report." Economics Letters 5:377-381.

Romer, C. D., and D. H. Romer (2000): "Federal Reserve Information and the Behavior of Interest Rates.” American Economic Review 90(3):429-457.

Rozeff, M. S., and M. A. Zaman (1988): "Market Efficiency and Insider Trading: New Evidence.” Journal of Business 61:25-44.

Scherer, F. M. (1965): "Firm Size, Market Structure, Opportunity, and the Output of Patented Innovations." American Economic Review 55:1097-1123.

Schmookler, J. (1966): Invention and Economic Growth. Cambridge: Harvard University Press.

Seyhun, N. (1986): “Insiders' Profits, Costs of Trading, and Market Efficiency.” Journal of Financial Economics 16:198-212.

Seyhun, N. (1990): "Do Bidder Managers Knowingly Pay Too Much for Target Firms?" Journal of Business 63:439-464.

Seyhun, N. and M. Bradley (1997): “Corporate Bankruptcy and Insider Trading.” Journal of Business 70:189-216.

Tasker, S. (1998): “Technology Company Conference Calls: A Small Sample Study." Journal of Financial Statement Analysis 4:6-14. 
Appendix

\section{Variable Description}

The specific variables used in the analysis are defined as follows:

. Patent Annual Counts (PACs) is defined as the number of granted patents that are applied for in a given year.

. Citation Annual Counts (CACs) is defined as the summed citation counts of those granted patents that are applied for in a given year. Here, citation counts of a patent are the number of citations that the patent received until August 2006.

. $R \& D$ Expenditures is $\mathrm{R} \& \mathrm{D}$ expenditures (Compustat item 46) in the fiscal year.

. Sales Revenues is sales revenues (Compustat item 12) in the fiscal year.

. Abnormal Return equals the stock annual return minus the S\&P Industrial Index annual return.

. Insider Selling Counts (ISCs) is the number of insiders who net sell the stock in a given year.

. Insider Purchase Counts (IPCs) the number of insiders who net buy the stock in a given year.

. Insider Selling Value is the sum of the value of each insider sale transaction within a given year. The value of an insider sale transaction equals the transaction volume times the transaction price.

. Insider Purchase Value is the sum of the value of each insider purchase transaction within a given year. The value of an insider purchase transaction equals the transaction volume times the transaction price. 


\section{A List of the 88 Firms by Categories}

\author{
Chemical \\ AIR PRODUCTS \& CHEMICALS \\ AMOCO CORP \\ ATLANTIC RICHFIELD CO \\ BETZDEARBORN INC \\ COLGATE-PALMOLIVE CO \\ DOW CHEMICAL \\ DRESSER INDUSTRIES INC \\ DU PONT (E I) DE NEMOURS \\ FMC CORP \\ GOODYEAR TIRE \& RUBBER C \\ HERCULES INC \\ INTL PAPER CO \\ KIMBERLY-CLARK CORP \\ LUBRIZOL CORP \\ MEAD CORP \\ NALCO CHEMICAL CO \\ PPG INDUSTRIES INC \\ PROCTER \& GAMBLE CO \\ ROHM AND HAAS CO \\ SCHLUMBERGER LTD \\ TEXACO INC \\ UNION CARBIDE CORP \\ Drugs \& Medical \\ ABBOTT LABORATORIES \\ ALZA CORP \\ BAXTER INTERNATIONAL INC \\ BECTON DICKINSON \& CO \\ BRISTOL-MYERS SQUIBB CO \\ JOHNSON \& JOHNSON \\ LILLY (ELI) \& CO \\ MEDTRONIC INC \\ MERCK \& CO \\ PFIZER INC \\ SCHERING-PLOUGH \\ U S SURGICAL CORP \\ WARNER-LAMBERT CO \\ Electrical \& Electronics \\ EASTMAN KODAK CO \\ EMERSON ELECTRIC CO \\ GENERAL ELECTRIC CO \\ RAYCHEM CORP \\ TEKTRONIX INC \\ WHIRLPOOL CORP \\ ZENITH ELECTRONICS CORP
}

Computers \& Communications

AT\&T CORP

ADVANCED MICRO DEVICES

AMP INC

APPLE COMPUTER INC

COMPAQ COMPUTER CORP

CORNING INC

DIGITAL EQUIPMENT

GTE CORP

HARRIS CORP

HEWLETT-PACKARD CO

HONEYWELL INC

INTEL CORP

INTL BUSINESS MACHINES C

MICRON TECHNOLOGY INC

MOLEX INC

MOTOROLA INC

NATIONAL SEMICONDUCTOR C

RAYTHEON CO

SEAGATE TECHNOLOGY-OLD

SUN MICROSYSTEMS INC

TEXAS INSTRUMENTS INC

UNISYS CORP

VLSI TECHNOLOGY INC

XEROX CORP

Mechanical \& Others
BAKER HUGHES INC
BOEING CO
BRUNSWICK CORP
CATERPILLAR INC
CHRYSLER CORP
DANA CORP
DEERE \& CO
EATON CORP
FORD MOTOR CO
GENERAL MOTORS CORP
GOODRICH CORP
HALLIBURTON CO
ILLINOIS TOOL WORKS
LITTON INDUSTRIES INC
MCDONNELL DOUGLAS CORP
OLIN CORP
OUTBOARD MARINE CORP
PITNEY BOWES INC
SUNDSTRAND CORP
TRW INC
TEXTRON INC
UNITED TECHNOLOGIES CORP




\section{HOW DO KNOWLEDGE STOCKS INFLUENCE THE START-UP AND}

\section{SURVIVAL OF NEW MANUFACTURING SEGMENTS IN U.S. PATENTING}

\section{FIRMS?}

\section{IV.1. Introduction}

Penrose (1959) explains how investment in research and development (R\&D) can induce later diversification. ${ }^{32}$ The reasoning is that the output of $R \& D$ is new knowledge, and markets for exchanging new knowledge are subject to well-known problems. ${ }^{33}$ This makes market exchange relatively costly for appropriating returns to new knowledge. As a result, firms often diversify into the new industry in order to more fully appropriate these returns.

Conversely, diversification may stimulate research activities. The idea - first explored by Nelson (1959) - is as follows. Research is an uncertain activity, resulting in inventions in unexpected areas. A diversified firm is more likely to be able to produce and market these unexpected inventions than a firm characterized by a narrow product line. Therefore, more diversified firms would expect a higher profit from research. And this, in turn, leads the firm to support more research. Inspired by this theory, subsequent studies have shown that there is a positive relation between diversification and R\&D intensity. ${ }^{34}$

\footnotetext{
${ }^{32} \mathrm{R} \& D$ is not the only reason for new industry entry. Supply relationships or marketing similarities may also induce diversification (Williamson (1979); Penrose (1959)). Montgomery (1994) provides an excellent summary.

${ }^{33}$ Teece (1980) first points out that the new knowledge Penrose describes has no implication for new industry entry unless the external exchange is subject to market failure.

${ }^{34}$ Using patent counts as a measure of a firm's knowledge intensity, Scherer (1983) finds that diversified firms patent more than other firms. Controlling for scale, Grabowski (1968) shows that firms' R\&D-tosales ratios are positively related to how diversified the firms are in the chemical and drug industries but
} 
With these diversification effects, it becomes unclear how new knowledge influences ensuing industry entry. Diversification stimulates R\&D activities and generates more knowledge. However, this newly acquired knowledge is more likely to be absorbed within the currently existing lines of business that the firm is operating, and thus is less likely to take the form of new industry entry. It is an empirical question how knowledge accumulation influences new industry entry in the presence of diversification effects.

Unfortunately, few clues to the solution can be found in the literature. Empirical studies mostly concentrate on diversification at a point in time (e.g., Gollop and Monahan (1991); Baldwin and Gu (2005)). They fail to identify the relationship between innovation and firm dynamics, specifically here new industry entry. Among the few exceptions are Gort (1969), who finds that firms with high proportions of technical personnel have a greater tendency to merge. Further, MacDonald (1985) and Hall (1988) both find that high $R \& D$ firms tend to enter other high R\&D industries.

By examining U.S. public patenting firms ${ }^{35}$ in manufacturing sectors for 1985-96, I find that cumulative patent counts, as a measure of knowledge stocks, predict the likelihood of new market entry. This predictive power is weakened when diversification effects are taken into account. Moreover, these diversification effects are significantly positive in predicting entry likelihood. What I find is consistent with a refined version of Nelson's theory: knowledge stocks stimulate R\&D productivity; the effect of absorbing

not in the oil industry. Gort (1962) shows that more diversified firms employ relatively more complex technology. Other empirical studies that relate diversification and innovation at the firm level are based on technological diversification measures (e.g., Audretsch and Feldman (1999)).

${ }^{35}$ A patenting firm is defined as having at least one patent registered by the USPTO (United States Patent and Trademark Office) before 1985. See more details in Section IV.3. 
new knowledge within lines of business does not dominate; and the appropriation still takes the form of new industry entry.

Knowledge stocks may also influence subsequent diversification of a firm by enhancing the survival likelihood of the newly established business. How firm characteristics influence plant survival is an active area of empirical research. Studies on plant deaths in declining industries confirm that larger plants are less likely to exit (e.g., Dunne, Robert, and Samuelson (1989a)). Studies on a wide range of industries generally report lower death rates for plants in multi-product firms (e.g., Dunne, Robert, and Samuelson (1989b); Disney, Haskel, and Heden (2003)). ${ }^{36}$ However, after controlling for plant and industry characteristics, Bernard and Jensen (2007) find that plants are more likely to close in multi-product firms or in U.S. multinationals. ${ }^{37}$

My survival study of newly established segments in patenting firms shows that initial knowledge stocks have a significantly positive influence on segment survival, and the influence fades over time. In contrast with traditional findings in plant survival studies, I find that neither initial segment size, initial firm size, nor the degree of diversification shows any significant effect. This insignificance persists when I include all manufacturing firms in my sample. Doing so also removes the significance of knowledge effects.

\footnotetext{
${ }^{36}$ In fact, the finding of Disney, Haskel, and Heden (2003) is undetermined. The result is reversed when conditioned on the average characteristics. Single establishments with average group characteristics have a lower hazard than group establishments with the characteristics of singles.

${ }^{37}$ They suggest that the ability to enter and exit flexibly may be itself a capability of firms. See also Sutton (2005).
} 
This chapter is organized as follows. In Section IV.2, I present a dynamic model of a firm's entry and exit along with a description of its implications. Section IV.3 describes the data used and Section IV.4 reports empirical results. Section IV.5 concludes.

\section{IV.2. A Simple Model}

The following dynamic model of a firm's entry and exit in different product lines is a modification of the model developed by Klette and Kortum (2004). A firm produces a portfolio of products. Each product is provided by only one firm and yields an equalized profit $0<\pi<1 .{ }^{38} \mathrm{~A}$ firm with $n$ products receives profit rate $\pi n$. Further, the firm is characterized by an independent Poisson process of becoming either a firm with $n-1$ products or $n+1$ products. By investing in innovation, the firm influences both hazard rates. A firm with $n$ products chooses an innovation policy $\left(I_{1}(n), I_{2}(n)\right)$ to maximize its expected present value, $V(n)$, given an interest rate $r$. A firm with $n=0$ exits permanently, so $V(0)=0$. The corresponding Bellman equation is

$$
r V(n)=\max _{I_{1}, I_{2}}\left\{\pi n-C_{1}\left(I_{1}, n\right)-n c_{2}\left(\frac{I_{2}}{n}\right)+\left(I_{1}+\gamma_{1} n\right) \Delta V(n+1)+\left(\gamma_{2} n-I_{2}\right) \Delta V(n-1)\right\}
$$

where $\Delta V(n) \equiv V(n)-V(n-1)$, and the Poisson hazard rate of losing a product equals 0 if $I_{2}>\gamma_{2} n$. When $I_{2}=0$ and $\gamma_{1}=0$, equation (4.1) collapses to the Klette and Kortum (2004) model.

\footnotetext{
${ }^{38}$ An interpretation of such a market structure is the quality ladder model of Grossman and Helpman (1991). Innovations take the form of quality improvements. The innovator with the highest quality for a particular good captures the entire market.
} 
A firm may employ resources in innovation in order to increase $I_{1}$, as a result of which the Poisson hazard rate of acquiring a good would increase. The innovation productivity is enhanced by the firm's cumulative knowledge stocks. These stocks are properly indexed by the number of product lines in which it is currently operating. The degree of diversification, which is also indexed by product scope $n$, is supposed to influence the entry hazard. This influence is measured by the rate $\gamma_{1}$. This parameter reflects the first-order effect of diversification. Given an innovation for a particular good, the firm would successfully beat the incumbent and take over the market.

Meanwhile, a firm faces the possibility that some other firm will innovate a good it is producing. Should this happen, the firm will lose that good from its portfolio. The Poisson hazard rate of this occurring for a particular product is $\gamma_{2}>0$. With the assumption of symmetry, the effort put forth to prevent losing any operating product should be equalized. Thus, a firm with $n$ products would put forth an equalized innovative effort to determine $I_{2} / n$ by which the hazard rate of losing a particular product would decrease.

In the above Bellman, $\mathrm{I}$ assumed that the production processes of $I_{1}$ and $I_{2} / n$ are divisible. I assume further that the production of $I_{1}$ follows constant returns to scale with respect to the knowledge stocks $n$. Therefore,

$$
C_{1}\left(I_{1}, n\right)=n C_{1}\left(\frac{I_{1}}{n}, 1\right)=n c_{1}\left(\frac{I_{1}}{n}\right)
$$

Both unit cost functions, $c_{1}$ and $c_{2}$, are well behaved. ${ }^{39}$

\footnotetext{
${ }^{39}$ That is $c(0)=0, c(x)$ is twice differentiable, and strictly convex for $x \geq 0$.
} 
Under these assumptions, equation (4.1) yields the following first-order conditions:

$$
\begin{aligned}
& c_{1}^{\prime}\left(\frac{I_{1}}{n}\right)=\Delta V(n+1) \\
& c_{2}^{\prime}\left(\frac{I_{2}}{n}\right)=\Delta V(n) .
\end{aligned}
$$

It is easy to verify that the solution to (4.1) is

$$
\begin{aligned}
& V(n)=v n, \\
& I_{1}(n)=\lambda_{1} n, \\
& I_{2}(n)=\lambda_{2} n,
\end{aligned}
$$

where $\lambda_{1}, \lambda_{2}$, and $v$ are constants and solve $\mathrm{e}^{40}$

$$
\begin{aligned}
& c_{1}^{\prime}\left(\lambda_{1}\right)=c_{2}^{\prime}\left(\lambda_{2}\right)=v, \\
& r v=\pi-c_{1}\left(\lambda_{1}\right)-c_{2}\left(\lambda_{2}\right)+\left(\lambda_{1}+\lambda_{2}\right) v+\left(\gamma_{1}-\gamma_{2}\right) v .
\end{aligned}
$$

I refer to the term $\lambda_{1}=I_{1}(n) / n$ as the firm's external innovation intensity, and $\lambda_{2}=I_{2}(n) / n$ to be the firm's internal innovation intensity. Both are independent of firm size since both production functions are homogeneous of degree one with respect to $n$. It turns out that the value of entering a product line and the value of preventing the loss of one are identical, so the firm would distribute its R\&D resources such that the marginal cost of innovation to favor its expansion in each area is equalized. This is what is shown in (4.6). The solution to (4.6) is unique. Furthermore, both innovation intensities are

\footnotetext{
${ }^{40}$ I exclude the possibility of corner solutions by assuming that it is always better off to invest in both innovations, and that investing all the profit in innovations is not optimal. I also assume that it is too expensive for $I_{2} / n$ to reach its upper bound $\gamma_{2}$. See the proof in the Appendix for details.
} 
increasing in $\pi$ and $\gamma_{2}$. They are decreasing in $\gamma_{1}, r$, and an upward shift of marginal cost $c^{\prime}$. See the Appendix for the proof.

We can now characterize the dynamic process for an individual firm. Consider a firm with $n$ products. At any given time it will remain in its current state, acquire a product and grow to $n+1$, or lose a product and shrink to $n-1$. The firm that is likely to become more diversified has a hazard rate of acquiring a product greater than that of losing one. ${ }^{41}$

In my setting, the hazard rate of acquiring a product (given product scope $n$ ) at period $T$ is

$$
H R(n+1 \mid n, T)=I_{1}+\gamma_{1} n=\lambda_{1} n+\gamma_{1} n .
$$

The first term indicates that the likelihood of entry is positively related to knowledge stocks when they enhance the productivity of external innovations. The second term captures the diversification effect. Following Nelson (1959), $\gamma_{1}$ is positive. This effect may not be detectable when new entry occurs within current lines of business. Moreover, my model indicates an identification problem between the knowledge effect and the diversification effect because of their linear correlation.

The hazard of losing a product at period $T$ is

$$
H R(n-1 \mid n, T)=\gamma_{2} n-I_{2}=\left(\gamma_{2}-\lambda_{2}\right) n
$$

\footnotetext{
${ }^{41}$ Klepper and Thompson (2006) obtain a similar result at the submarket level. They construct a model of industry evolution in which the central force for change is the creation and destruction of submarkets. A firm expands when it is able to exploit new opportunities that arrive in the form of submarkets; it contracts when its submarkets are destroyed. They prove that the number of submarkets it is involved in, which is a good measure of diversification, in the stationary state is $\theta \lambda \mu$, where $\theta$ is the mean entry rate and $\lambda \mu$ is the mean active life of submarkets.
} 
It is proportional to product scope $n$, and increasing in the internal innovation intensity $\lambda_{2}$. The odds favor expansion if the hazard of acquiring a good is larger than that of losing one; they favor shrinking if the former is smaller; and they are neutral if the two are equal.

We now turn to segment survival. The hazard rate that product $i$ is dropped given product scope $n$ at period $T$ is

$$
H R(\text { dropping } \quad i \mid n, T)=\frac{\gamma_{2} n-I_{2}}{n}=\gamma_{2}-\lambda_{2} .
$$

That is, the hazard of losing a particular product is irrelevant to product scope $n$, but it is decreasing in the internal innovation intensity $\lambda_{2}$. Theoretically, knowledge stocks may enter the production function of $I_{2} / n$, thereby influencing $\lambda_{2}$.

Given the heterogeneity of innovation productivities amongst firms, the current degree of diversification would be a good indicator of a firm's overall innovation productivity. In a stationary state, if a firm becomes diversified through frequently entering new industries, then the degree of diversification would predict its subsequent entry into a new industry. If the diversification is due to higher internal innovation productivity, then the degree of diversification would intimate the later survival of these newly established segments.

\section{IV.3. Data}

The variables used in this chapter are taken from two major data sources. One is patent data; they are obtained from the NBER (National Bureau of Economic Research) and the USPTO website. This includes information on granted patents and their citations. 
Another source is firm-level and segment-level financial data taken from the Compustat annual company and segment files. Both active and delisted companies are included.

IV.3.1. Dependent Variable: New Industry Entry

In general, products are identified as belonging to separate markets if they are classified into separate industries on the basis of the Standard Industrial Classification (SIC) code. In practice, there is little choice since most data follow the SIC code. According to Gort (1962), the SIC code was developed and based mainly in the differences and similarities between products. Sometimes, classification occurs on the basis of production processes and raw materials employed. In most circumstances all three criteria lead to the same classification.

Public firms in the U.S. are required to report information about their operations in different industries under FAS14 issued by the Financial Accounting Standards Board (FASB) in 1976. FAS14 defined reportable segments by industries ${ }^{42}$ and geographic area. Firms were required to disclose revenues, assets, capital expenditures, depreciation, and earnings by industries if the segment revenues, assets, or earnings exceeded $10 \%$ of the consolidated amounts. Compustat later assigned a four-digit SIC (SIC4) code to each reported segment. Henceforth, an industry is defined at the SIC4 code level.

\footnotetext{
${ }^{42}$ An industry segment is defined as "a component of an enterprise engaged in providing a product or service or a group of related products and services primarily to unaffiliated customers for a profit" (FAS 14, para. 10).
} 
The accounting rule associated with reporting segment information changed in 1997.

Firms are required to report "operation segments" instead of "industry segments". ${ }^{43}$ To ensure that the standard of segments is consistent over time, I only use data prior to 1997. ${ }^{44}$ In addition, the earliest year with all relevant information available is 1984. Taken together then, I examine firm dynamics for the period 1984-96.

I restrict my attention to manufacturing firms. These firms should have had at least one manufacturing segment (SIC4 codes 2011 to 3999) in 1984 and have survived in 1985. Since my interest is in knowledge effects, I focus on patenting firms. This results in a total of 1,101 firms left in the sample. A patenting firm is defined to have at least one patent count before 1985 .

Table 4.1. Characteristics in 1984 of Patenting firms and Non-Patenting Firms

\begin{tabular}{lcc}
\hline \multicolumn{1}{c}{ Variable } & Patenting firms & Non-Patenting Firms \\
\hline Shares of sales revenues & $55 \%$ & $45 \%$ \\
Shares of R\&D expenditures & $72 \%$ & $28 \%$ \\
$\%$ that reported R\&D & $73 \%$ & $56 \%$ \\
Sales revenues (mil. \$) & $1349(4950)$ & $645(3868)$ \\
R\&D Expenditures (mil. \$) & $35(172)$ & $8(55)$ \\
Manufacturing segment counts & $1.9(1.1)$ & $1.4(0.8)$ \\
\hline \multicolumn{1}{c}{ Firm Counts } & 1101 & 1877 \\
\hline
\end{tabular}

Standard deviations are in parentheses.

\footnotetext{
${ }^{43}$ A new statement on segment disclosures, FAS131 (1997) has replaced FAS14 (1976). FAS131 takes a different approach. Segments are defined as the way "management organizes segments internally in making operating decisions and assessing firm performance" (FAS 131, para. 4). To emphasize this change, the FASB abandoned the term "industry segments" and now refers to "operating segments".

${ }^{44}$ The consistency is a real concern. According to Herrmann and Thomas (2000), among 100 sample firms, 50 increased the number of segments reported, 8 decreased the number of segments reported, and 42 did not change upon switching to FAS131.
} 
Table 4.1 compares firm characteristics in 1984 of patenting firms with non-patenting firms. On average, patenting firms were twice as large, more R\&D intensive, and more diversified. Notice that even though they had no patent, non-patenting firms still made up $28 \%$ of total R\&D expenditures in 1984 . It is likely that these firms are mainly involved in internal innovation, therefore their $R \& D$ output did not take the form of patenting.

\section{Figure 4.1. Entry Counts of the 1,101 Firms for 1985-96}

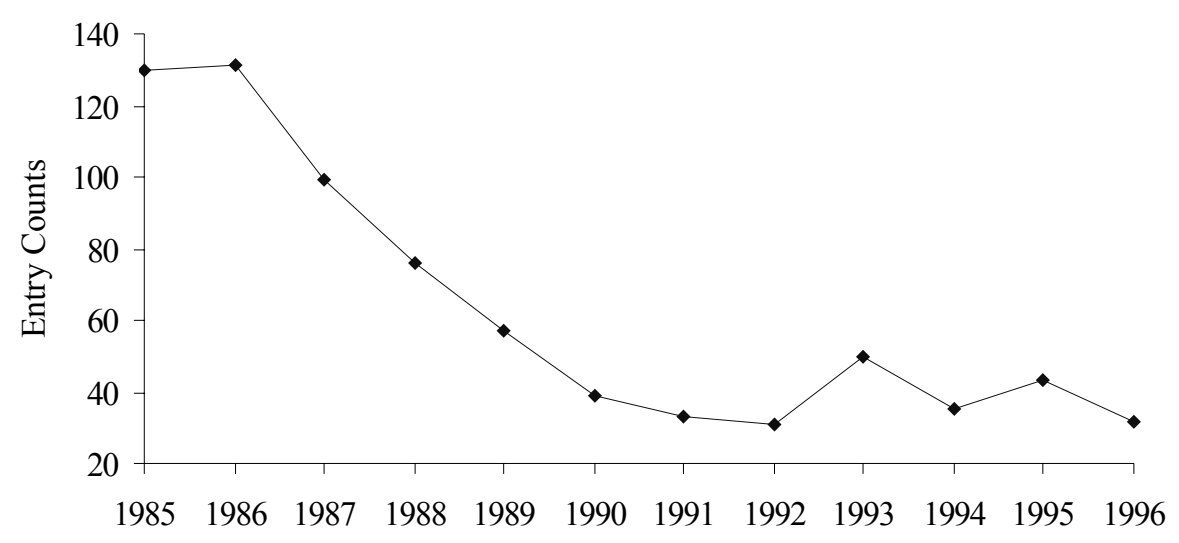

A firm should have entered a new industry when it is observed to report a new segment. I define a firm's "new industry entry" when its annual financial report presents a SIC4 code that is different from the former year. I only count SIC4 codes between 2011 and 3999. Difficulties in trying to precisely time an entry come from the reporting rule on "exceeding 10 percent of the consolidated amounts". If strictly followed, ${ }^{45}$ this rule

\footnotetext{
${ }^{45}$ In my sample, 25 percent of segments have their initial sales revenue less than 10 percent of the consolidated amounts; 28 percent have their initial assets less than 10 percent; 17 percent have both less than 10 percent.
} 
implies that firms may have already established a new business but have delayed reporting it because it is less than 10 percent. Second, a new business may have been dropped before growing large enough. If there is a lower bound for entry size ${ }^{46}$ small firms should be more likely to report their entries in time and less likely to fail reporting. Conversely, large firms are more likely to delay and fail to report. This may lead to an underestimate of firm size effects on entry likelihood. I control for firm size in my estimations.

Among these 1,101 patenting firms, there are 753 counts of new industry entry from 1985 to 1996 . Figure 4.1 shows the annual entry count. It dropped sharply prior to 1991 and then stabilized near 40 . The plunge could be explained by the contemporaneous decline of U.S. manufacturing industries. Year dummies are included in my regressions to control for different propensities of entry over time.

Among the 1,101 firms, 36 percent have one entry, 17 percent have two, 8 percent with three, and 4 percent with four. Due to sparseness of data beyond the fourth recurrence, I only examine hazard rates for the first four entries. Figure 4.2 presents the time distribution of recurrent entry times. For the first entry, 60 percent of its counts were accomplished within the first three years. Comparatively, half of the fourth entry counts took place in the last four years.

\footnotetext{
${ }^{46}$ I run the OLS regression of first-reported segment sales on the lagged firm sales. The result is: LOG(Segment sales $)=\frac{-1.84+\underset{(0.05)}{(0.03)}}{0.91} *$ LOG(Firm sales),

with $R^{2}=0.70, N=520$. The elasticity of first-reported segment sales to lagged firm sales is close to one. This seems to be evidence of no minimum entry size. However, the elasticity may be overestimated given the requirement of " 10 percent of the consolidated amounts". The first-reported segment size in a larger firm tends to be larger only because the firm waits until the segment size is large enough to report.
} 
Figure 4.2. Distributions of Recurrent Entries for 1985-96

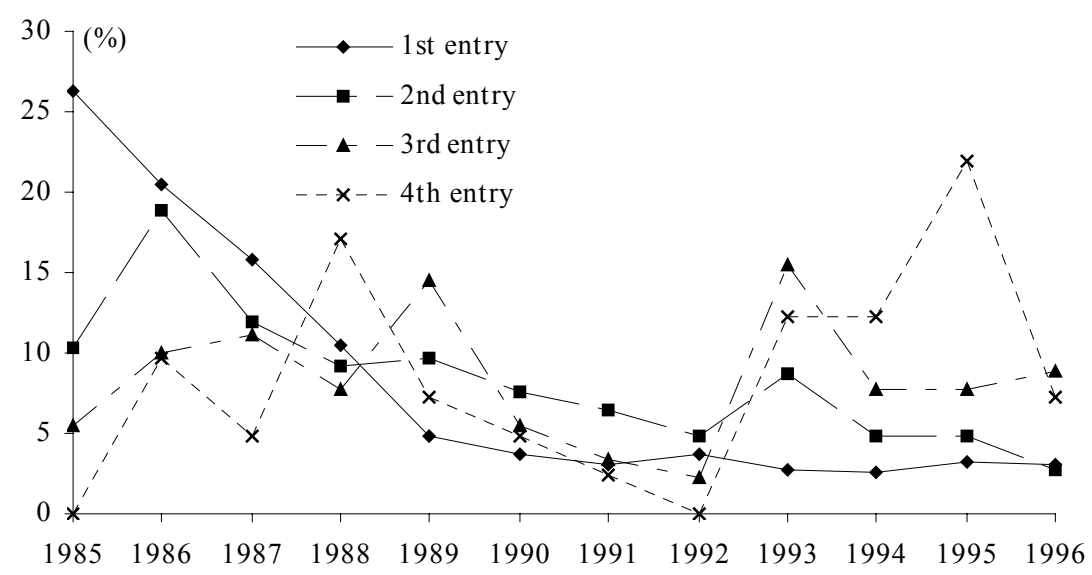

IV.3.2. Independent Variable: Knowledge stocks

Patents and R\&D information are commonly used to measure a firm's knowledge stocks. To capitalize on this, I use patent annual counts (hereafter, PACs). PACs indicate the number of granted patents applied for in a given year. This serves to quantify realized annual patent output. Following Hall, Jaffe, and Trajtenberg (2005), I include the traditional 15 percent depreciation rate to calculate cumulative PACs as my measure of knowledge stocks ${ }^{47}$.

I also use cumulative citation annual counts (hereafter, cumulative CACs) as another measure. CACs refer to the summed citation counts of granted patents applied for in a given year. ${ }^{48}$ It is well known that the lifetime of citation is long - some patents receive

\footnotetext{
${ }^{47}$ Depreciation is endogenous to what is going on in the industry, as in Thompson (1996). It would be a big concern if the results were sensitive to the depreciation rate. Fortunately, changing the percentage to either $10 \%$ or $20 \%$ does not influence the main results.

${ }^{48}$ The citations received by a patent are often interpreted as a signal of economic importance. Hall, Jaffe, and Trajtenberg (2005) find evidence that patent citations are useful to measure the "importance" of a firm's patents as the intangible knowledge stocks.
} 
citations after 30 years. To minimize the influence of the truncated data when calculating CACs, I expand the citation records for each patent in the NBER dataset. I allow the period to run from 1999 to August 2006. The appropriate citation information is retrieved from the USPTO website. I then calculate cumulative CACs using a depreciation rate of 15 percent. $^{49}$

Cumulative $R \& D$ expenditures are the third measure. I use real $R \& D$ expenditures ${ }^{50}$ and calculate the cumulative value using the 15 percent depreciation rate. Because firmlevel $R \& D$ information is available as early as in 1970 , the cumulative value may not be severely understated in the early years. This is also true of the previous two measures: information on patenting is available as early as in 1975 . If we relate these measures to either internal or external innovation, patents are more likely to reflect external innovations while R\&D expenditures are more likely to reflect internal innovations.

Figure 4.3 shows the trend of the mean characteristics from 1984 to 1996. Each variable is normalized by dividing through by its 1984 value. For consistency, I only count firms that continuously operated during the observation period. $R \& D$ expenditures and sales revenues are all in real terms. They increased three-fold from 1984 to 1996, and cumulative R\&D expenditures increased close to five-fold. Cumulative PACs and cumulative CACs increased less than two-fold. It is unclear why the cumulative R\&D expenditures increased faster than R\&D expenditures while the cumulative PACs and

\footnotetext{
${ }^{49}$ Hall, Jaff, and Trajtenberg (2005) use the same measure. But there is limiting effect. It is more likely that a patent in 1985 with 50 CACs is less valuable than one in 1996 with the same CACs. Thus, comparability of CACs over time is doubtful. For this aspect, PACs are more reliable, and I use CACs as a robustness check.

${ }^{50}$ I use the GDP implicit deflator from the FRED (Federal Reserve Economic Data). Its value in 2000 is set to 1 . I follow the same approach when I later calculate the real value for sales revenues.
} 
cumulative CACs increased more slowly. One explanation might come from the understatement of cumulative $\mathrm{R} \& \mathrm{D}$ expenditures in the early years of the dataset. It is more severe here than in the other two measures. The reason may be that patenting records have been backdated to the period before a firm was listed, but this backdating does not apply to R\&D expenditures.

Figure 4.3. Mean Characteristics of Persistent Firms for 1984-96

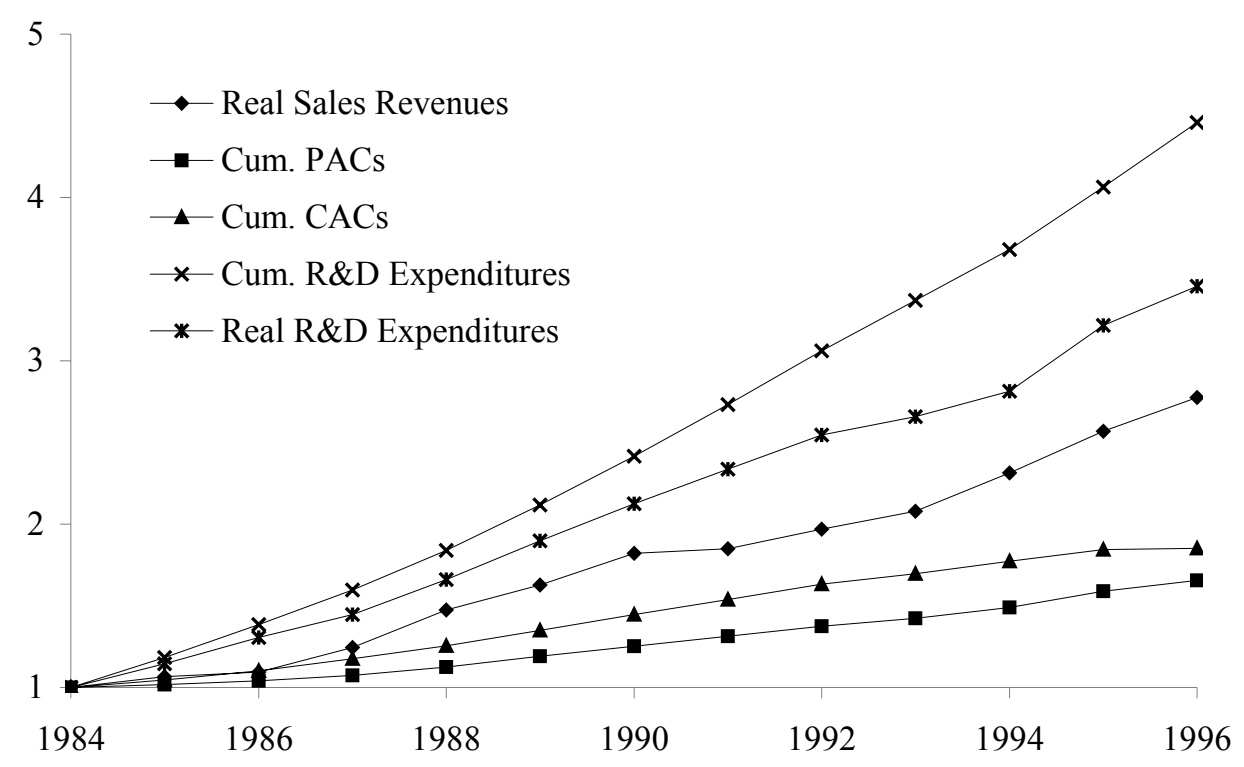

IV.4. Results

Table 4.2 provides summary statistics for 1984 of those patenting firms that had at least one entry during 1985-96. Definitions for each variable are given in the Appendix. For comparison, I also report summary statistics for the remaining firms - those with no entry. Knowledge stocks in firms with entry were twice as large as in firms without. The same is true of sales revenues. The Liability/Asset ratio and the rate of return on assets 
are analogous. The manufacturing segment counts in firms with entry was 2.4 in 1984 . The comparable figure for firms without entry was 1.5 . This seems to be evidence that the degree of diversification does influence later entry. Multivariate analyses below will determine whether it is knowledge stocks or the degree of diversification that matters.

\section{Table 4.2. Characteristics in 1984 of Patenting firms with Entry VS Those without}

\begin{tabular}{lcc}
\hline \multicolumn{1}{c}{ Variable } & With Entry & Without Entry \\
\hline Real sales revenues (mil. \$) & $1296(4120)$ & $701(2827)$ \\
Liability/Assets ratio & $0.49(0.18)$ & $0.47(0.22)$ \\
Return on assets & $0.051(0.078)$ & $0.045(0.103)$ \\
Cumulative PACs & $120(357)$ & $54(228)$ \\
Cumulative CACs & $1259(3827)$ & $622(3037)$ \\
Cumulative R\&D expenditures (mil. \$) & $123(489)$ & $56(343)$ \\
Real R\&D expenditures (mil. \$) & $35(139)$ & $17(102)$ \\
Manufacturing segment counts & $2.4(1.3)$ & $1.5(0.9)$ \\
\hline \multicolumn{1}{c}{ Firm Counts } & 399 & 702 \\
\hline
\end{tabular}

Standard deviations are in parentheses.

Incorporating all 1,101 patenting firms, I first employ a probit model to estimate the likelihood of new industry entry for each firm-year from 1985 to 1996 . I use the three measures of knowledge stocks, respectively, with control for firm characteristics and fixed year effects. The dependent variable is an entry dummy; it represents that the firm reported at least one manufacturing segment new to the prior year. All firm characteristic variables - including the measure of knowledge stocks - are lagged one-year. Sales revenues are in real values; they proxy for firm size. Also, they capture a firm's marketing and supply capabilities. ${ }^{51}$ The rate of return on assets (ROA) equals the

\footnotetext{
${ }^{51}$ Firm size may also capture some characteristics of diversification. Gort (1962) shows a strong positive relationship between firm size and the number of industries it is involved in. Big pharmaceutical firms are more diversified than small pharmaceutical firms, big chemicals producers are more diversified than small
} 
operating profit divided by total assets. It measures a firm's profitability. The Liability/Asset (L/A) ratio equals total liabilities divided by total assets. It measures a firm's propensity to finance by issuing debt.

Table 4.3. Probit Estimations of Entry Likelihood on Knowledge Stocks

\begin{tabular}{|c|c|c|c|c|c|c|}
\hline \multirow{2}{*}{ Variable } & \multicolumn{2}{|c|}{ Cum. PACs $/ 100$} & \multicolumn{2}{|c|}{ Cum. CACs $/ 1000$} & \multicolumn{2}{|c|}{ Cum. R\&D Expenditures (bil. \$) } \\
\hline & Est. & S.E. & Est. & S.E. & Est. & S.E. \\
\hline Knowledge stocks & $0.012 * *$ & 0.005 & 0.003 & 0.004 & -0.05 & 0.03 \\
\hline \multicolumn{7}{|l|}{ Controls: } \\
\hline Sales revenues (bil. \$) & 0.003 & 0.004 & $0.007 * *$ & 0.003 & $0.018 * * *$ & 0.006 \\
\hline ROA & 0.12 & 0.16 & 0.12 & 0.16 & 0.11 & 0.16 \\
\hline $\mathrm{L} / \mathrm{A}$ ratio & 0.04 & 0.04 & 0.04 & 0.04 & 0.04 & 0.04 \\
\hline Intercept & & & & $\mathrm{Y}$ & & \\
\hline Year fixed effects & & & & $\mathrm{Y}$ & & \\
\hline Industry fixed effects & & & & $\mathrm{N}$ & & \\
\hline Log Likelihood & \multicolumn{2}{|c|}{-2356} & \multicolumn{2}{|c|}{-2358} & \multicolumn{2}{|c|}{-2357} \\
\hline Observations & \multicolumn{2}{|c|}{10483} & \multicolumn{2}{|c|}{10483} & \multicolumn{2}{|c|}{10483} \\
\hline
\end{tabular}

Table 4.3 reports maximum likelihood estimates from the probit model. The estimated coefficient on cumulative PACs is significantly positive; the other two measures are insignificant. The estimated coefficient on sales revenues is insignificant when using cumulative PACs, but turns significantly positive under the other two measures. Estimated coefficients on both the L/A ratio and the ROA are insignificant.

The process of knowledge accumulation may come from two different levels. First, as predicted by Penrose (1959) and Nelson (1959), higher R\&D productivities or higher diversification at the firm level would induce more R\&D investment. This accumulates

chemicals producers, and big oil producers are more diversified than small oil producers, as found by Grabowski (1968) and Teece (1980). 
more knowledge stocks. Second, at the industry level, firms facing more technological opportunities tend to stimulate R\&D. Again, this helps them to accumulate more knowledge stocks. The second effect can be controlled for by adding SIC4 code dummies to identify each firm's main line of manufacturing businesses in 1984.

Unfortunately, the probit estimation fails to converge when SIC4 code dummies are included. I estimate a linear probability (LP) model instead. The results are given in columns (1) and (4) of Table 4.4. The estimated coefficient on cumulative PACs or cumulative CACs is significantly positive. The significance of sales revenues disappears with the inclusion of SIC4 code dummies. I obtain similar results when using firm dummies in place of industry dummies in the LP model. ${ }^{52}$

\section{Table 4.4. LP Estimations of Entry Likelihood on Knowledge Stocks}

\begin{tabular}{|c|c|c|c|c|c|c|c|c|c|c|c|c|}
\hline \multirow{3}{*}{ Variable } & \multicolumn{6}{|c|}{ Cum. PACs $/ 100$} & \multicolumn{6}{|c|}{ Cum. CACs $/ 1000$} \\
\hline & \multicolumn{2}{|c|}{ (1) } & \multicolumn{2}{|l|}{ (2) } & \multicolumn{2}{|l|}{ (3) } & \multicolumn{2}{|l|}{ (4) } & \multicolumn{2}{|l|}{ (5) } & \multicolumn{2}{|c|}{ (6) } \\
\hline & Est. & S.E. & Est. & S.E. & Est. & S.E. & Est. & S.E. & Est. & S.E. & Est. & S.E. \\
\hline Knowledge stocks & $0.004 * * *$ & * 0.001 & $0.007 * * *$ & 0.002 & $0.002 * *$ & 0.001 & $0.002 * * *$ & * 0.001 & $0.005 * * *$ & * 0.002 & 0.001 & 0.001 \\
\hline Lagged counts & & & -0.008 & 0.009 & & & & & $-0.011 *$ & 0.006 & & \\
\hline \multicolumn{13}{|c|}{ Controls: } \\
\hline Sales revenues (bil. \$) & -0.001 & 0.001 & -0.001 & 0.001 & -0.001 & 0.001 & 0.000 & 0.001 & 0.000 & 0.001 & 0.000 & 0.001 \\
\hline ROA & -0.004 & 0.019 & -0.004 & 0.019 & -0.014 & 0.019 & -0.002 & 0.019 & -0.002 & 0.019 & -0.013 & 0.019 \\
\hline $\mathrm{L} / \mathrm{A}$ ratio & -0.001 & 0.005 & -0.001 & 0.005 & -0.004 & 0.005 & -0.001 & 0.005 & -0.001 & 0.005 & -0.004 & 0.005 \\
\hline Segment counts & \multicolumn{10}{|c|}{$0.033 * * * 0.003$} & \multicolumn{2}{|c|}{$0.034 * * * 0.003$} \\
\hline Intercept & \multicolumn{12}{|c|}{$\mathrm{Y}$} \\
\hline Year fixed effects & \multicolumn{12}{|c|}{ Y } \\
\hline Industry fixed effects & \multicolumn{12}{|c|}{$\mathrm{Y}$} \\
\hline $\mathrm{R}^{2}$ & \multicolumn{4}{|c|}{0.06} & \multicolumn{2}{|c|}{0.08} & \multicolumn{2}{|c|}{0.06} & \multicolumn{2}{|c|}{0.06} & \multicolumn{2}{|c|}{0.08} \\
\hline Observations & \multicolumn{2}{|c|}{10483} & \multicolumn{2}{|c|}{10483} & \multicolumn{2}{|c|}{10483} & \multicolumn{2}{|c|}{10483} & \multicolumn{2}{|c|}{10483} & \multicolumn{2}{|c|}{10483} \\
\hline
\end{tabular}

${ }^{52}$ Results are provided in Table 4.A1 of the Appendix. 
An alternative explanation to why patent measures predict entry likelihood is that the lagged PACs (or CACs) - which have been summed in the cumulative values - may capture the information of latest innovations. According to Penrose (1959), innovations result in new industry entry. If this is where the predictive power lies, we should expect the effect of one-year lagged PACs (or CACs) to be significantly positive and the rest to be insignificant after splitting the cumulative PACs (or CACs) into these two parts. I repeat the LP estimations after the split and report the results in columns (2) and (5) of Table 4.4. In either case, the estimated coefficient on the lagged counts is not significantly positive while that on the rest part is. Therefore, I conclude that the predictive power does not come from that these measures capture the latest innovations.

Table 4.5. Entry Ratio by Manufacturing Segment Counts in 1984

\begin{tabular}{ccc}
\hline Manufacturing Segment Counts & Firm Counts & Entry Ratio (\%) \\
\hline 1 & 576 & 21 \\
2 & 259 & 45 \\
3 & 169 & 53 \\
4 & 61 & 72 \\
5 & 27 & 78 \\
6 & 5 & 80 \\
7 & 2 & 100 \\
8 & 2 & 100 \\
\hline Summary & 1101 & 36 \\
\hline
\end{tabular}

I then include the degree of diversification. To do so, I use the number of manufacturing segments that the firm is operating in. Manufacturing segment counts change when a firm enters or exits a relevant segment. In columns (3) and (6) of Table 4.4, I add the manufacturing segment counts. The estimated coefficient on cumulative 
PACs, previously significantly positive, decreases. With respect to cumulative CACs, including this control results in a switch to statistical insignificance. The coefficient on manufacturing segment counts is significantly positive under either scenario. This is not surprising given the fact that the entry ratio increases with the initial manufacturing segment counts in 1984 (shown in Table 4.5). The positive sign is consistent with the hypothesis that a firm's diversification comes from frequently entering new industries. ${ }^{53}$ The weakening of knowledge effects reaffirms my concern about collinearity between knowledge stocks and the degree of diversification.

Table 4.6. LP Estimations of Entry Likelihood in all Manufacturing Firms

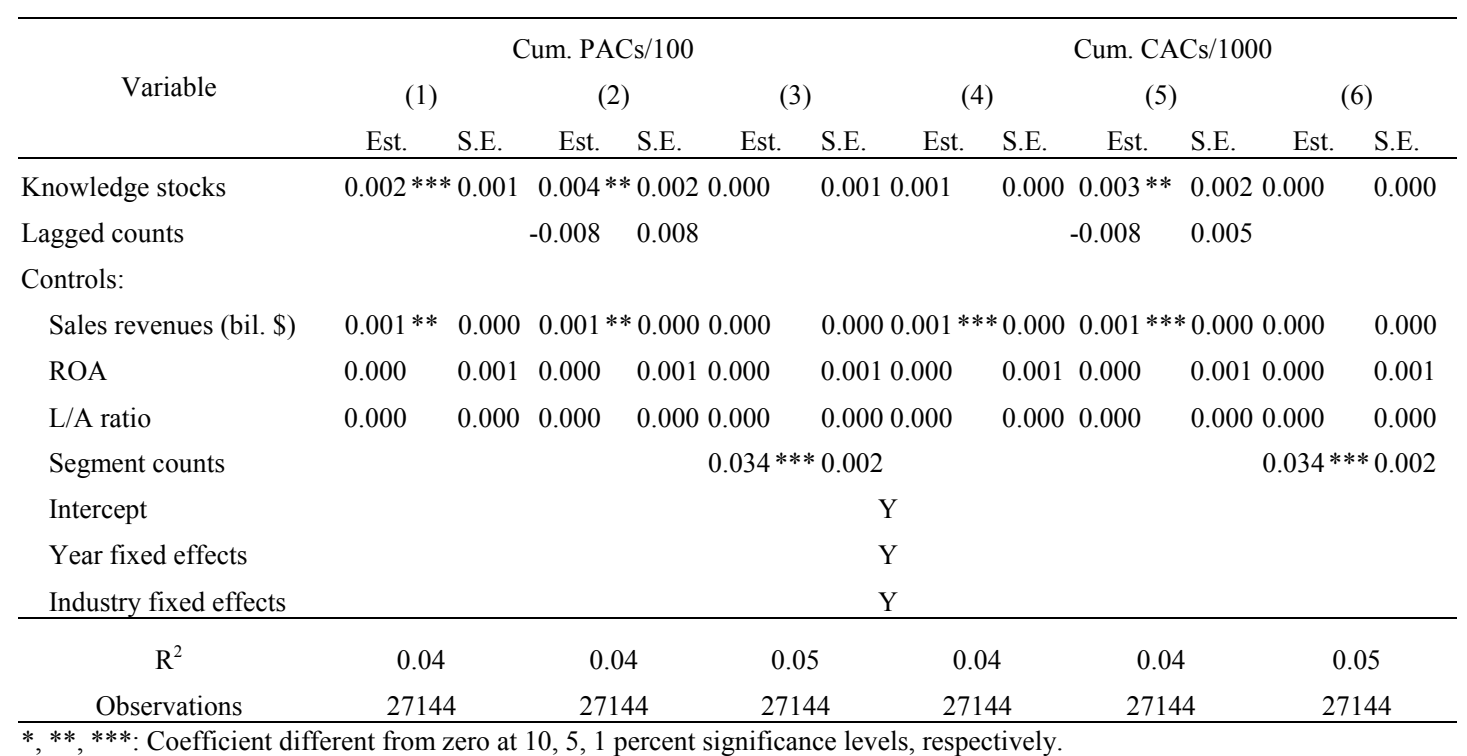

\footnotetext{
${ }^{53}$ I need to reject an alternative hypothesis: the estimated coefficient on segment counts is significantly positive only because former entry experiences matter. To test this hypothesis, I split manufacturing segment counts into two measures. The first measure is a dummy indicating whether a firm has multiple segments. If so, the second measure equals the number of segments; otherwise, it equals zero. This treatment differentiates the experience effect from the diversification effect, with the dummy capturing the experience effect and the conditional segment counts capturing the first-order diversification effect. It turns out that both effects are significantly positive, with the estimated coefficient on the former slightly larger. Therefore, I reject the null hypothesis that former entry experiences are the only reason.
} 
Since those firms with no patent before 1985 shared $28 \%$ of the total R\&D expenditures in 1984, I include them in the sample and examine how the results are influenced. With the inclusion of 1877 non-patenting firms as shown in Table 4.1, I repeat the LP estimations as in Table 4.4, and report the results in Table 4.6. The estimated coefficient on sales revenues becomes significantly positive. However, it turns to be insignificant with the inclusion of Manufacturing segment counts. When using cumulative PACs as the measure of knowledge stocks, their coefficient is significantly positive. It also turns to be insignificant with the inclusion of segment counts. When using cumulative CACs, the coefficient is insignificant except for in column (5) when the cumulative CACs are splitted into two parts. Diversification effects remain significantly positive. The weakening of knowledge effects comes from the sample expansion. One explanation may be that knowledge stocks stimulate innovation productivities only when the capacity is large enough; thus, including less R\&D intensive firms weakens the average knowledge effects.

Is it possible that the positive relationship between knowledge stocks and entry likelihood comes from the fact that destination industry R\&D attracts diversification, as asserted by Scherer (1965)? McGowan (1971) provides a reason for this: R\&D intensive industries are often populated by rapidly growing firms. These firms find themselves short of managerial, financial, and marketing skills. Merging with a diversified firm remedies this problem. If this is true, the firm in shortage should be the smaller one thus, it would be acquired. One likely outcome is that the acquired firm remains listed. Another outcome could be that it becomes a private sector. In either case, it would not appear in the data as if the acquired firm had added a new segment. The acquiring firm, 
however, would have a new entry. However, this hypothesis provides no intuition for its knowledge characteristics. In conclusion, McGowan's theory does not explain this positive relationship.

However, it may be problematic for either the probit or the LP model to assume entry decisions are made independently across firm-years. In fact, many firms reported more than one entry during the observation period. Two specific characteristics of these recurrent entries should be taken into account. First, a firm may already have planned the second entry before it accomplishes the first one. Second, a firm may enter more than one industry in a single year. ${ }^{54}$

Concerned with these characteristics, I adopt the methodology of Wei, Lin, and Weissfeld (1989) - hereafter referred to as the WLW model. Their treatment of recurrent failure times imposes no particular structure of dependence between the distinct failure times of each subject. Each marginal distribution of the failure times takes the form of a Cox proportional hazards $(\mathrm{PH})$ model. Estimators are asymptotically jointly normal with a covariance matrix that can be consistently estimated.

Failure time is defined to be an event that adds a new segment. Consider a firm with no entry in the first year, but two in the second. The event of the second entry is in the second year, simultaneous to that of the first entry. Firm characteristics, such as real sales

\footnotetext{
${ }^{54}$ Allowing comparison of independent variables over time may lead to underestimation of the positive relationship between knowledge stocks and entry likelihood. For a persistently existing firm, its real sales revenues increase over time, so do knowledge stocks, as shown in Figure 4.3. Meanwhile, most of entries were clustered in the first several years as shown in Figure 4.2.
} 
revenue, ROA, and the L/A ratio, are time covariates. I include SIC4 code dummies to control for industry fixed effects. ${ }^{55}$

Table 4.7. WLW Estimation of Entry Hazard on Knowledge Stocks

\begin{tabular}{|c|c|c|c|c|c|c|c|c|c|}
\hline \multirow{2}{*}{ Variable } & \multicolumn{3}{|c|}{ Cum. PACs/100 } & \multicolumn{3}{|c|}{ Cum. CACs/1000 } & \multicolumn{3}{|c|}{ R\&D Expenditures (bil. \$) } \\
\hline & Est. & S.E. & Hazard Ratio & Est. & S.E. & Hazard Ratio & Est. & S.E. & Hazard Ratio \\
\hline \multicolumn{10}{|l|}{ Knowledge stocks } \\
\hline 1st entry & $0.07 * * *$ & 0.02 & 1.07 & 0.02 & 0.01 & 1.02 & -0.06 & 0.09 & 0.94 \\
\hline 2nd entry & $0.07 * * *$ & 0.02 & 1.08 & $0.03 *$ & 0.01 & 1.03 & $-0.18 *$ & 0.10 & 0.84 \\
\hline 3rd entry & $0.08 * * *$ & 0.02 & 1.08 & $0.02 * *$ & 0.01 & 1.03 & 0.01 & 0.09 & 1.01 \\
\hline 4th entry & 0.03 & 0.04 & 1.03 & -0.01 & 0.03 & 0.99 & 0.02 & 0.11 & 1.02 \\
\hline \multicolumn{10}{|l|}{ Sales revenues (bil. \$) } \\
\hline 1st entry & 0.00 & 0.02 & 1.00 & 0.02 & 0.01 & 1.02 & $0.04 * *$ & 0.02 & 1.04 \\
\hline 2nd entry & 0.00 & 0.02 & 1.00 & 0.02 & 0.02 & 1.02 & $0.07 * * *$ & 0.02 & 1.07 \\
\hline 3rd entry & 0.00 & 0.02 & 1.00 & 0.02 & 0.01 & 1.02 & $0.03 *$ & 0.02 & 1.04 \\
\hline 4th entry & 0.01 & 0.01 & 1.01 & $0.02 * *$ & 0.01 & 1.02 & 0.02 & 0.02 & 1.02 \\
\hline \multicolumn{10}{|l|}{$\mathrm{ROA}$} \\
\hline 1st entry & -0.43 & 0.38 & 0.65 & -0.33 & 0.38 & 0.72 & -0.30 & 0.39 & 0.74 \\
\hline 2nd entry & 0.43 & 0.45 & 1.54 & 0.50 & 0.42 & 1.65 & 0.49 & 0.42 & 1.63 \\
\hline 3rd entry & 0.31 & 0.58 & 1.36 & 0.37 & 0.59 & 1.46 & 0.39 & 0.58 & 1.48 \\
\hline 4th entry & 0.45 & 0.34 & 1.58 & 0.48 & 0.34 & 1.62 & 0.50 & 0.33 & 1.66 \\
\hline \multicolumn{10}{|l|}{$\mathrm{L} / \mathrm{A}$ ratio } \\
\hline 1 st entry & 0.18 & 0.17 & 1.20 & 0.20 & 0.17 & 1.22 & 0.21 & 0.17 & 1.24 \\
\hline 2nd entry & $0.37 * *$ & 0.17 & 1.44 & $0.38 * *$ & 0.16 & 1.47 & $0.38 * *$ & 0.17 & 1.46 \\
\hline 3rd entry & $0.40 * *$ & 0.16 & 1.49 & $0.41 * * *$ & 0.16 & 1.51 & $0.42 * * *$ & 0.16 & 1.52 \\
\hline 4th entry & $0.52 * * *$ & 0.16 & 1.68 & $0.52 * * *$ & 0.17 & 1.69 & $0.53 * * *$ & 0.17 & 1.70 \\
\hline Industry fixed effects & \multicolumn{9}{|c|}{$\mathrm{Y}$} \\
\hline$-2 *$ Log Likelihood & \multicolumn{3}{|c|}{8626} & \multicolumn{3}{|c|}{8645} & \multicolumn{3}{|c|}{8650} \\
\hline Firm Counts & \multicolumn{3}{|c|}{1101} & \multicolumn{3}{|c|}{1101} & \multicolumn{3}{|c|}{1101} \\
\hline
\end{tabular}

Table 4.7 reports maximum likelihood estimates of the WLW model using the three measures of knowledge stocks. The estimated coefficient on cumulative PACs is

\footnotetext{
${ }^{55}$ With the inclusion of SIC4 code dummies, dependence among failure times is imposed. I also estimate the WLW model without SIC4 code dummies, and reach similar conclusions. The major difference is that the estimated coefficients on cumulative CACs are insignificant. Table 4.A2 in the Appendix reports the results.
} 
significant and positive up to the third entry. This indicates that knowledge stocks contributed to entry likelihood. For the first entry, each addition of 100 cumulative PACs increased the probability by 7 percent per year. The clustering of the forth entry in the later years and the sparseness of its counts may be the reason for the insignificance of cumulative PACs. The coefficient on cumulative CACs is positively significant in the second and the third entry.

New industry entry may stimulate R\&D investment. Thus, any fluctuation in knowledge stocks may reflect a firm's early entries. With respect to the hazard of multiple entries, this would result in an overestimation of knowledge effects. To examine the seriousness of this endogeneity problem, I run an OLS regression of knowledge stocks on the current entry dummy with control for fixed year effects and fixed firm effects. I include firm dummies instead of industry dummies because the focus here is on the fluctuation of knowledge stocks within a firm. The estimated coefficient on the entry dummy is insignificant at a significance level of 10 percent. I therefore conclude that even for multiple entries, overestimation is not a serious problem.

Again I stress that there is no evidence that cumulative R\&D expenditures significantly influence entry likelihood. Based on my model, it indicates that cumulative R\&D expenditures are not a good measure of the knowledge stocks that would favor external innovations. An explanation is that R\&D investment focuses mainly on internal innovation, and the proportion spent on external innovations is random. This result is also consistent with my concern that cumulative R\&D expenditures may be understated in the early years. The coefficient on sales revenues achieves significance when using 
cumulative R\&D expenditures; this indicates that firm size captures some characteristics of knowledge stocks. ${ }^{56}$

No matter what knowledge measures are used, the estimated coefficient on the L/A ratio remains positive and significant with respect to the hazards of the second, third, and fourth entry, respectively. This characteristic indicates that a high frequency of entry is closely related to a firm's financial leverage: firms with high leverage tend to enter new industries more frequently. However, profitability does not matter.

I rerun the WLW estimations with the inclusion of all manufacturing firms. The knowledge effect is insignificant no matter which proxy is used to measure knowledge stocks. Comparatively, the effect of sales revenues is persistently significantly positive while the effect of the L/A ratio is barely significant. See Table 4.A3 in the Appendix for the estimation results.

Figure 4.4. Kaplan Meier Survival Estimates

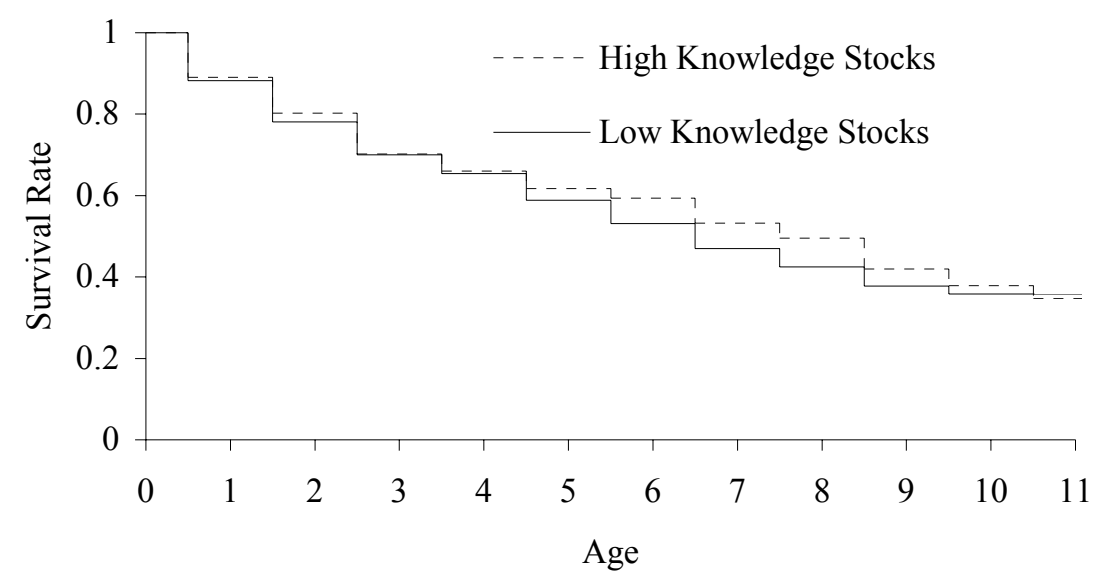

\footnotetext{
${ }^{56}$ Additionally, the knowledge effect is insignificant when using knowledge intensity as the measure. Knowledge intensity is defined as knowledge stocks divided by the real sales revenues. My theoretical model takes this for granted since the knowledge intensity constantly equals 1 , regardless of firm size $n$.
} 
I then turn to a survival study of the segments established since 1985. Note that establishments in 1996 are excluded because there is no information about their survival. Also excluded are segments with initial assets equal to the contemporary total assets of their firms. ${ }^{57}$ This leaves 682 segments distributed in 399 firms; 54 percent have one entry, 24 percent with two, 13 percent with three, and the others with four and above. I label a "firm exit" as when an established segment (based on the SIC4 code) is dropped from the financial report. Under this definition, if a firm terminates its financial report, it exits all of its business segments. I treat these exits as ordinary.

To proceed, I first separate these 682 segments into two groups, one from high knowledge firms and the other from low knowledge firms, based on the median cumulative PACs in 1984. Figure 4.4 shows the estimated segment survival curves of these two groups. Both survival curves are much flatter than start-up firms. In either group, half of the segments are still alive when six years old. Segments in high patenting firms seem to have a survival advantage - albeit quite mild. The following multivariate analyses determine the importance of knowledge stocks.

MacDonald (1985) and Hall (1988) show that R\&D intensive firms are more likely to enter high R\&D industries, which are generally riskier. Even if these firms have some advantage in survival because of knowledge stocks, this selective entry may offset this. I therefore include SIC4 code dummies to control for any industry fixed effects that a segment may be subject to. I also include year dummies to control for the cohort of establishments. All firm characteristic variables are static and take the value when the

${ }^{57}$ I also run the estimations when keeping these segments, and reach similar conclusions. 
segment is first reported. Both firm-level and segment-level sales revenues are in real value. ${ }^{58}$ The $\mathrm{PH}$ model requires the impact of initial endowment on the hazard to be the same, regardless of whether the segment is one year old or ten. This seems too restrictive, given the learning process that may have taken place and the depreciation of new knowledge over time. Hence, I interact all basis variables with AGE.

\section{Table 4.8. PH Estimation for Segment Exit Hazard in Patenting Firms}

\begin{tabular}{|c|c|c|c|c|c|c|c|c|}
\hline \multirow{3}{*}{ Variable } & \multicolumn{4}{|c|}{ Cum. PACs/100 } & \multicolumn{4}{|c|}{ Cum. CACs/1000 } \\
\hline & \multicolumn{2}{|r|}{ (1) } & \multicolumn{2}{|c|}{ (2) } & \multicolumn{2}{|r|}{ (3) } & \multicolumn{2}{|c|}{ (4) } \\
\hline & Est. & S.E. H.R & Est. & S.E. H.R & Est. & S.E. H.R & Est. & S.E. H.R \\
\hline Sales (bil.\$) & 0.11 & 0.111 .11 & 0.10 & 0.111 .11 & 0.10 & 0.111 .11 & 0.10 & 0.111 .10 \\
\hline Sales*age & $-0.07 *$ & 0.040 .93 & $-0.07 *$ & 0.040 .93 & -0.06 & 0.040 .94 & -0.06 & 0.040 .94 \\
\hline Total sales (bil.\$) & 0.00 & 0.031 .00 & 0.00 & 0.031 .00 & 0.00 & 0.031 .00 & 0.00 & 0.031 .00 \\
\hline Total sales*Age & 0.00 & $0.01 \quad 1.00$ & 0.00 & $0.01 \quad 1.00$ & 0.00 & $0.01 \quad 1.00$ & 0.00 & $0.01 \quad 1.00$ \\
\hline Knowledge stocks & $-0.09 * *$ & 0.040 .92 & $-0.09 * *$ & 0.040 .92 & $-0.08 *$ & $* 0.030 .92$ & $-0.08 * *$ & * 0.030 .92 \\
\hline Knowledge stocks*Age & $0.02 * * *$ & * 0.011 .02 & $0.02 * * *$ & 0.011 .02 & $0.02 *$ & $* 0.011 .02$ & $0.02 * *$ & * 0.011 .02 \\
\hline Segment counts & & & -0.06 & 0.090 .94 & & & -0.06 & 0.090 .94 \\
\hline Segment counts*Age & & & 0.00 & $0.02 \quad 1.00$ & & & 0.00 & 0.021 .00 \\
\hline Cohort effects & & & & $\mathrm{Y}$ & & & & \\
\hline Industry fixed effects & & & & $\mathrm{Y}$ & & & & \\
\hline$-2 * \log$ Likelihood & & 456 & & 456 & & 4457 & & 4456 \\
\hline Observations & & 682 & & 82 & & 682 & & 682 \\
\hline
\end{tabular}

$*, * *, * * *$ : Coefficient different from zero at $10,5,1$ percent significance levels, respectively.

Table 4.8 presents the estimation results. Note that 276 out of these 682 segments are right-censored. Without controlling for diversification effects, columns (1) and (3) suggest a strong negative relationship between initial knowledge stocks and exit hazard. These effects decay as the segment ages - initial knowledge stocks become less important over time. In columns (2) and (4), I add the manufacturing segment counts. Knowledge

\footnotetext{
${ }^{58}$ Choosing to merge or to build up its original production capacity may also influence segment survival. It is uncertain how this choice relates to the knowledge level.
} 
effects persist and the estimated coefficient on segment counts is insignificant. This implies diversification effects are ignorable for segment survival. These results persist when I ignore survival information for beyond ten years of being established. The coefficients fail to achieve significance when using cumulative $R \& D$ expenditures as the measure of knowledge stocks.

Given the average age of segments is around 5, the estimated average knowledge effect is closed to zero. We should make sure that the knowledge effect in segments' early years is not negative. When I ignore the survival information beyond five years of establishment, estimation results indicate that knowledge effects are significantly positive.

Table 4.9. PH Estimation for Segment Exit Hazard in Persistent Patenting Firms

\begin{tabular}{|c|c|c|c|c|c|c|c|c|c|c|c|}
\hline \multirow{3}{*}{ Variable } & \multicolumn{5}{|c|}{ Cum. PACs/100 } & \multicolumn{6}{|c|}{ Cum. CACs $/ 1000$} \\
\hline & \multicolumn{2}{|r|}{ (1) } & \multicolumn{3}{|c|}{ (2) } & \multicolumn{3}{|c|}{ (3) } & \multicolumn{3}{|c|}{ (4) } \\
\hline & Est. & S.E. H.R & Est. & S.E. & H.R & Est. & S.E. & H.R & Est. & S.E. & H.R \\
\hline Sales (bil.\$) & 0.05 & 0.111 .05 & 0.05 & 0.11 & 1.05 & 0.03 & 0.11 & 1.03 & 0.03 & 0.11 & 1.03 \\
\hline Sales*age & -0.05 & 0.040 .95 & -0.05 & 0.04 & 0.95 & -0.04 & 0.04 & 0.96 & -0.04 & 0.04 & 0.96 \\
\hline Total sales (bil.\$) & 0.02 & 0.031 .03 & 0.02 & 0.03 & 1.03 & 0.02 & 0.03 & 1.02 & 0.02 & 0.03 & 1.02 \\
\hline Total sales*Age & 0.00 & $0.01 \quad 1.00$ & 0.00 & 0.01 & 1.00 & 0.00 & 0.01 & 1.00 & 0.00 & 0.01 & 1.00 \\
\hline Knowledge stocks & $-0.14 * *$ & 0.060 .87 & $-0.14 * *$ & 0.06 & 0.87 & $-0.11 * *$ & * 0.05 & 0.90 & $-0.11 * *$ & $* 0.05$ & 0.90 \\
\hline Knowledge stocks*Age & $0.03 * * *$ & * 0.011 .03 & $0.03 * * *$ & ${ }^{*} 0.01$ & 1.03 & $0.02 * *$ & $* 0.01$ & 1.02 & $0.02 * *$ & $* 0.01$ & 1.02 \\
\hline Segment counts & & & 0.02 & 0.11 & 1.02 & & & & 0.01 & 0.11 & 1.01 \\
\hline Segment counts*Age & & & 0.01 & 0.02 & 1.01 & & & & 0.01 & 0.02 & 1.01 \\
\hline Cohort effects & & & & & $\mathrm{Y}$ & & & & & & \\
\hline Industry fixed effects & & & & & $\mathrm{Y}$ & & & & & & \\
\hline$-2 * \log$ Likelihood & & 2813 & & 812 & & & 2814 & & & 2814 & \\
\hline Observations & & 552 & & 552 & & & 552 & & & 552 & \\
\hline
\end{tabular}

$*, * *, * * *$ : Coefficient different from zero at 10, 5, 1 percent significance levels, respectively.

My treatment of firm terminations as ordinary exits may be problematic. The mechanism of shutting down a firm should be different from that of dropping a 
business. ${ }^{59}$ Moreover, the firm and its segments may continue operations in private. To avoid these complications, I restrict the sample to include only firms that survived all the way to $1996 .{ }^{60}$ I rerun the estimations, and report the results in Table 4.9. The knowledge effects become stronger.

I then expand the sample to all manufacturing firms that survived all the way to 1996. $17 \%$ of the business segments have their assets equal to the total assets of their firms. After deleting these segments and further refining the data, I end up with 1098 segments.

Table 4.10. PH Estimation for Segment Exit Hazard in Persistent Manufacturing

Firms

\begin{tabular}{|c|c|c|c|c|c|c|c|c|c|c|c|c|}
\hline \multirow{3}{*}{ Variable } & \multicolumn{6}{|c|}{ Cum. PACs/100 } & \multicolumn{6}{|c|}{ Cum. CACs/1000 } \\
\hline & \multicolumn{3}{|c|}{ (1) } & \multicolumn{3}{|c|}{ (2) } & \multicolumn{3}{|c|}{ (3) } & \multicolumn{3}{|c|}{ (4) } \\
\hline & Est. & S.E. & H.R & Est. & S.E. & H.R & Est. & S.E. & H.R & Est. & S.E. & H.R \\
\hline Sales (bil.\$) & -0.14 & 0.14 & 0.87 & -0.14 & 0.14 & 0.87 & -0.14 & 0.14 & 0.87 & -0.14 & 0.14 & 0.87 \\
\hline Sales*Age & -0.01 & 0.03 & 0.99 & -0.01 & 0.03 & 0.99 & -0.01 & 0.03 & 1.00 & 0.00 & 0.03 & 1.00 \\
\hline Total sales (bil.\$) & 0.02 & 0.02 & 1.02 & 0.02 & 0.02 & 1.02 & 0.02 & 0.02 & 1.02 & 0.02 & 0.02 & 1.02 \\
\hline Total sales*Age & 0.00 & 0.00 & 1.00 & 0.00 & 0.00 & 1.00 & 0.00 & 0.00 & 1.00 & 0.00 & 0.00 & 1.00 \\
\hline Knowledge st & -0.05 & 0.04 & 0.95 & -0.05 & 0.04 & 0.95 & -0.04 & 0.03 & 0.96 & -0.04 & 0.03 & 0.96 \\
\hline Knowledge stocks*Age & $0.01 *$ & $* 0.01$ & 1.01 & $0.01 *$ & $* 0.01$ & 1.02 & 0.01 & 0.01 & 1.01 & 0.01 & * 0.01 & 1.01 \\
\hline Segment counts & & & & 0.09 & 0.07 & 1.10 & & & & 0.09 & 0.07 & 1.10 \\
\hline Segment counts*Age & & & & 0.00 & 0.01 & 1.00 & & & & 0.00 & 0.01 & 1.00 \\
\hline Cohort effects & & & & & & $\mathrm{Y}$ & & & & & & \\
\hline Industry fixed effects & & & & & & Y & & & & & & \\
\hline$-2 *$ Log Likelihood & & 6699 & & & 6693 & & & 6697 & & & 6694 & \\
\hline Observations & & 1098 & & & 1098 & & & 1098 & & & 1098 & \\
\hline
\end{tabular}

$*, * *, * * *$ : Coefficient different from zero at 10, 5, 1 percent significance levels, respectively.

\footnotetext{
${ }^{59}$ Disney, Haskel, and Heden (2003) estimate exit hazard separately for single establishments and for those that are part of a larger group; they find different patterns between these two groups.

${ }^{60}$ There is a new implication for those segments with initial assets equal to the total assets of their firms. After the treatment, the type of segments that remain must be alive through 1996. Those who failed should have been deleted from the sample. To avoid this sampling bias, I delete them from the sample. I end up with 552 segments of which 276 are right-censored.
} 
I rerun the $\mathrm{PH}$ estimations as in Table 4.9, and report the results in Table 4.10. Among these 1098 segments, 540 are right-censored. The coefficient on initial knowledge stocks, though keeping a negative sign, shows no statistical significance. These results persist when I follow the process as in Table 4.8. This difference also comes from the sample expansion. One explanation may be that new industry entry in patenting firms follows a mechanism different from that in non-patenting firms: patenting firms are more likely to enter R\&D intensive industries, where knowledge stocks play a more important role in segment survival.

There is evidence that a firm's pre-entry background plays an important role in its survival. According to Klepper and Simons (2000), the surviving firms in the U.S. television receiver industry were almost exclusively those that had diversified out of producing radios. Knowledge effects and background effects may be correlated. To address this background question, I employ a fixed effects estimation procedure. Unfortunately, the regressions fail to converge when firm dummies are included.

\section{IV.5. Conclusions}

By examining U.S. public patenting firms in manufacturing sectors for 1984-96, I find that knowledge stocks predict the likelihood of a firm's new market entry. However, this predictive power is vanished when diversification effects are taken into account. The diversification effects are significantly positive in predicting entry likelihood. The knowledge effect is weaker when I include all manufacturing firms in my sample. 
One shortcoming of my results is that there may involve an endogeneity problem because of the interactions between knowledge stocks and diversification. The detected positive significance of knowledge effects may come from the positive correlation of knowledge stocks and the degree of diversification. Ignoring the endogeneity problem would lead to overestimation of the coefficient on knowledge stocks.

A survival study of newly established segments in patenting firms shows that initial knowledge stocks have significantly positive influence on the segments' later survival. However, contradictory to traditional findings in plant survival studies, neither initial segment size, initial firm size, nor degree of diversification shows any significant effect. When I expand my examination to all manufacturing firms, the hazard estimations of segment exits show no significant knowledge effects. Meanwhile, diversification effects are insignificant.

My study provides a preliminary basis for which to select the measure of knowledge stocks. Patent measures consistently perform better than R\&D measures, either in estimating entry likelihood or in estimating segment exit hazard. 


\section{References}

Audretsch, D., and M. Feldman (1999): "Innovation in Cities: Science-Based Diversity, Specialization and Localized Competition." European Economic Review 43(2):409-429.

Baldwin, J., and Gu, W. (2005): "The Impact of Trade on Plant Scale, Production-Run Length and Diversification." Statistics Canada, mimeograph.

Bernard, A. B., and J. B. Jensen. (2007):" Firm Structure, Multinationals and Manufacturing Plant Deaths." Review of Economics and Statistics 89(2):193-204.

Disney, R., J. Haskel, and Y. Heden (2003): "Entry, Exit, and Establishment Survival in UK Manufacturing." Journal of Industrial Economics 51(1):91-112.

Dunne, T., M. J. Roberts, and L. Samuelson (1989a): "The Growth and Failure of U.S. Manufacturing Plants.” Quarterly Journal of Economics 104(4):671-698.

Dunne, T., M. J. Roberts, and L. Samuelson (1989b): "Plant Turnover and Gross Employment Flows in the U.S. Manufacturing Sector." Journal of Labor Economics 7(1):48-71.

Gollop, F. M., and J. L. Monahan (1991): “A Generalized Index of Diversification: Trends in U.S. Manufacturing." Review of Economics and Statistics 73(2):318330 .

Gort, M. (1962): Diversification and Integration in American Industry. Princeton: Princeton University Press.

- (1969): “An Economic Disturbance Theory of Mergers." Quarterly Journal of Economics 83(4):624-642.

Grabowski, H. G. (1968): "The Determinants of Industrial Research and Development: A Study of the Chemical, Drug, and Petroleum Industries." Journal of Political Economy 76(2):292-306.

Grossman, G. M., and E. Helpman (1991): innovation and Growth in the Global Economy. Cambridge: MIT Press.

Hall, B. (1988): "The Effect of Takeover Activity on Corporate Research and Development." In Alan Auerbach, ed., Corporate Takeovers: Causes and Consequences. Chicago: University of Chicago Press.

-, A. B. Jaffe, and M. Trajtenberg (2005): "Market Value and Patent Citations.” RAND Journal of Economics 36(1):16-38. 
Herrmann, D., and W. B. Thomas (2000): “An Analysis of Segment Disclosures under SFAS No. 131 and SFAS No. 14.” Accounting Horizons 14(3):287-302.

Klepper, S., and K. Simons (2000): "Dominance by Birthright: Entry of Prior Radio Producers and Competitive Ramifications in the U.S. Television Receiver Industry.” Strategic Management Journal 21:997-1016.

- and P. Thompson (2006): "Submarkets and the Evolution of market Structure." RAND Journal of Economics 37(4):862-888.

Klette, T. J., and S. Kortum (2004): "Innovating Firms and Aggregate Innovation." Journal of Political Economy 112(5):986-1018.

MacDonald, J. M. (1985): "R\&D and the Direction of Diversification." Review of Economics and Statistics 67(4):583-590.

McGowan, J. J. (1971): “International Comparisons of Merger Activity." Journal of Law and Economics 14(1):233-250.

Montgomery, C. A. (1994): “Corporate Diversification." Journal of Economic Perspectives 8(3):163-178.

Nelson, R. R. (1959): “The Simple Economics of Basic Scientific Research.” Journal of Political Economy 67(3):297-306.

Penrose, E. (1959): The Growth of the Firm. White Pains, N.Y.: Sharpe.

Scherer, F. M. (1965): "Firm Size, Market Structure, Opportunity, and the Output of Patented Inventions." American Economic Review 55(5):1097-1125.

- (1983): “The propensity to patent." International Journal of Industrial Organization 1(1):107-128.

Shaked, A., and Sutton, J. (1990): "Multi-product Firms and Market Structure." Rand Journal of Economics 21(1):45-62.

Sutton, J. (2005): Competing in Capabilities, Clarendon Lectures. Oxford: Oxford University Press.

Teece, D. (1980): "Economies of Scope and the Scope of the Enterprise." Journal of Economic Behavior and Organization 1(3):223-247.

Thompson, P. (1996): “Technological Opportunity and the Growth of Knowledge: A Schumpeterian Approach to Measurement." Journal of Evolutionary Economics 6(1):77-98 
Wei, L. J., D. Y. Lin, and L. Weissfeld (1989): "Regression Analysis of Multivariate Incomplete Failure Time Data by Modeling Marginal Distributions." Journal of the American Statistical Association 84(408):1065-1073.

Williamson, O. E. (1979): "Transaction-Cost Economics: The Governance of Contractual Relations." Journal of Law \& Economics 22(2):233-261. 
Appendix

\section{Variable Description}

Specific variables used in the analysis are defined as follows:

. Patent Annual Counts (PACs) is defined as the number of granted patents applied for in a given year.

- Cumulative PACs is the summation of PACs before a given year using a depreciation rate of 15 percent.

. Citation Annual Counts (CACs) is defined as the summed citation counts of granted patents applied for in a given year. Here, citation counts of a patent are the number of citations that the patent received until August 2006.

. Cumulative CACs is the sum of CACs before a given year using 15 percent as the depreciate rate.

. $R \& D$ expenditures is $\mathrm{R} \& \mathrm{D}$ expenditures (Compustat item 46) in the fiscal year. In real 2000 values.

. Cumulative $R \& D$ expenditures is the sum of real $R \& D$ expenditures before a given year using 15 percent as the depreciation rate.

. Sales revenues is sales revenues (Compustat item 12) in the fiscal year. In real 2000 values.

. Ratio of return on assets (ROA) equals operating profit (Compustat item 181) divided by total assets (Compustat item 6).

. Liability/Asset ratio (L/A) equals total liabilities (Compustat item 12) divided by total assets (Compustat item 6).

- Manufacturing segment counts is the number of manufacturing segments (SIC4 codes 2011 to 3999) that the firm is involved in. 


\section{The Firm's Innovation Policy}

To derive the properties of the innovation policy of a firm with product scope $n$, I construct a function

$$
f\left(x_{1}, x_{2}\right)=\frac{\pi-c_{1}\left(x_{1}\right)-c_{2}\left(x_{2}\right)}{r-\gamma_{1}+\gamma_{2}-\left(x_{1}+x_{2}\right)}
$$

The solution (4.6) to the Bellman equation (4.1) implies $f\left(\lambda_{1}, \lambda_{2}\right)=v$.

I first introduce Lemma 4.1 as follows.

Lemma 4.1: If there is $\left(x_{1}^{*}, x_{2}^{*}\right)$ such that $f\left(x_{1}^{*}, x_{2}^{*}\right)=c_{1}{ }^{\prime}\left(x_{1}^{*}\right)=c_{2}{ }^{\prime}\left(x_{2}^{*}\right)$, then $f_{11}\left(x_{1}^{*}, x_{2}^{*}\right)<0$ and $f_{22}\left(x_{1}^{*}, x_{2}^{*}\right)<0$.

Proof. The first-order derivatives of $f\left(x_{1}, x_{2}\right)$ are

$$
\begin{aligned}
& f_{1}\left(x_{1}, x_{2}\right)=\frac{f\left(x_{1}, x_{2}\right)-c_{1}{ }^{\prime}\left(x_{1}\right)}{r-\gamma_{1}+\gamma_{2}-\left(x_{1}+x_{2}\right)}, \\
& f_{2}\left(x_{1}, x_{2}\right)=\frac{f\left(x_{1}, x_{2}\right)-c_{2}{ }^{\prime}\left(x_{1}\right)}{r-\gamma_{1}+\gamma_{2}-\left(x_{1}+x_{2}\right)} .
\end{aligned}
$$

And its second-order derivatives are

$$
\begin{aligned}
& f_{11}\left(x_{1}, x_{2}\right)=\frac{\left[f_{1}\left(x_{1}, x_{2}\right)-c_{1}{ }^{\prime \prime}\left(x_{1}\right)\right]\left[r-\gamma_{1}+\gamma_{2}-\left(x_{1}+x_{2}\right)\right]+\left[f\left(x_{1}, x_{2}\right)-c_{1}{ }^{\prime}\left(x_{1}\right)\right]}{\left[r-\gamma_{1}+\gamma_{2}-\left(x_{1}+x_{2}\right)\right]^{2}}, \\
& f_{22}\left(x_{1}, x_{2}\right)=\frac{\left[f_{2}\left(x_{1}, x_{2}\right)-c_{2}{ }^{\prime \prime}\left(x_{2}\right)\right]\left[r-\gamma_{1}+\gamma_{2}-\left(x_{1}+x_{2}\right)\right]+\left[f\left(x_{1}, x_{2}\right)-c_{2}{ }^{\prime}\left(x_{2}\right)\right]}{\left[r-\gamma_{1}+\gamma_{2}-\left(x_{1}+x_{2}\right)\right]^{2}} .
\end{aligned}
$$

Given $f\left(x_{1}^{*}, x_{2}^{*}\right)=c_{1}{ }^{\prime}\left(x_{1}^{*}\right)=c_{2}{ }^{\prime}\left(x_{2}^{*}\right)$, we have $f_{1}\left(x_{1}^{*}, x_{2}^{*}\right)=f_{2}\left(x_{1}^{*}, x_{2}^{*}\right)=0$. Substitute them into (4.A4) and (4.A5), we have 


$$
\begin{aligned}
& f_{11}\left(x_{1}^{*}, x_{2}^{*}\right)=\frac{f_{1}\left(x_{1}^{*}, x_{2}^{*}\right)-c_{1}{ }^{\prime \prime}\left(x_{1}^{*}\right)}{r-\gamma_{1}+\gamma_{2}-\left(x_{1}^{*}+x_{2}^{*}\right)}=\frac{-c_{1}{ }^{\prime \prime}\left(x_{1}^{*}\right)}{r-\gamma_{1}+\gamma_{2}-\left(x_{1}^{*}+x_{2}^{*}\right)}<0 \\
& f_{22}\left(x_{1}^{*}, x_{2}^{*}\right)=\frac{f_{2}\left(x_{1}^{*}, x_{2}^{*}\right)-c_{2}{ }^{\prime \prime}\left(x_{2}^{*}\right)}{r-\gamma_{1}+\gamma_{2}-\left(x_{1}^{*}+x_{2}^{*}\right)}=\frac{-c_{2}{ }^{\prime \prime}\left(x_{2}^{*}\right)}{r-\gamma_{1}+\gamma_{2}-\left(x_{1}^{*}+x_{2}^{*}\right)}<0
\end{aligned}
$$

since $c^{\prime \prime}()>$.

I then prove that the optimal innovation policy exists and is unique in Proposition 4.1.

Proposition 4.1: Given that

(1) At the point $\left(0, x_{2}^{0}\right)$ such that $c_{1}{ }^{\prime}(0)=c_{2}{ }^{\prime}\left(x_{2}^{0}\right)$ with $x_{2}^{0} \geq 0, f\left(0, x_{2}^{0}\right)>c_{1}{ }^{\prime}(0)$ and $f\left(0, x_{2}^{0}\right)>c_{2}{ }^{\prime}\left(x_{2}^{0}\right) ;^{61}$

(2) At the point $\left(\bar{x}_{1}, \bar{x}_{2}\right)$ such that $\bar{x}_{1}+\bar{x}_{2}=n \pi$ and $c_{1}{ }^{\prime}\left(\bar{x}_{1}\right)=c_{2}{ }^{\prime}\left(\bar{x}_{2}\right), f\left(\bar{x}_{1}, \bar{x}_{2}\right)<c_{1}{ }^{\prime}\left(\bar{x}_{1}\right)$ and

$f\left(\bar{x}_{1}, \bar{x}_{2}\right)<c_{2}{ }^{\prime}\left(\bar{x}_{2}\right)$;

(3) $f\left(x_{1}, \gamma_{2}\right)<c_{2}{ }^{\prime}\left(\gamma_{2}\right), \forall x_{1} \in\left[0, \pi-\gamma_{2}\right]$,

then there exists one and only one solution to (4.6), $\left(\lambda_{1}, \lambda_{2}\right)$, which is the optimal innovation policy of the firm.

Proof. First I prove that there exists $\left(0, x_{2}^{0}\right) \ll\left(x_{1}^{*}, x_{2}^{*}\right) \ll\left(\bar{x}_{1}, \bar{x}_{2}\right)$, such that $f\left(x_{1}^{*}, x_{2}^{*}\right)=c_{1}{ }^{\prime}\left(x_{1}^{*}\right)=c_{2}{ }^{\prime}\left(x_{2}^{*}\right) . \quad$ Let $\quad g\left(x_{1}\right)=f\left(x_{1}, x_{2}\right)-c_{1}{ }^{\prime}\left(x_{1}\right) \quad$ with $\quad x_{2} \quad$ satisfying $c_{1}^{\prime}\left(x_{1}\right)=c_{2}{ }^{\prime}\left(x_{2}\right) \cdot g\left(x_{1}\right)$ is continuous since each component in it is continuous. With

${ }^{61}$ Proposition 4.1 holds when condition (1) changes to: At the point $\left(x_{1}^{0}, 0\right)$ such that $c_{1}{ }^{\prime}\left(x_{1}^{0}\right)=c_{2}{ }^{\prime}(0)$ with $x_{1}^{0} \geq 0, f\left(x_{1}^{0}, 0\right)>c_{1}{ }^{\prime}(0)$ and $f\left(x_{1}^{0}, 0\right)>c_{2}{ }^{\prime}(0)$. 
condition (1) and (2), we have $g(0)>0$ and $g\left(\bar{x}_{1}\right)<0$. By the intermediate value theorem, there exits a point $\left(\lambda_{1}, \lambda_{2}\right)$ with $\lambda_{1} \in\left(0, \bar{x}_{1}\right)$, such that $g\left(\lambda_{1}\right)=0$ and $c_{1}^{\prime}\left(\lambda_{1}\right)=c_{2}^{\prime}\left(\lambda_{2}\right)$.

I then prove the uniqueness of $\left(\lambda_{1}, \lambda_{2}\right)$. Suppose not, and there is more than one solution to $g\left(x_{1}\right)=0$. Then the curve $g\left(x_{1}\right)$ should cross the $\mathrm{x}$-axis from negative to positive at one of the intersections, denoted as $\hat{x}_{1}$. This implies that the first differentiation $g^{\prime}\left(\hat{x_{1}}\right) \geq 0$. Therefore, either $f_{11}\left(\hat{x_{1}}, \hat{x_{2}}\right) \geq 0$ or $f_{22}\left(\hat{x_{1}}, \hat{x_{2}}\right) \geq 0$ given $c_{1}{ }^{\prime}\left(\hat{x_{1}}\right)=c_{2}{ }^{\prime}\left(\hat{x_{2}}\right)$. This contradicts Lemma 4.1. Therefore, I prove that the solution to (4.6) is unique.

It is straightforward that $\left(\lambda_{1}, \lambda_{2}\right)$ is global optimal given its uniqueness. Because $\forall x_{1} \in\left(0, \lambda_{1}\right), g\left(x_{1}\right)<0$, thus $f_{1}\left(x_{1}, x_{2}\right)<0$ and $f_{2}\left(x_{1}, x_{2}\right)<0 ; \forall x_{1} \in\left(\lambda_{1}, \bar{x}_{1}\right), g\left(x_{1}\right)>0$, thus $f_{1}\left(x_{1}, x_{2}\right)>0$ and $f_{2}\left(x_{1}, x_{2}\right)>0$. Therefore, $f\left(x_{1}, x_{2}\right)$ is decreasing when $x_{1}$ deviates from $\lambda_{1}$. This ends the proof that $\left(\lambda_{1}, \lambda_{2}\right)$ is global optimal.

The unique intersection between $g\left(x_{1}\right)$ and the $\mathrm{x}$-axis determines $\lambda_{1}$, and $g\left(x_{1}\right)$ is downward sloping. An increase of $\pi$ shifts up $g\left(x_{1}\right)$, leading to an increasing in $\lambda_{1}$. Similarly, an increase in $r$ and $\gamma_{1}$, or a decrease in $\gamma_{2}$ shifts $g\left(x_{1}\right)$ down, leading to a decrease in $\lambda_{1}$. A shift up in $c_{1}{ }^{\prime}$ leads to an increase in $c_{1}$ and an increase in $c_{1}{ }^{\prime}$. Both shift down $g\left(x_{1}\right)$, leading to a decrease in $\lambda_{1}$. Similarly, a shift up in $c_{2}{ }^{\prime}$ leads to a decrease in $\lambda_{1}$. 
Table 4.A1. LP Estimations of Entry Likelihood with Control for Firm Fixed Effects

\begin{tabular}{|c|c|c|c|c|c|c|}
\hline \multirow{2}{*}{ Variable } & \multicolumn{2}{|c|}{ Cum. PACs/100 } & \multicolumn{2}{|c|}{ Cum. CACs $/ 1000$} & \multicolumn{2}{|c|}{ Cum. R\&D Expenditures (bil. \$) } \\
\hline & Est. & S.E. & Est. & S.E. & Est. & S.E. \\
\hline Knowledge stocks & $0.005 *$ & 0.003 & $0.003 * *$ & 0.001 & 0.003 & 0.009 \\
\hline \multicolumn{7}{|l|}{ Controls: } \\
\hline Sales revenues (bil. \$) & -0.002 & 0.001 & -0.002 & 0.001 & -0.001 & 0.002 \\
\hline ROA & -0.013 & 0.021 & -0.013 & 0.021 & -0.013 & 0.021 \\
\hline $\mathrm{L} / \mathrm{A}$ ratio & -0.008 & 0.005 & -0.008 & 0.005 & -0.008 & 0.005 \\
\hline Intercept & & & & $\mathrm{Y}$ & & \\
\hline Year fixed effects & & & & $\mathrm{Y}$ & & \\
\hline Firm fixed effects & & & & $\mathrm{Y}$ & & \\
\hline $\mathrm{R}^{2}$ & \multicolumn{2}{|c|}{0.16} & \multicolumn{2}{|c|}{0.16} & \multicolumn{2}{|c|}{0.16} \\
\hline Observations & \multicolumn{2}{|c|}{10483} & \multicolumn{2}{|c|}{10483} & \multicolumn{2}{|c|}{10483} \\
\hline
\end{tabular}

$*, * *, * * *$ : Coefficient different from zero at $10,5,1$ percent significance levels, respectively. 
Table 4.A2. WLW Estimation of Entry Hazard without Control for Industry Fixed

Effects

\begin{tabular}{|c|c|c|c|c|c|c|c|c|c|}
\hline \multirow{2}{*}{ Variable } & \multicolumn{3}{|c|}{ Cum. PACs/100 } & \multicolumn{3}{|c|}{ Cum. CACs/1000 } & \multicolumn{3}{|c|}{ R\&D Expenditures (bil. \$) } \\
\hline & Est. & S.E. & H.R. & Est. & S.E. & H.R. & Est. & S.E. & H.R. \\
\hline \multicolumn{10}{|l|}{ Knowledge stocks } \\
\hline 1 st entry & $0.03 * *$ & 0.01 & 1.03 & 0.00 & 0.01 & 1.00 & -0.05 & 0.08 & 0.95 \\
\hline 2nd entry & $0.03 * *$ & 0.02 & 1.03 & 0.01 & 0.01 & 1.01 & $-0.21 * *$ & 0.09 & 0.81 \\
\hline 3rd entry & $0.04 * *$ & 0.02 & 1.04 & 0.01 & 0.01 & 1.01 & -0.04 & 0.10 & 0.96 \\
\hline 4 th entry & -0.03 & 0.05 & 0.97 & -0.05 & 0.06 & 0.95 & -0.12 & 0.13 & 0.89 \\
\hline \multicolumn{10}{|c|}{ Sales revenues (bil. \$) } \\
\hline 1 st entry & 0.00 & 0.01 & 1.00 & 0.01 & 0.01 & 1.01 & $0.02 * *$ & 0.01 & 1.02 \\
\hline 2nd entry & 0.00 & 0.01 & 1.00 & 0.01 & 0.01 & 1.01 & $0.05 * * *$ & 0.01 & 1.05 \\
\hline 3rd entry & 0.00 & 0.01 & 1.00 & 0.01 & 0.01 & 1.01 & 0.02 & 0.02 & 1.02 \\
\hline 4th entry & 0.02 & 0.02 & 1.02 & 0.03 & 0.02 & 1.03 & 0.03 & 0.03 & 1.04 \\
\hline \multicolumn{10}{|l|}{ ROA } \\
\hline 1 st entry & -0.16 & 0.32 & 0.85 & -0.15 & 0.32 & 0.86 & -0.16 & 0.32 & 0.86 \\
\hline 2nd entry & $0.52 *$ & 0.32 & 1.69 & $0.53 *$ & 0.31 & 1.70 & 0.52 & 0.32 & 1.67 \\
\hline 3rd entry & 0.48 & 0.55 & 1.61 & 0.50 & 0.54 & 1.65 & 0.49 & 0.54 & 1.63 \\
\hline 4th entry & 0.52 & 0.32 & 1.68 & $0.54 *$ & 0.32 & 1.71 & 0.49 & 0.33 & 1.63 \\
\hline \multicolumn{10}{|l|}{$\mathrm{L} / \mathrm{A}$ ratio } \\
\hline 1 st entry & $0.24 * * *$ & 0.09 & 1.27 & $0.24 * * *$ & 0.09 & 1.27 & $0.24 * * *$ & 0.09 & 1.27 \\
\hline 2nd entry & $0.32 * * *$ & 0.09 & 1.38 & $0.33 * * *$ & 0.09 & 1.39 & $0.32 * * *$ & 0.09 & 1.38 \\
\hline 3rd entry & $0.34 * * *$ & 0.10 & 1.40 & $0.34 * * *$ & 0.10 & 1.41 & $0.34 * * *$ & 0.10 & 1.40 \\
\hline 4th entry & $0.43 * * *$ & 0.10 & 1.53 & $0.43 * * *$ & 0.10 & 1.53 & $0.43 * * *$ & 0.10 & 1.53 \\
\hline Industry fixed effects & \multicolumn{9}{|c|}{$\mathrm{N}$} \\
\hline$-2 * \log$ Likelihood & \multicolumn{3}{|c|}{9473} & \multicolumn{3}{|c|}{9481} & \multicolumn{3}{|c|}{9480} \\
\hline Firm Counts & \multicolumn{3}{|c|}{1101} & \multicolumn{3}{|c|}{1101} & \multicolumn{3}{|c|}{1101} \\
\hline
\end{tabular}


Table 4.A3. WLW Estimation of Entry Hazard in all Manufacturing Firms

\begin{tabular}{|c|c|c|c|c|c|c|c|c|c|}
\hline \multirow{2}{*}{ Variable } & \multicolumn{3}{|c|}{ Cum. PACs/100 } & \multicolumn{3}{|c|}{ Cum. CACs $/ 1000$} & \multicolumn{3}{|c|}{ R\&D Expenditures (bil. \$) } \\
\hline & Est. & S.E. & H.R. & Est. & S.E. & H.R. & Est. & S.E. & H.R. \\
\hline \multicolumn{10}{|l|}{ Knowledge stocks } \\
\hline 1 st entry & 0.00 & 0.00 & 1.00 & 0.00 & 0.00 & 1.00 & 0.08 & 0.06 & 1.08 \\
\hline 2nd entry & 0.00 & 0.00 & 1.00 & 0.00 & 0.00 & 1.00 & 0.03 & 0.05 & 1.04 \\
\hline 3rd entry & 0.00 & 0.00 & 1.00 & 0.00 & 0.00 & 1.00 & 0.05 & 0.06 & 1.05 \\
\hline 4th entry & 0.00 & 0.00 & 1.00 & 0.00 & 0.00 & 1.00 & 0.01 & 0.07 & 1.01 \\
\hline \multicolumn{10}{|l|}{ Sales revenues (bil. \$) } \\
\hline 1 st entry & $0.02 *$ & 0.01 & 1.02 & $0.02 * *$ & 0.01 & 1.02 & 0.01 & 0.01 & 1.01 \\
\hline 2nd entry & $0.03 * * *$ & 0.01 & 1.03 & $0.03^{* * *}$ & 0.01 & 1.03 & $0.02 * *$ & 0.01 & 1.02 \\
\hline 3rd entry & $0.03 * * *$ & 0.01 & 1.03 & $0.03^{* * *}$ & 0.01 & 1.03 & $0.02 *$ & 0.01 & 1.02 \\
\hline 4th entry & $0.04 * * *$ & 0.01 & 1.04 & $0.04^{* * *}$ & 0.01 & 1.04 & $0.03 * *$ & 0.01 & 1.03 \\
\hline \multicolumn{10}{|l|}{ ROA } \\
\hline 1st entry & 0.01 & 0.01 & 1.01 & 0.01 & 0.01 & 1.01 & 0.01 & 0.01 & 1.01 \\
\hline 2nd entry & $0.10 *$ & 0.05 & 1.10 & $0.10 *$ & 0.05 & 1.10 & $0.10 *$ & 0.05 & 1.10 \\
\hline 3rd entry & 0.06 & 0.06 & 1.06 & 0.06 & 0.06 & 1.06 & 0.06 & 0.06 & 1.06 \\
\hline 4th entry & 0.02 & 0.02 & 1.02 & 0.02 & 0.02 & 1.02 & 0.02 & 0.02 & 1.03 \\
\hline \multicolumn{10}{|l|}{$\mathrm{L} / \mathrm{A}$ ratio } \\
\hline 1 st entry & -0.01 & 0.01 & 0.99 & -0.01 & 0.01 & 0.99 & -0.01 & 0.01 & 0.99 \\
\hline 2nd entry & $-0.09 *$ & 0.05 & 0.92 & $-0.09 *$ & 0.05 & 0.92 & $-0.09 *$ & 0.05 & 0.92 \\
\hline 3rd entry & -0.04 & 0.06 & 0.96 & -0.04 & 0.06 & 0.96 & -0.04 & 0.06 & 0.96 \\
\hline 4th entry & -0.01 & 0.01 & 0.99 & -0.01 & 0.01 & 0.99 & -0.01 & 0.02 & 0.99 \\
\hline Industry fixed effects & \multirow{2}{*}{\multicolumn{3}{|c|}{22882}} & \multicolumn{3}{|c|}{$\mathrm{Y}$} & & & \\
\hline$-2 *$ Log Likelihood & & & & \multirow{2}{*}{\multicolumn{3}{|c|}{$\begin{array}{c}22882 \\
2978\end{array}$}} & \multicolumn{3}{|c|}{22883} \\
\hline Firm Counts & \multicolumn{3}{|c|}{2978} & & & & \multicolumn{3}{|c|}{2978} \\
\hline
\end{tabular}

$*, * *, * *$ : Coefficient different from zero at 10,5, 1 percent significance levels, respectively. 
VITA

\section{ZHAO RONG}

1993-1997

$1997-2000$

2000-2002

2003-2008
B.E., Industrial Management Engineering Xi'an Jiaotong University

Xi'an, China

M.A., Economics

Peking University

Beijing, China

Project manager

Beijing State-Owned Assets Management Co. Ltd.

Beijing, China

Doctoral Candidate in Economics

Florida International University

Miami, FL, USA

\section{PUBLICATION}

Rong, Zhao and Yang Yao (2003): "Public Service Provision and the Demand for Electric Appliances in Rural China.” China Economic Review 14(2):131-141. 